\title{
REDEMAT
}

Rede Temática em EngenHaria de Materiais

UFOP - CETEC - UEMG

\author{
Dissertação de Mestrado
}

"Distribuição de gás inerte dentro do sistema de refratário durante o lingotamento contínuo de placas: modelo físico e matemático"

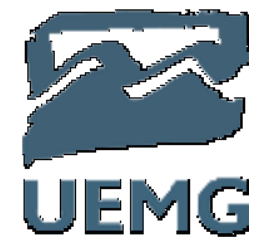

Autor: Paulo Luiz Santos Junior Orientador: Prof. Dr. Carlos Antônio Silva

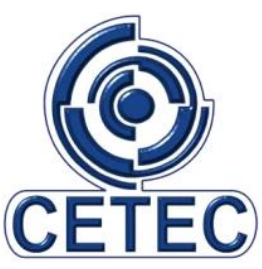

Novembro de 2012 


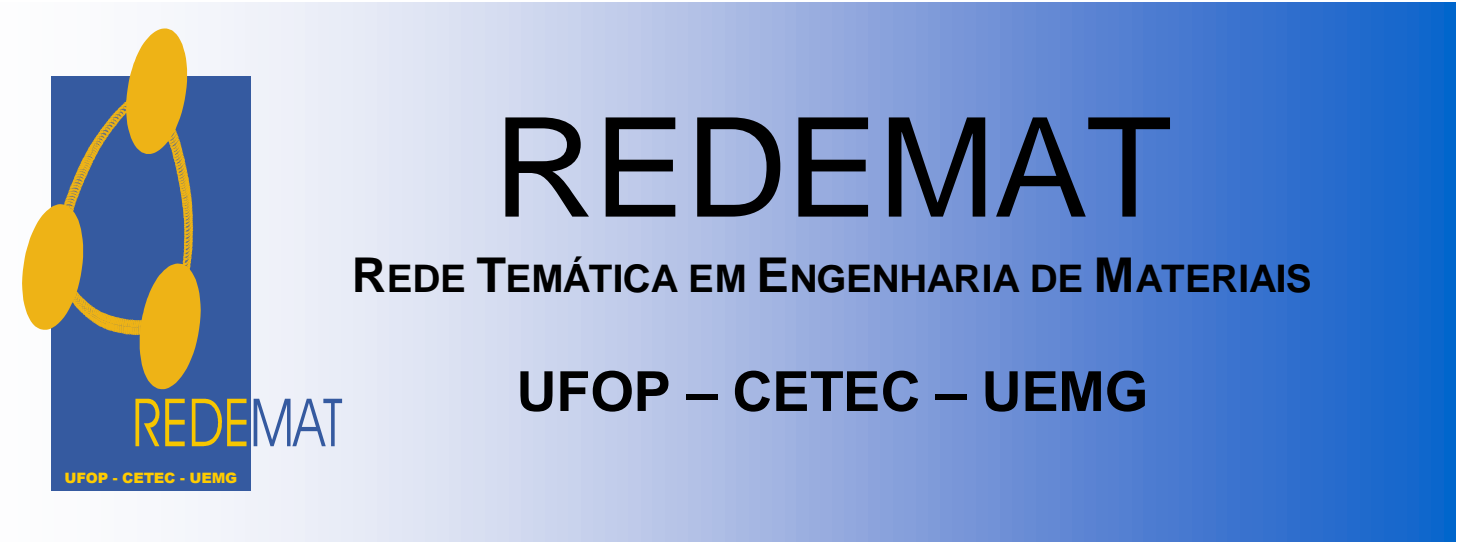

Paulo Luiz Santos Junior

"Distribuição de gás inerte dentro do sistema de refratário durante o lingotamento contínuo de placas: modelo físico e matemático."

Dissertação de Mestrado apresentada ao Programa de Pós-Graduação em Engenharia de Materiais da REDEMAT, como parte integrante dos requisitos para a obtenção do título de Mestre em Engenharia de Materiais.

Área de concentração: Processos de Fabricação

Orientador: Prof. Dr. Carlos Antônio Silva

Ouro Preto, Novembro de 2012 
S237d Santos Junior, Paulo Luiz.

Distribuição de gás inerte dentro do sistema de refratário durante o lingotamento contínuo de placas [manuscrito] : modelo físico e matemático / Paulo Luiz Santos Junior. - 2012.

xvii, 83 f. : il. color.; grafs.; tabs.

Orientador: Prof. Dr. Carlos Antônio Silva.

Dissertação (Mestrado) - Universidade Federal de Ouro Preto. Escola de Minas. Rede Temática em Engenharia de Materiais.

Área de concentração: Processos de Fabricação.

1. Fundição contínua - Lingotamento contínuo - Teses. 2. Materiais refratários - Teses. 3. Modelagem de dados - Modelo físico - Teses. 4. Métodos de simulação - Teses. I. Universidade Federal de Ouro Preto. II. Título.

CDU: 669-41:004.652

Catalogação: sisbin@sisbin.ufop.br 


\title{
REDE TEMÁTICA EM ENGENHARIA DE MATERIAIS UFOP - CETEC - UEMG \\ Pós-Graduação em Engenharia de Materiais
}

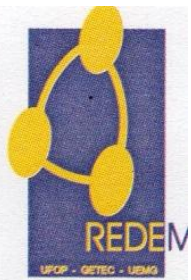

\section{"Distribuição de Gás Inerte Dentro do Sistema de Refratário Durante o Lingotamento Contínuo de Placas: Modelo Físico e Matemático"}

\author{
Autor: Paulo Luiz Santos Júnior
}

Dissertação defendida e aprovada, em 17 de dezembro de 2012, pela banca examinadora constituida pelos professores:

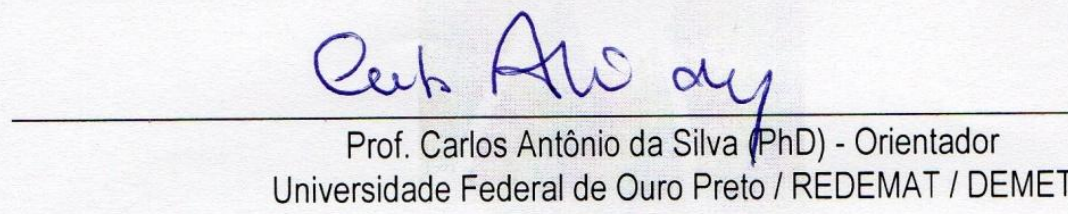

Penice morëra Pralinari

Psq. Clenice Moreira Galinari (Doutora)

Magnesita/Centro de Pesquisa

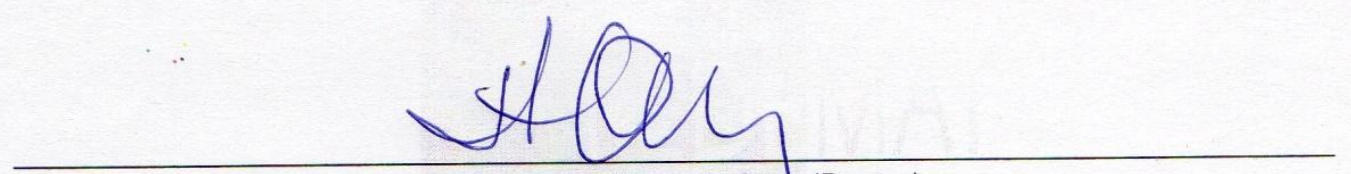

Prof. Itavahn Alves da Silva (Doutor)

Universidade Federal de Ouro Preto / DEMET 
Dedico...

Aos meus filhos, Luíza e Gabriel, recém-chegados neste mundo, mas que modificaram completamente minha percepção da vida, preenchendo-a de amor e alegria. 


\section{AGRADECIMENTOS}

Em primeiro lugar, a Deus, força maior que me inspira e sustenta em todos os momentos.

Ao professor Dr. Carlos Antônio Silva, pela preciosa orientação e apoio, fundamentais para a conclusão deste estudo.

A minha querida esposa, minha eterna companheira, pelo apoio e incentivo contínuo na realização deste sonho.

A minha mãe, Maria de Lourdes, e meu pai, Paulo, primeiramente pela oportunidade de estudo, e atualmente por ajudarem a cuidar dos meus filhos para que eu pudesse finalizar este estudo.

Aos discentes, Luiza Pessoa Moreira e Michel Vieira Santos, bolsistas do Laboratório de Pirometalurgia, em especial ao Michel pela dedicação e horas inumeráveis despendidas na montagem e nas filmagens do modelo físico.

As Áreas de Assistência Técnica e ao Centro de Pesquisa e Desenvolvimento da Magnesita Refratários S.A, pelo apoio e recursos, para desenvolvimento deste projeto, em especial ao Eng. Bruno Augusto Batista Ribeiro e ao Eng. Herbert Amarildo dos Santos pela ajuda no uso do software de modelamento matemático.

Enfim, a todos os que, direta ou indiretamente, contribuíram para a realização deste projeto. 


\section{RESUMO}

Gás inerte é frequentemente injetado no sistema refratário durante o lingotamento contínuo de placas. O objetivo principal é evitar a deposição de inclusões, mas existem algumas consequências indesejáveis. Gás em excesso desestabiliza a interface metal-escória no molde, incrementando o aprisionamento de inclusões. Para uma determinada geometria os efeitos gerais são definidos pela vazão de gás, pontos de injeção, vazão de aço e características dos refratários. Neste estudo a distribuição de gás dentro da válvula submersa (SEN) e no molde é analisada utilizando modelamento matemático (computational fluid dynamics - CFD) e modelo físico. Foi construído um molde em tamanho real, com uma réplica em acrílico da SEN e utilizado dois tipos de válvula superior para injeção do gás. As consequências da distribuição do gás no campo de fluxo e os efeitos metalúrgicos são discutidos.

Para baixas vazões de água e vazões intermediárias e elevadas de gás observou-se a ocorrência de coalescência de bolhas com grandes diâmetros no fundo e na porta da SEN ocasionando um fluxo ascendente próximo à saída da SEN, o que interfere contrariamente à formação do fluxo de duplo rolo e gera regiões de baixa velocidade de menisco e espumação na superfície do molde. Este fenômeno por sua vez não foi observado para maiores vazões de água, independentemente das vazões de gás, utilizadas neste estudo. Quanto ao modelo matemático, o fator crítico para sua adequação ao observado no modelo físico, é o diâmetro de bolha, o que reforça a necessidade de se contemplar o processo de coalescência e ruptura de bolhas no fundo e na saída da SEN. Para baixas vazões da fase líquida um diâmetro maior de bolha se apresentou adequado, enquanto que para vazões mais elevadas da fase líquida o diâmetro menor da bolha representa a condição no interior da SEN e próximo a sua saída, mas não representa adequadamente o comportamento do fluxo no interior do molde. 


\begin{abstract}
Inert gas is usually injected in the nozzles through the refractories during continuous casting of slabs. Although the main objective is to avoid deposition of inclusions on the ceramic parts there are some unavoidable consequences. Too much gas disturbs the metal-slag interface improving slag entrapment. The flow field inside the mold is affected since the gas shows a lift effect on the metal leaving the submerged entry nozzle. For a given geometry the net effects are defined by gas flow rate, number and location of injection points, metal throughput and refractories characteristics. In this study gas distribution inside the Submerged Entry Nozzle (SEN) and inside the mold is analysed using mathematical modelling (computational fluid dynamics - CFD) and physical modelling. The late was done in an actual size mold, with an acrylic replica of the submerged entry nozzle (SEN) and two upper nozzles for gas distribution: double inlet porous material with different configuration. The consequences of gas distribution in the flow field and metallurgical aspects are discussed.

For low and intermediate flow rates of water and high rates of gas injection was observed an occurrence of bubble's coalescence with large diameters, from the bottom and the exit port of the SEN, leading to an upward flow next to the exit SEN. That situation interferes with the structure of superior double roll, causing a region of low velocity in the meniscus and foamy layer on the surface. Though, for high water flow rates that situation was not observed for any injection rates used in this study. About the mathematical modelling a critical factor for adjust it to the physical model is the set of bubble diameter, which reinforce the importance of consider the coalescence-breakup phenomena in the SEN. For low flow rates of liquid phase a large bubble diameter fits better, while for high flow rates of liquid a minor diameter is more adequate to represent the condition inside and near the SEN, however it is not represented satisfactorily the flux behavior inside the mold.
\end{abstract}




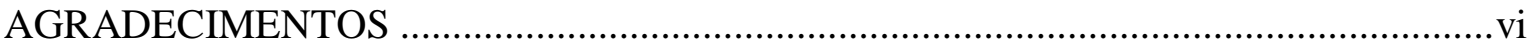

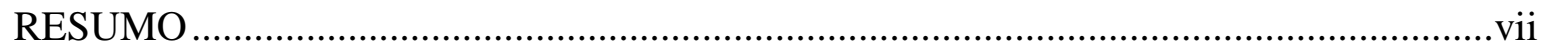

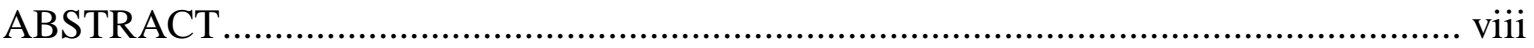

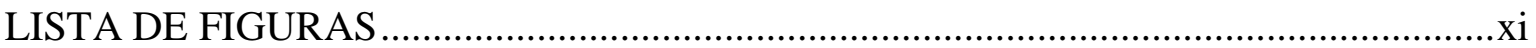

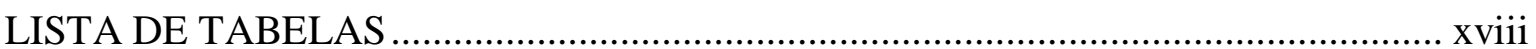

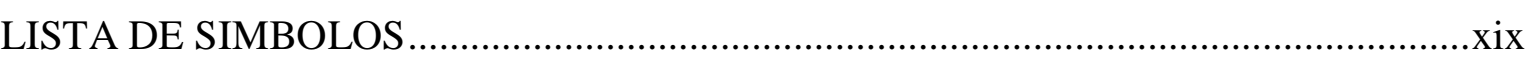

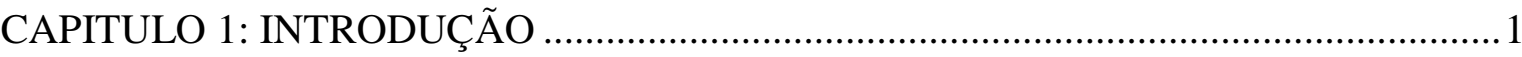

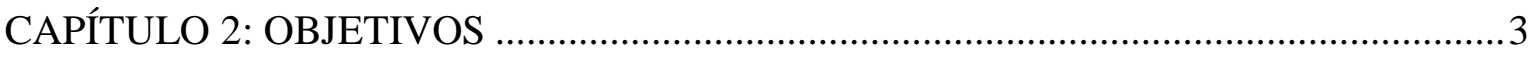

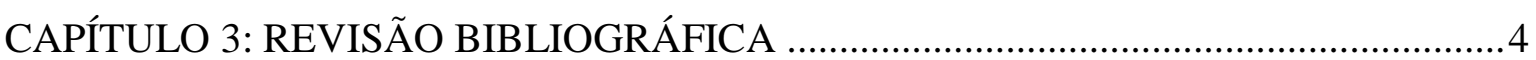

3.1. Defeitos subsuperficiais de alumina em aço Ultra Baixo Carbono (UBC) .................4

3.2. Configuração Típica de Conjunto de válvulas com controle de fluxo por válvula

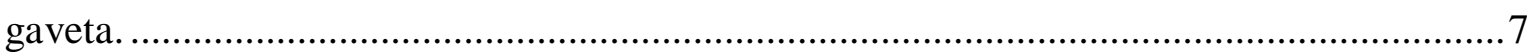

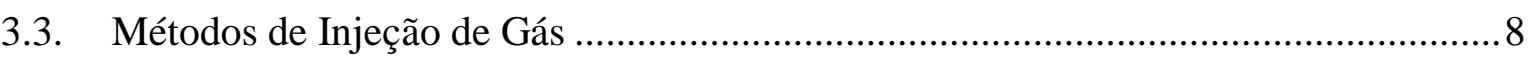

3.4. Mecanismos da obstrução de válvulas do distribuidor............................................. 10

3.5. Comportamento do gás injetado na válvula superior ............................................... 17

3.6. Tipos de configurações da válvula superior do distribuidor ....................................23

3.7. Comportamento das bolhas de Argônio no sistema de refratários e no molde .........24

3.8. Distribuição das bolhas em tubo e no molde................................................................. 32

3.9. Comportamento do fluxo em função da geometria da válvula submersa ..................40

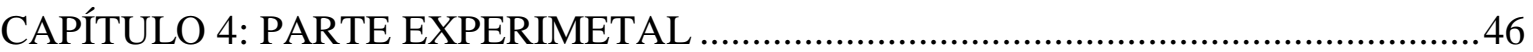

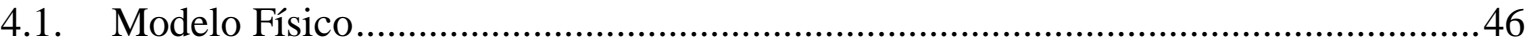

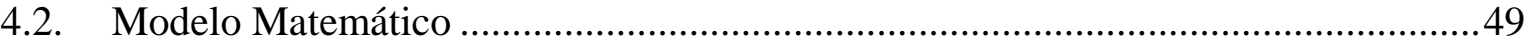

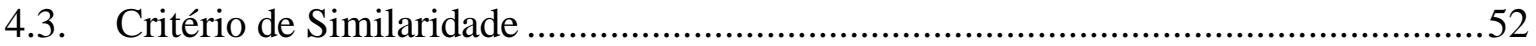

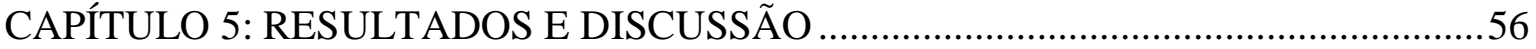

5.1. Diâmetro médio das bolhas dentro da SEN …............................................................56

5.2. Distribuição de gás no interior do molde para válvula superior totalmente porosa ..58

5.3. Distribuição de gás no interior do molde para válvula superior com duas seções porosas

5.4. Condição de transição de gás no interior do molde para válvula superior com dupla seção porosa 


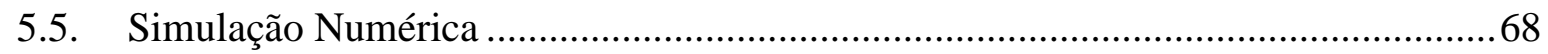

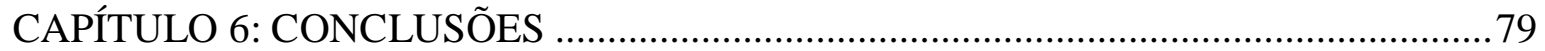

CAPÍTULO 7: SUGESTÕES PARA TRABALHOS FUTUROS ...................................... 81

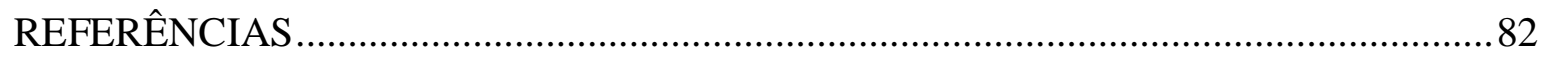




\section{LISTA DE FIGURAS}

Figura 3.1-1: (a) fotografia de uma esfoliação observada na superfície de uma bobina, e (b) imagem de MEV de um corte transversal de uma esfoliação mostrando partículas aprisionadas abaixo da superfície da bobina. .4

Figura 3.1-2: Esquema típico do fluxo de duplo rolo em molde de lingotamento contínuo. Condições de vazão de fluido na região do rolo superior podem promover o aprisionamento subsuperficial de partículas, tais como: (a) o aprisionamento de partículas por ganchos para baixas vazões de aço; (b) e retenção de partículas de pó devido a flutuações do nível de aço no molde para elevadas vazões de aço.

Figura 3.1-3: Ilustração esquemática da curva de formação de gancho em placa de aço ultra baixo carbono através da solidificação do menisco e subsequente transbordamento do aço líquido. Marcas de oscilação são formadas pelo crescimento normal da casca após o transbordamento.

Figura 3.2-1: Configuração típica montagem refratária para os sistemas de válvulas gavetas. 8 Figura 3.3-1: Típico exemplo de adesão de alumina e métodos de injeção de gás no sistema de refratários do lingotamento contínuo de placas.

Figura 3.4-1: Imagem ilustrativa do cálculo da distribuição de velocidade do fluido na região da válvula gaveta (Magnesita, 2003). 10

Figura 3.4-2: Efeito da taxa de injeção de argônio sobre a pressão interna ao longo da linha central : (a) $\mathrm{K}=66,45 \%$, (b) $\mathrm{K}=50,46 \%$ e (c) $\mathrm{K}=42,82 \%$ (sendo $\mathrm{K}$ o \% de abertura de válvula gaveta). 12

Figura 3.4-3: Influência da taxa de argônio sobre a deposição de alumina. .13 Figura 3.4-4: Taxa de deposição de alumina para diferentes percentuais de alumina no aço em diferentes velocidades.

Figura 3.4-5: Efeito da vazão de argônio e pontos de injeção sobre a pressão interna ao longo da linha central do sistema de refratários para casos diversos. .14

Figura 3.4-6: Pontos de injeção de argônio para diferentes diâmetros do furo das placas do sistema de válvula gaveta.

Figura 3.4-7: Fração volumétrica de argônio no sistema de refratários com controle de fluxo tipo válvula gaveta. .16

Figura 3.4-8: Efeito da vazão de argônio sobre a pressão interna ao longo da linha central do sistema de refratários para diâmetro de furo (a) $75 \mathrm{~mm}$ e (b) $65 \mathrm{~mm}$. .16 
Figura 3.5-1: Desenho esquemático da geração de bolhas no modelo em água.

Figura 3.5-2: Projeto válvula superior padrão, utilizada rotineiramente em lingotamento contínuo, e modificada, avaliada em modelo matemático para comparar perfil de velocidade do aço líquido e comportamento da fase gasosa. .18

Figura 3.5-3: Fração volumétrica para válvula superior projeto padrão e modificada para injeção de argônio, Caso 1, superior 12Nl/min e inferior 3Nl/min, e Caso 2, superior 9N1/min e inferior $6 \mathrm{Nl} / \mathrm{min}$ 20

Figura 3.5-4: Fração volumétrica para válvula superior modifica para vazão de aço 2 e 4 t/min.veio. 20

Figura 3.5-5: Injeção de gás através de refratário poroso de $\mathrm{MgO}$. .21

Figura 3.5-6: Fotos do experimento em água com várias velocidade de água, Vl, e velocidade de gás na válvula, $\mathrm{Vg}$ : (a) $\mathrm{Vl}=0,97 \mathrm{~m} / \mathrm{s} ; \mathrm{Vg}=0,0027 \mathrm{~m} / \mathrm{s}$ (b) $\mathrm{Vl}=0,97 \mathrm{~m} / \mathrm{s} ; \mathrm{Vg}=0,0081 \mathrm{~m} / \mathrm{s}$; (c) $\mathrm{Vl}=1,27 \mathrm{~m} / \mathrm{s} ; \mathrm{Vg}=0,0081 \mathrm{~m} / \mathrm{s}$. .22

Figura 3.5-7: Distribuição de tamanho de bolhas com diferente velocidade de água e taxa de vazão de gás $\left(6,2 \mathrm{~cm}^{2}\right.$ de área superficial da amostra sem revestimento do refratário). .........23

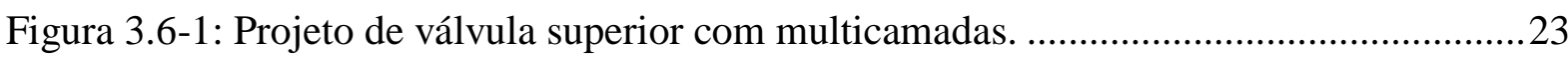
Figura 3.7-1: Trajetória do gás desde a válvula superior até o molde. ..................................24 Figura 3.7-2: Esquema modelo físico para avaliação comportamento das bolhas de gás. ......25

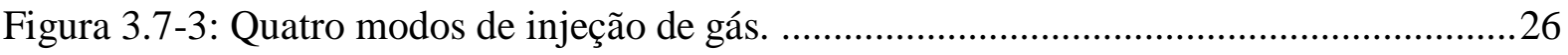
Figura 3.7-4: Modos de injeção de gás e sua relação com o número de Reynolds para gás e líquido. .27

Figura 3.7-5: Medida do tamanho da bolha em fluxo transversal de água para diâmetro de poro de injeção igual a $0,4 \mathrm{~mm}$. .28 Figura 3.7-6: Efeito do tamanho do poro de injeção do gás no tamanho das bolhas para velocidade transversal da água de $0,9 \mathrm{~m} / \mathrm{s}$.

Figura 3.7-7: Efeito do tamanho da bolha de argônio e a injeção de gás no ângulo horizontal e vertical jato (Thomas, Parte II - 2001). .30 Figura 3.7-8: Modelo em água em escala 0,4 apresenta o padrão de fluxo e ângulo vertical do jato com a válvula de validação (Thomas, Parte I - 2001). 30 Figura 3.7-9: (a) Dados da variação da velocidade de lingotamento e vazão de argônio, e evolução da medida da velocidade do menisco na Máquina 1 (veio 1). (b) Imagem PIV do modelo em água. 32 
Figura 3.7-10: Fração volumétrica de gás (calculada para condição a quente) e seu efeito

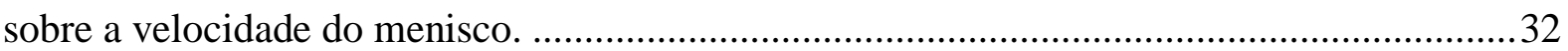

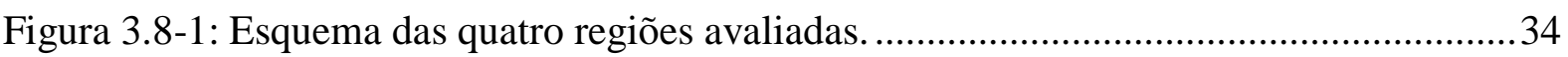

Figura 3.8-2: Quantidade de bolhas por área para velocidades de lingotamento de (a) 0,8, (b)

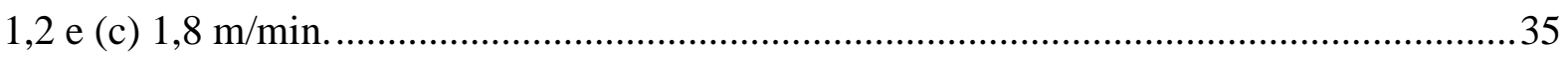

Figura 3.8-3: Diâmetro de bolhas para velocidades de lingotamento de (a) 0,8, (b) 1,2 e (c) $1,8 \mathrm{~m} / \mathrm{min}$ .36

Figura 3.8-4: Padrão de fluxo para injeção de $1,67 \times 10^{-3} \mathrm{~m}^{3} / \mathrm{s}$ com velocidade de lingotamento (a) de $0,8 \mathrm{~m} / \mathrm{s}$ (fluxo estruturalmente ajustado) e (b) $1,8 \mathrm{~m} / \mathrm{min}$ (fluxo estruturalmente ajustado)

Figura 3.8-5: Vetores de velocidade determinados via PIV de (a) fluxo monofásico de água (b) fluxo bifásico com taxa de injeção de gás de 1,2Nl/min com velocidade de lingotamento de $1,8 \mathrm{~m} / \mathrm{min}$. .38

Figura 3.8-6: Teste da seção vertical equipado com injeção de ar e sensor de malha de arame .39

Figura 3.8-7: Distribuição primária de gás e evolução dos perfis da fração de gás radial para velocidades superficiais de água $=1 \mathrm{~m} / \mathrm{s}$ e ar $=0,02 \mathrm{~m} / \mathrm{s}$ (abstendo do fenômeno de

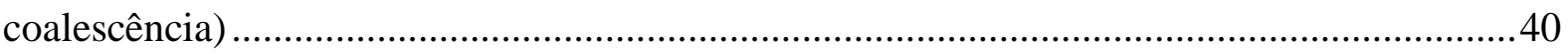

Figura 3.9-1: Projetos do fundo da Válvula Submersa........................................................... 41

Figura 3.9-2: Fluxo do molde para molde largo. .................................................................. 41

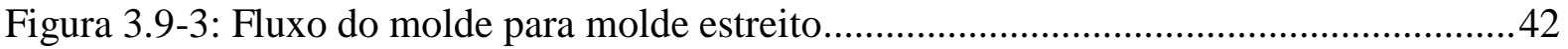

Figura 3.9-4: Resultado do modelo matemático CFD para fluxo no molde utilizando válvula formato tipo telhado para molde com largura estreita e larga.

Figura 3.9-5: Relação entre a velocidade máxima de submenisco, velocidade de lingotamento e largura do molde para válvula submersa tipo telhado. .44 Figura 3.9-6: Gráfico comparativo da velocidade de menisco e das condições limites da vazão de aço para válvulas tipo copo e telhado para largura de molde estreita e larga. .45 Figura 4.1-1: SEN Construída em Acrílico ao lado da SEN Refratária (a) e Desenho da SEN (b).

Figura 4.1-2: Desenho válvula superior porosa (a) e desenho válvula superior com material denso (b).

Figura 4.1-3: Montagem modelo em escala 1:1 (a) e esquema de montagem dos refratários para lingotamento contínuo (b). 48 
Figura 4.1-4: Válvula em acrílico com escala de referência; exemplo de foto para 336 lpm e 2 lpm de ar, válvula superior completamente porosa.

Figura 4.2-1: Imagem em 3-D do modelo físico gerada pelo software CFX. .50

Figura 4.2-2: Imagem gerada pelo software CFX do molde e da válvula submersa com ênfase na malha. .50

Figura 4.2-3: Representação da geometria de 1/4 de um molde de lingotamento contínuo de placas e condições de contorno típicas aplicáveis ao sistema em estudo. .52 Figura 4.3-1: Mapas de distribuição de fração volumétrica de gás, modelo e na máquina industrial.

Figura 4.3-2: Mapas de distribuição de velocidades do líquido, no modelo e na máquina industrial.

Figura 5.1-1: Válvula bloco superior com porosidade uniforme a) foto frame $3361 \mathrm{pm}$ com $21 \mathrm{pm}$ de ar, b) foto frame $3361 \mathrm{pm}$ com $2 \mathrm{lpm}$ de $\mathrm{He}$, c) foto frame $4001 \mathrm{pm}$ com $21 \mathrm{pm}$ de ar e d) foto frame 4001pm com 2lpm de He. .56

Figura 5.2-1: Foto modelo físico em funcionamento duplo rolo bem definido com a) 3361/min de água sem gás b) Imagem vetores gerados pelo software PIVVIEW para o caso de 3361/min de água sem gás.

Figura 5.2-2: Foto modelo físico em funcionamento duplo rolo bem definido com a) 4001/min de água sem gás b) Imagem vetores gerados pelo software PIVVIEW para o caso de 4001/min de água sem gás.

Figura 5.2-3: Foto modelo físico em funcionamento duplo rolo bem definido com a) 3361/min de água e 4Nl/min de ar b) Imagem vetores gerados pelo software PIVVIEW para o caso de $3361 / \mathrm{min}$ de água e $4 \mathrm{Nl} / \mathrm{min}$ de ar.

Figura 5.2-4: Foto modelo físico em funcionamento duplo rolo prejudicado com a) 3361/min de água e $8 \mathrm{Nl} / \mathrm{min}$ de ar b) Imagem vetores gerados pelo software PIVVIEW para o caso de 3361/min de água e $8 \mathrm{Nl} / \mathrm{min}$ de ar.

Figura 5.2-5: Foto modelo físico em funcionamento duplo rolo prejudicado com a) 3361/min de água e $12 \mathrm{Nl} / \mathrm{min}$ de ar b) Imagem vetores gerados pelo software PIVVIEW para o caso de $3361 /$ min de água e $12 \mathrm{Nl} / \mathrm{min}$ de ar.

Figura 5.2-6: Foto modelo físico em funcionamento duplo rolo prejudicado com a) 3361/min de água e $16 \mathrm{Nl} / \mathrm{min}$ de ar b) Imagem vetores gerados pelo software PIVVIEW para o caso de $3361 / \mathrm{min}$ de água e $16 \mathrm{Nl} / \mathrm{min}$ de ar. 
Figura 5.2-7: Foto modelo físico em funcionamento com a) 3361/min de água e 4Nl/min de ar b) $3361 / \mathrm{min}$ de água e $12 \mathrm{Nl} / \mathrm{min}$ de ar.

Figura 5.2-8: Fotos evidenciando as bolhas na saída da SEN para 3361/min com injeção de gás (a) $12 \mathrm{Nl} / \mathrm{min} \mathrm{e} \mathrm{(b)} 16 \mathrm{Nl} / \mathrm{min}$.

Figura 5.2-9: Foto modelo físico em funcionamento com 4001/min de água e 4Nl/min de ar; Imagem vetores gerados pelo software PIVVIEW para o caso de 4001/min de água e $4 \mathrm{Nl} / \mathrm{min}$ de ar.

Figura 5.2-10: Foto modelo físico em funcionamento com 4001/min de água e $8 \mathrm{Nl} / \mathrm{min}$ de ar; Imagem vetores gerados pelo software PIVVIEW para o caso de $4001 / \mathrm{min}$ de água e $8 \mathrm{Nl} / \mathrm{min}$ de ar

Figura 5.2-11: Foto modelo físico em funcionamento com 4001/min de água e 12N1/min de ar; Imagem vetores gerados pelo software PIVVIEW para o caso de 4001/min de água e $12 \mathrm{Nl} / \mathrm{min}$ de ar .

Figura 5.2-12: Foto modelo físico em funcionamento com 4001/min de água e 16N1/min de ar; Imagem vetores gerados pelo software PIVVIEW para o caso de 4001/min de água e $16 \mathrm{Nl} / \mathrm{min}$ de ar .

Figura 5.3-1: Foto modelo físico em funcionamento válvula superior com duas seções porosas a) 3361/min de água e 4N1/min de ar b) Imagem vetores gerados pelo software PIVVIEW para o caso de 3361/min de água e 4N1/min de ar .

Figura 5.3-2: Foto modelo físico em funcionamento válvula superior com duas seções porosas a) 3361/min de água e $12 \mathrm{Nl} / \mathrm{min}$ de ar b) Imagem vetores gerados pelo software PIVVIEW para o caso de 3361/min de água e 12N1/min de ar .

Figura 5.3-3: Foto modelo físico em funcionamento válvula superior com duas seções porosas (a) 4001/min de água e 4N1/min de ar (b) Imagem vetores gerados pelo software PIVVIEW para o caso de 4001/min de água e 4N1/min de ar . .66

Figura 5.3-4: Foto modelo físico em funcionamento válvula superior com duas seções porosas (a) 4001/min de água e $12 \mathrm{Nl} / \mathrm{min}$ de ar (b) Imagem vetores gerados pelo software PIVVIEW para o caso de 4001/min de água e 12N1/min de ar

Figura 5.4-1: Foto modelo físico em funcionamento válvula superior com duas seções porosas a) 3361/min de água e $5 \mathrm{Nl} / \mathrm{min}$ de ar b) 3361/min de água e $7 \mathrm{Nl} / \mathrm{min}$ de ar.

Figura 5.4-2: Foto modelo físico em funcionamento válvula superior com duas seções porosas a) 3601/min de água e $13 \mathrm{Nl} / \mathrm{min}$ de ar b) 3601/min de água e $15 \mathrm{Nl} / \mathrm{min}$ de ar. .68 
Figura 5.5-1: Distribuição gasosa gerada na simulação matemática vista 3-D, vazão 336 lpm e $12 \mathrm{Nl} / \mathrm{min}$ de gás com diâmetro de bolha de $3 \mathrm{~mm}$ sem empuxo.

Figura 5.5-2: Imagem da distribuição gasosa gerada na simulação matemática (a), gás vai até a parede estreita do molde (sem empuxo), e foto da simulação física (b), com fluxo de gás ascendente próximo a saída da SEN, ambas com 336 lpm e $12 \mathrm{Nl}$ de gás por minuto sem partículas

Figura 5.5-3: Imagem distribuição gasosa gerada na simulação matemática (com empuxo) e na simulação física, $336 \mathrm{lpm}$ e $12 \mathrm{Nl}$ de gás por minuto. .70

Figura 5.5-4: Imagem 2-D da distribuição gasosa no plano central do molde gerada na simulação matemática, (a) sem e (b) com empuxo, para 336 lpm e 12 N1/min. .71 Figura 5.5-5: Imagem distribuição gasosa gerada na simulação matemática vista 3-D, vazão 336 lpm e 12 Nl/min de gás com empuxo (a) diâmetro de bolha de 3 mm e (b) diâmetro de bolha $2 \mathrm{~mm}$. .71

Figura 5.5-6: Imagem 2-D da distribuição gasosa do plano central do molde gerada na simulação matemática, com empuxo, para 336 lpm e $12 \mathrm{Nl} / \mathrm{min}$ (a) diâmetro de bolha $2 \mathrm{~mm}$ e (b) diâmetro de bolha $3 \mathrm{~mm}$. .72 Figura 5.5-7: Imagem 2-D ampliada da distribuição gasosa do plano central do molde gerada na simulação matemática, com empuxo, para $336 \mathrm{lpm}$ e $12 \mathrm{Nl} / \mathrm{min}$ (a) diâmetro de bolha $2 \mathrm{~mm}$ e (b) diâmetro de bolha $3 \mathrm{~mm}$. 72

Figura 5.5-8: Imagens referentes a 336 lpm e 12 Nl/min, (a) simulação física e (b) simulação matemática com diâmetro de bolha de $3 \mathrm{~mm}$ com empuxo, corte no plano central. .73 Figura 5.5-9: Imagem distribuição gasosa gerada na simulação matemática vista 3-D, (a) vazão 336 lpm e 12 Nl/min de gás com empuxo e diâmetro de bolha de 2 mm e (b) 400 lpm e $12 \mathrm{NL} / \mathrm{min}$ diâmetro de bolha com empuxo e diâmetro de bolha de $3 \mathrm{~mm}$ .74 Figura 5.5-10: Imagem 2-D da distribuição gasosa do plano central do molde gerada na simulação matemática, com empuxo, para (a) 336 lpm e $12 \mathrm{Nl} / \mathrm{min}$ diâmetro de bolha de $2 \mathrm{~mm}$ e (b) $4001 \mathrm{pm}$ e $12 \mathrm{Nl} / \mathrm{min}$ com diâmetro de bolha de $3 \mathrm{~mm}$. .74

Figura 5.5-11: Imagem distribuição gasosa gerada na simulação matemática vista 3-D vazão de $400 \mathrm{lpm}$ e 12N1/min, com diâmetro de (a) $2 \mathrm{~mm}$ e (b) $3 \mathrm{~mm}$. .75 Figura 5.5-12: Imagem distribuição gasosa gerada na simulação física e matemática, 400 lpm e $12 \mathrm{Nl}$ de gás por minuto, diâmetro de bolha $2 \mathrm{~mm}$.

Figura 5.5-13: Imagem vetores de velocidade $336 \mathrm{lpm}$ e 12N1/min de gás com bolhas com diâmetro de $3 \mathrm{~mm}$ (a) com empuxo e (b) sem empuxo. .76 
Figura 5.5-14: Imagem vetores de velocidade $400 \mathrm{lpm}$ e $12 \mathrm{Nl} / \mathrm{min}$ de gás com bolhas com

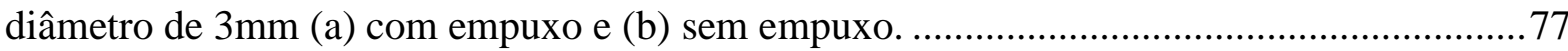
Figura 5.5-15: Imagem vetores de velocidade com bolhas com diâmetro de $3 \mathrm{~mm}$ e empuxo para (a) $3361 \mathrm{pm}$ e $12 \mathrm{Nl} / \mathrm{min}$ e (b) $400 \mathrm{lpm}$ e $12 \mathrm{Nl} / \mathrm{min}$.

Figura 5.5-16: Imagem vetores de velocidade $400 \mathrm{lpm}$ e 12Nl/min de gás com bolhas com diâmetro de, (a) $2 \mathrm{~mm}$ e (b) $3 \mathrm{~mm}$. .78 


\section{LISTA DE TABELAS}

Tabela 3.3-1: Características do método de injeção de gás para refratários de lingotamento

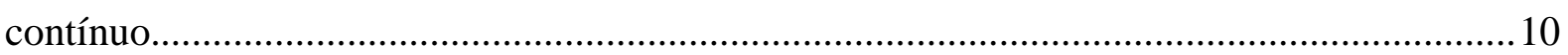

Tabela 3.4-1: Condições de Injeção de gás na válvula superior e válvula submersa. ............. 14

Tabela 5.1-1: Tamanho médio das bolhas de acordo com as condições de injeção para válvula

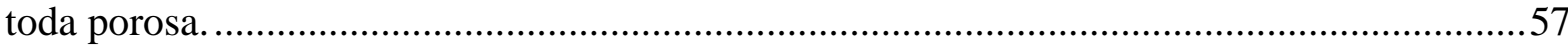

Tabela 5.1-2: Tamanho médio das bolhas de acordo com as condições de injeção para válvula

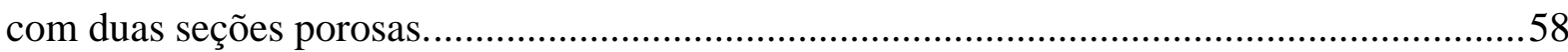

Tabela 5.4-1: Reynolds e Velocidade em Função da Vazão de Água e Diâmetro ...................68 


\section{LISTA DE SIMBOLOS}

SEN - submerged entry nozzle

SGV - sistema de válvula gaveta

CFD - computacional fluid dynamics

Ar - Argônio

LPM - litros por minuto

Fps - quadros por segundo

Re - Reynolds

UBC - Ultra Baixo Carbono

PIV - Particle Image Velocimetry

CCD - Charged Coupled Device 


\section{CAPITULO 1: INTRODUÇÃO}

Nas últimas décadas a indústria automobilística tem constantemente demandado novos aços para produção de automóveis, em especial os aços ultra baixo carbono. Estes aços, além da sua característica principal relacionada à ausência de carbono na sua microestrutura, demandam uma elevada limpidez, visto que durante sua laminação, estampagem e pintura os defeitos provenientes da Aciaria podem se tornar evidentes, o que acarreta na redução de rendimento do processo e/ou desvio de produtos para qualidades inferiores.

Por sua vez esta demanda crescente da indústria automobilística por aços ultra baixo carbono com elevada limpidez e custos competitivos tem levado as usinas siderúrgicas produtoras de placas e os fornecedores de refratários ao desenvolvimento contínuo de tecnologias de novos materiais, projetos e processos para produção de aço.

Conforme Yuan (2008) durante a produção dos aços baixo e ultra baixo carbono acalmados ao alumínio um dos fenômenos que prejudicam em muito a produtividade e a qualidade deste produto é a deposição de inclusões de alto ponto de fusão, tais como: alumina $\left(\mathrm{Al}_{2} \mathrm{O}_{3}\right)$ e alguns tipos de aluminatos de cálcio, o que acarreta em obstrução parcial ou total das válvulas e dos sistemas de controle de fluxo e consequente necessidade de troca da válvula submersa (SEN). Isto acarreta num processo de lingotamento instável, numa elevação dos custos e em uma redução na produtividade e na qualidade do produto. Logo, obstrução por alumina é um sério problema associado com a produção de aço acalmado ao alumínio.

A obstrução do sistema de válvulas do distribuidor afeta o fluxo de aço para o molde fazendo com que este seja assimétrico e assim cause excessiva variação do nível de aço no molde. Além disto, esta situação pode reduzir a vazão e provocar ocasionalmente a liberação de aglomerados de partículas no fluxo de aço. Todos estes problemas causados pela obstrução lideram os defeitos em produtos, especialmente os defeitos superficiais formados pelo aprisionamento de inclusões durante condições instáveis de lingotamento. Em relação ao processo de deposição do $\mathrm{Al} 2 \mathrm{O} 3$ nas paredes dos refratários, esta depende de vários fatores, tais como: velocidade de lingotamento, concentração de Al2O3 no aço líquido, vazão de Argônio, material e estrutura das válvulas (YUAN, 2008 ). 
Conforme Suzuki (2003), para a produção de aço via lingotamento contínuo à injeção de Argônio (Ar) através dos refratários tem um papel fundamental no controle da obstrução, na melhora da uniformização da temperatura superficial do aço no molde e na promoção da separação das inclusões não metálicas. Por outro lado, quando as bolhas de Argônio ficam presas na frente de solidificação durante o lingotamento, estas podem acarretar defeitos internos no processamento do aço. Da mesma forma que as práticas de injeção do argônio na válvula superior do distribuidor, a estrutura da válvula e o material poroso estão bem estabelecidos há mais de dez anos, (Suzuki, 2003). Porém, recentemente observa-se que as novas práticas de utilização de baixas vazões de Argônio e sequenciais de longa duração tornaram-se comuns, o que implica em necessidade de novos desenvolvimentos do design e dos materiais refratários da válvula.

Neste estudo a distribuição de gás no interior da válvula submersa e do molde é analisada utilizando modelamento matemático (computacional fluid dynamics - CFD) e modelo físico em água. O modelo em água tem dimensões em escala industrial, com uma réplica em acrílico da válvula submersa (SEN) e duas válvulas superiores para injeção do gás, com configuração diferente e dois pontos de injeção. Os efeitos da distribuição do gás no sistema de válvulas e no molde e os aspectos metalúrgicos são discutidos. 


\section{CAPÍTULO 2: OBJETIVOS}

Analisar a distribuição de gás no interior da válvula submersa e do molde utilizando modelamento matemático (computational fluid dynamics - CFD) e modelo físico em água. $\mathrm{O}$ modelo em água tem dimensões em escala industrial, com uma réplica em acrílico da válvula submersa (SEN) e duas válvulas superiores para injeção do gás, com configuração diferente e dois pontos de injeção.

Estudar os efeitos da distribuição do gás no sistema de válvulas e no molde e os aspectos metalúrgicos. 


\section{CAPÍTULO 3: REVISÃO BIBLIOGRÁFICA}

\subsection{Defeitos subsuperficiais de alumina em aço Ultra Baixo Carbono (UBC)}

Para Yavuz (2010) o aprisionamento de inclusões subsuperficiais de alumina, de escória e de partículas de pó-fluxante em lingotamento contínuo de placas frequentemente lideram a formação de defeitos tipo "esfoliação" (ver Figura 3.1-1) sobre a superfície de produtos finais laminados. Isto causa rejeição e retrabalho em bobinas defeituosas, particularmente aquelas produzidas em aço UBC programados para aplicações em superfícies críticas. Adicionalmente, sistemas de inspeção de superfície são instalados nos laminadores para inspecionar todas as bobinas e detectar eventuais defeitos, de maneira a resguardar os interesses dos clientes. Assim, do ponto de vista de custo da má qualidade, o aprisionamento de partículas durante o processo de lingotamento é a principal preocupação para as empresas siderúrgicas.

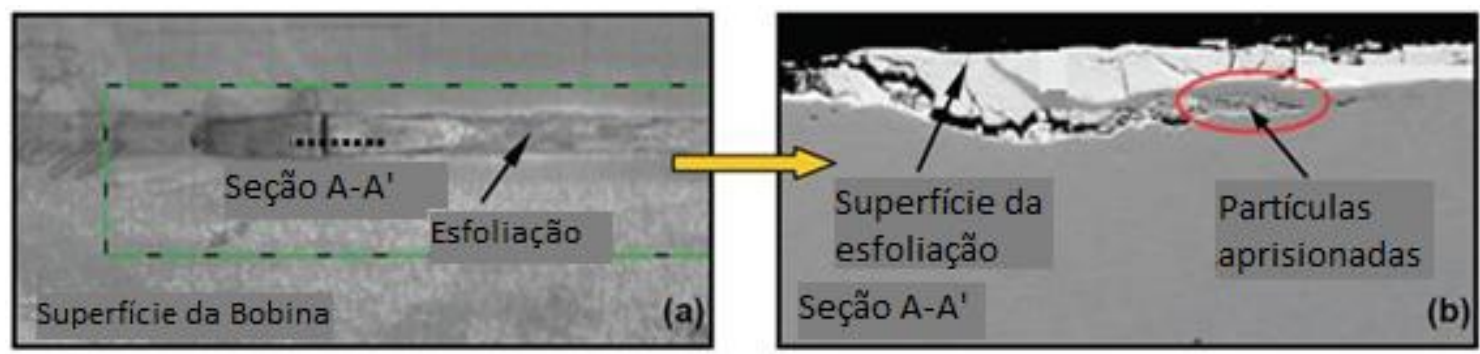

Figura 3.1-1: (a) fotografia de uma esfoliação observada na superfície de uma bobina, e (b) imagem de MEV de um corte transversal de uma esfoliação mostrando partículas aprisionadas abaixo da superfície da bobina.

A Figura 3.1-2 (a) esquematicamente resume vários fenômenos que ocorrem no molde em máquina de lingotamento contínuo que lideram o aprisionamento de partículas na pele de aço em solidificação. O jato de metal sai pela válvula submersa (SEN) e transmite energia cinética para o líquido no molde criando desta maneira um fluxo de duplo rolo. Durante este processo partículas de alumina, provenientes do processo de refino secundário de produção de aços acalmados ao Alumínio (Al), frequentemente presentes no aço líquido são arrastadas para dentro do molde. Outra situação que ocorre também é o arraste de escória para o molde, a qual pode ser proveniente da panela ou do distribuidor. A trajetória e o tempo de residência destas partículas no molde são influenciadas pelo padrão transiente de fluxo de aço desenvolvido no interior do molde. Adicionalmente, tem-se também a interação entre a 
turbulência do aço líquido e a camada de pó-fluxante, o que pode acarretar no aprisionamento de partículas de pó-fluxante na pele de aço em solidificação (Yavuz, 2010).

De acordo com esse mesmo autor um padrão de fluxo ótimo perto do menisco é esperado, para se transportar estas partículas para superfície, de maneira a que estas sejam absorvidas pela camada pó-fluxante fundida. Entretanto, em certas condições de lingotamento, o padrão do fluxo se apresenta em condições abaixo das ideais e tem um impacto negativo sobre o processo de solidificação inicial do menisco e o arraste das partículas no molde. Em última análise, as partículas circulantes no molde irão interagir com a frente de solidificação de aço resultando no aprisionamento das inclusões/ partículas.

Para baixas vazões de aço, um rolo superior de baixa intensidade implica em um menisco relativamente calmo, o que impede o transporte eficiente de energia do aço líquido saído da SEN para o menisco e para as faces do molde, resultando na solidificação de aço na região subsuperficial do menisco em formatos de ganchos, devido ao resfriamento do menisco. Placas de aço ultra baixo carbono são particularmente susceptíveis a este problema, devido à sua faixa estreita de solidificação. Na presença de ganchos na frente de solidificação, as partículas flutuantes acabam por ser capturadas antes que tenham a condição de atingir a camada fundida de pó-fluxante Figura 3.1-2 (a) (Yavuz, 2010)

Em contraste, altas vazões de aço acarretam em excesso de flutuações no menisco e na parte superior do molde. Em função da turbulência e da instabilidade do fluxo de aço na região do menisco, partículas de pó fundido são frequentemente arrastadas para o interior do molde, aumentando a probabilidade de aprisionamento destas pela frente de solidificação (mostrado esquematicamente na Figura 3.1-2 (b)). As flutuações repentinas do nível de aço no molde causam uma distorção na espessura da pele, formando ganchos e acarretando no aprisionamento de inclusões. Mesmo sem a presença de ganchos, o aprisionamento de partículas pode ocorrer; este depende do espaçamento do braço dendrítico na frente de solidificação, do tamanho da partícula e do equilíbrio das forças hidrodinâmicas que atuam na partícula. Padrões de fluxo distorcidos produzidos pela obstrução da válvula submersa e a liberação destas partículas no banho de aço líquido irão agravar ainda mais estes problemas (Yavuz, 2010). 

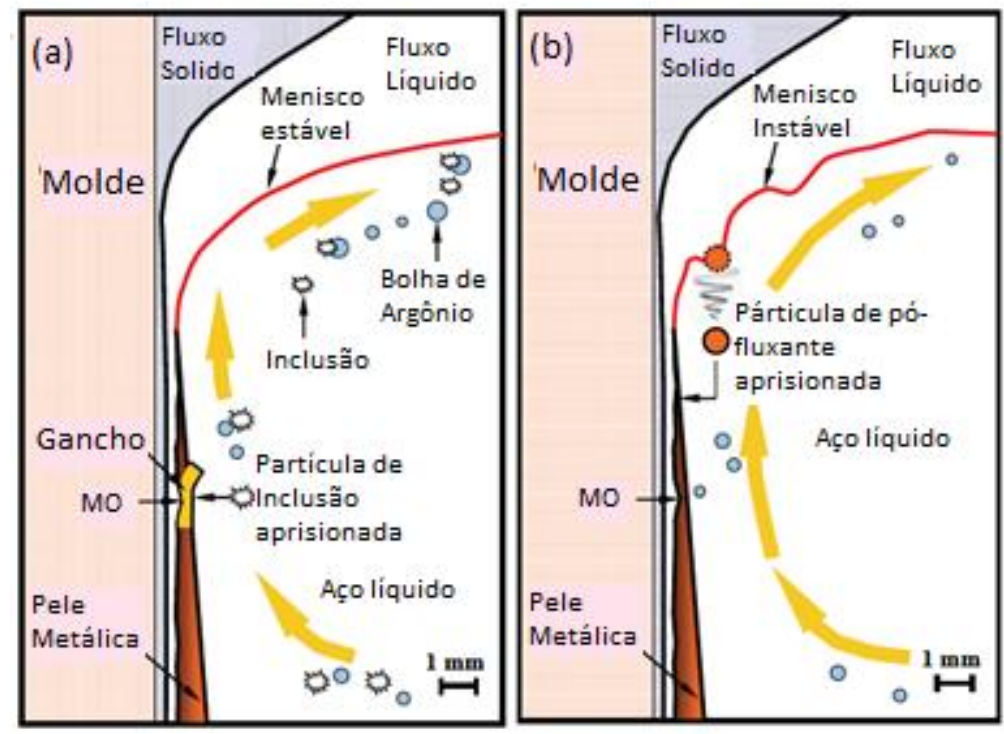

Figura 3.1-2: Esquema típico do fluxo de duplo rolo em molde de lingotamento contínuo. Condições de vazão de fluido na região do rolo superior podem promover o aprisionamento subsuperficial de partículas, tais como: (a) o aprisionamento de partículas por ganchos para baixas vazões de aço; (b) e retenção de partículas de pó devido a flutuações do nível de aço no molde para elevadas vazões de aço.

Sengupta (2006), através de análises simultâneas em microscópio ótico e microscópio eletrônico de varredura, revelou novas informações sobre o mecanismo de formação de ganchos em aços ultra baixo carbonos.

Este mecanismo foi resumido por Sengupta (2006) como descrito a seguir:

- "A formação do gancho se inicia pela solidificação do menisco. O formato instantâneo do menisco determina a curvatura da linha original do gancho. Este evento frequentemente ocorre quando se inicia o estripamento negativo (Figura 3.1-3(a)).

- A espessura do gancho abaixo da linha de origem deste é determinada pelo crescimento dendrítico, originado da nucleação localizada ao longo da linha de formação do gancho.

- Parte do fluxante fundido em contato com o menisco penetra entre as dendritas da solidificação do gancho, onde este fica retido.

- O transbordamento subsequente do menisco sobre a linha original do gancho (Figura 3.1-3 (b)). Dendritas crescem rapidamente acima da linha original do gancho em direção a parede do molde no líquido transbordado. O crescimento dendrítico para repentinamente na medida em que a região ganha temperatura.

- O fluxante fundido fica retido ao longo da linha original do gancho.

- A linha de origem do gancho persiste como fronteira de grão na microestrutura final, apesar da ocorrência da transformação de duas fases separadamente. Os grãos acima e abaixo da linha do gancho têm diferentes orientações cristalográficas devido ao diferente momento de solidificação do menisco e do líquido transbordado. 
- O formato final do gancho fica completo com a ocorrência da fratura da ponta (Figura 3.1-3 (c)).

- A região de tranbordamento solidifica formando a marca de oscilação. A extensão da penetração do aço líquido no canal de fluxo determina o formato final da parte superior da marca de oscilação. A parte saliente do gancho aprisiona inclusões e bolhas no aço líquido até o momento em que a frente solidificação ultrapassa o gancho (Figura 3.1-3(d)).
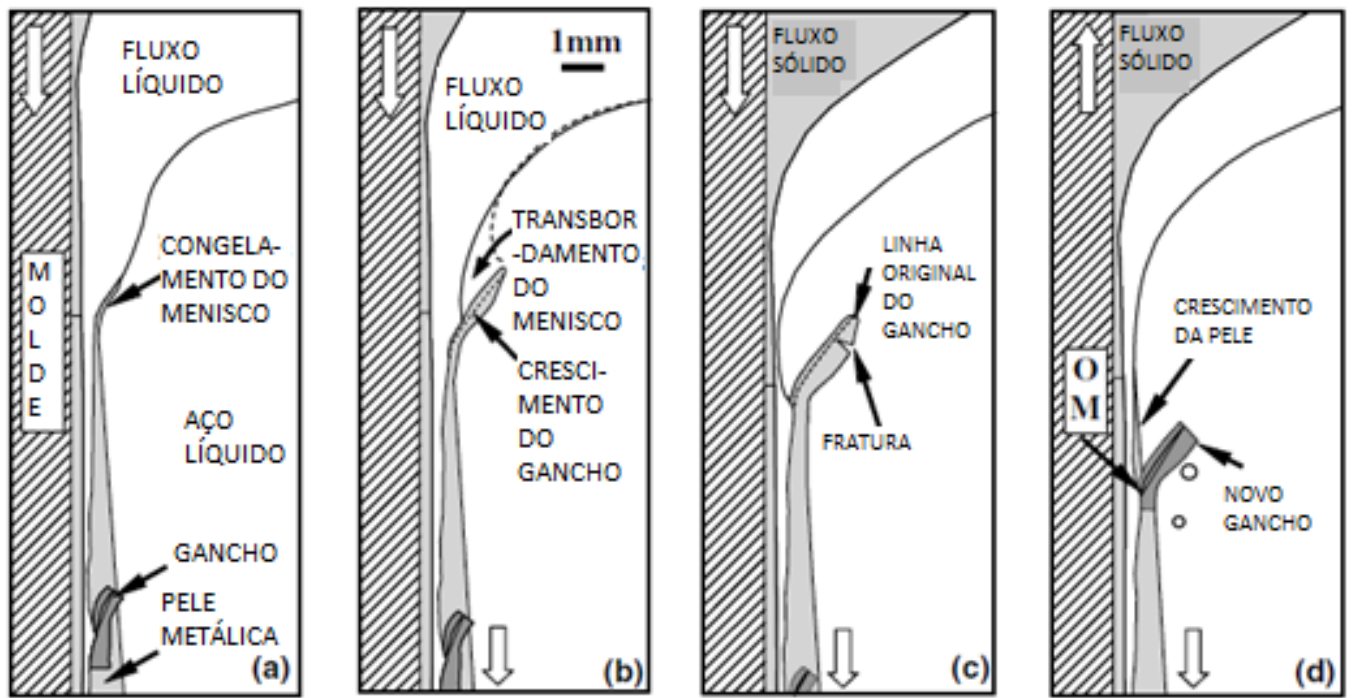

Figura 3.1-3: Ilustração esquemática da curva de formação de gancho em placa de aço ultra baixo carbono através da solidificação do menisco e subsequente transbordamento do aço líquido. Marcas de oscilação são formadas pelo crescimento normal da casca após o transbordamento.

\subsection{Configuração Típica de Conjunto de válvulas com controle de fluxo por válvula gaveta.}

De acordo com Yuan (2008) uma configuração típica para os sistemas de válvulas gavetas compreende várias peças: válvula superior, placa superior, placa intermediária, monobloco e válvula submersa, como apresentado na Figura 3.2-1. 


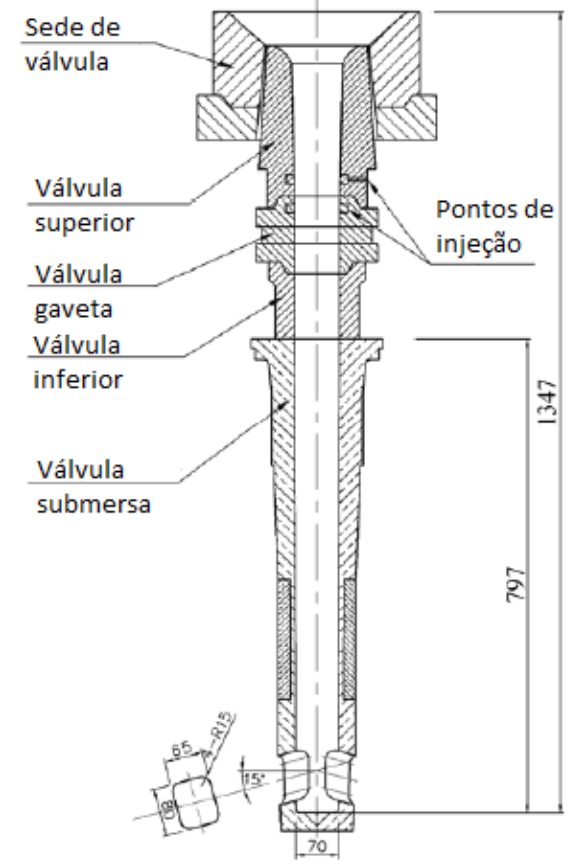

Figura 3.2-1: Configuração típica montagem refratária para os sistemas de válvulas gavetas.

\subsection{Métodos de Injeção de Gás}

Suzuki (2003) apresenta e discute sobre os locais comuns de adesão da alumina e possíveis pontos de injeção de gás no sistema refratário de válvula gaveta para reduzir a taxa de deposição de alumina (Figura 3.3-1). Embora, a injeção de Argônio (Ar) possa ser realizada em várias regiões do sistema de refratários, cada sistema de injeção tem suas vantagens e desvantagens, conforme apresentado na Tabela 3.3-1. 

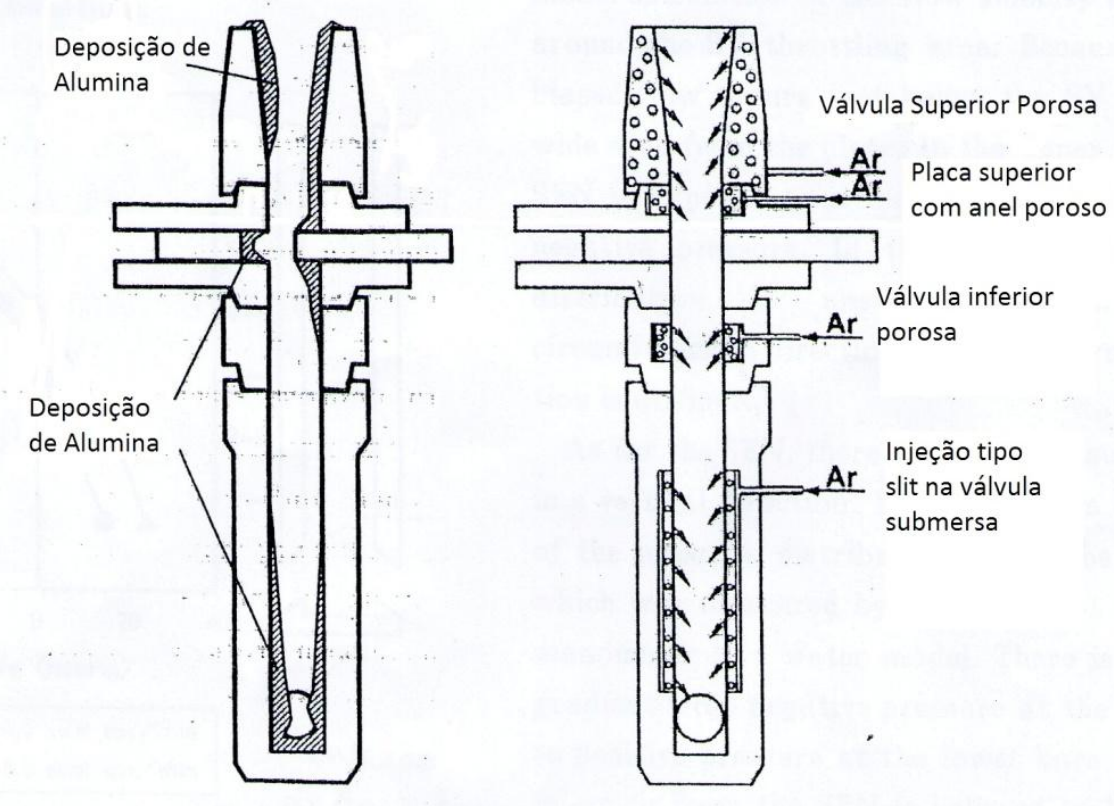

Figura 3.3-1: Típico exemplo de adesão de alumina e métodos de injeção de gás no sistema de refratários do lingotamento contínuo de placas.

Para Suzuki (2003) o método mais efetivo para prevenir obstrução na válvula submersa é a injeção de Ar através de uma área porosa dentro da própria válvula. Porém, em casos onde a obstrução de alumina não se forma somente na válvula submersa, mas também na válvula superior e nas placas deslizantes, a injeção de Ar na válvula superior é benéfica porque as bolhas de gás fluem de cima para baixo pelo sistema reduzindo a área de baixa pressão do sistema de válvula gaveta e prevenindo a formação de obstrução por alumina em todo o conjunto.

Na seleção do método de injeção de gás, não se deve levar em conta somente a prevenção da obstrução, mas também o comportamento das bolhas de gás no molde. Em relação a essa questão Suzuki (2003) enfatiza os seguintes fatores (Tabela 3.3-1):

- Efeito da distribuição da pressão do fluido sobre uniformidade da injeção de gás;

- Estabilidade estrutural da selagem de gás;

- Otimização do tamanho das bolhas através do controle da porosidade do refratário. 
Tabela 3.3-1: Características do método de injeção de gás para refratários de lingotamento contínuo.

\begin{tabular}{|c|c|c|c|}
\hline $\begin{array}{l}\text { Local de injeção } \\
\text { de gás }\end{array}$ & $\begin{array}{l}\text { Uniformidade da injeção de } \\
\text { gás (uniformidade da } \\
\text { distribuição de pressão na } \\
\text { região de baixa pressão do } \\
\text { refratário da válvula gaveta) }\end{array}$ & $\begin{array}{c}\text { Estabilidade estrutural } \\
\text { do sistema da selagem } \\
\text { de gás }\end{array}$ & $\begin{array}{l}\text { Otimização do tamanho das } \\
\text { bolhas }\end{array}$ \\
\hline Válvula superior & Bom. & Bom. & \multirow{3}{*}{$\begin{array}{l}\text { Possível através do uso de tijolo } \\
\text { queimado com tamanho de poro } \\
\text { adequado. }\end{array}$} \\
\hline Placa superior & $\begin{array}{c}\text { Afetado pela abertura da } \\
\text { válvula gaveta. }\end{array}$ & Susceptível a trincas. & \\
\hline Válvula inferior & $\begin{array}{l}\text { Extremamente afetada pela } \\
\text { abertura da válvula gaveta. }\end{array}$ & $\begin{array}{c}\text { A vedação das faces } \\
\text { superior e inferior é difícil. }\end{array}$ & \\
\hline $\begin{array}{l}\text { Válvula submersa } \\
\text { (SEN) }\end{array}$ & $\begin{array}{l}\text { Bom na direção cilíndrica, } \\
\text { mas elevado gradiente de } \\
\text { pressão na direção vertical. }\end{array}$ & Bom. & $\begin{array}{c}\text { Material poroso tem apenas micro } \\
\text { poros, as bolhas coalescem } \\
\text { facilmente, o tamanho dos poros } \\
\text { se modificam durante o } \\
\text { lingotamento. }\end{array}$ \\
\hline
\end{tabular}

\subsection{Mecanismos da obstrução de válvulas do distribuidor}

A Figura 3.4-1 apresenta um exemplo de simulação de modelo computacional da distribuição de velocidade na região do estrangulamento do sistema de válvula gaveta. Devido a um forte desvio do fluxo logo abaixo do estrangulamento da válvula gaveta, tem-se uma considerável região exposta a uma pressão negativa. Nesta região, a distribuição de pressão do fluido é irregular, particularmente na direção cilíndrica, ocasionando uma difícil distribuição uniforme do gás (Yuan, 2008; Magnesita, 2003).

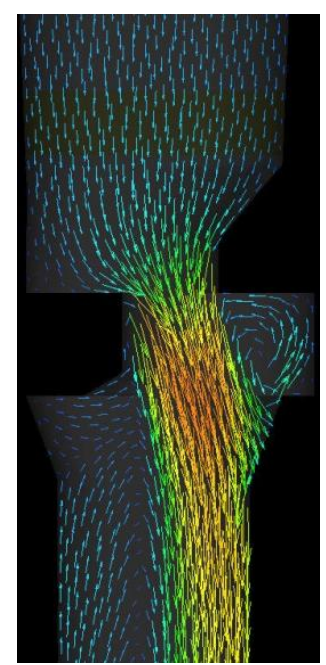

Figura 3.4-1: Imagem ilustrativa do cálculo da distribuição de velocidade do fluido na região da válvula gaveta (Magnesita, 2003). 
De acordo com YUAN (2008) a pressão no sistema de válvulas é significativamente afetada pela taxa de injeção de Ar e abertura das placas. Para manter a pressão positiva a taxa de injeção de Ar deve ser aumentada e a taxa de abertura das placas deve ser reduzida. O efeito da elevação da taxa de Ar sobre a deposição de Alumina não é obvio quando se aplica uma redução na abertura das placas.

Esse mesmo autor afirma que um dos fatores críticos para a deposição de alumina é a limpidez do aço. Ele confirmou esta observação através do acompanhamento da obstrução de um considerável número de válvulas submersas e da análise da composição química do aço líquido. Utilizando o software comercial CFX para o modelamento foram comparadas diversas condições de lingotamento. A partir destas simulações foi observado que o comportamento do fluxo de aço líquido no conjunto de válvulas é determinado por diferentes parâmetros, tais como: velocidade de lingotamento, percentual da abertura da válvula gaveta e taxa de injeção de argônio.

Pressões negativas são geradas quando o aço líquido flui através da válvula gaveta, de forma que o ar é facilmente aspirado para dentro do aço através do espaço entre as peças do sistema de refratários. A reoxidação causada pela aspiração de ar é uma importante razão para obstrução da válvula. Para se evitar esta situação as juntas das válvulas devem ser seladas e a pressão causada pela injeção de argônio deve ser positiva (Yuan, 2008).

A Figura 3.4-2 apresenta a relação do fluxo de Argônio (Q) e a distribuição de pressão através do centro do conjunto de válvula para diferentes taxas de abertura da válvula gaveta.

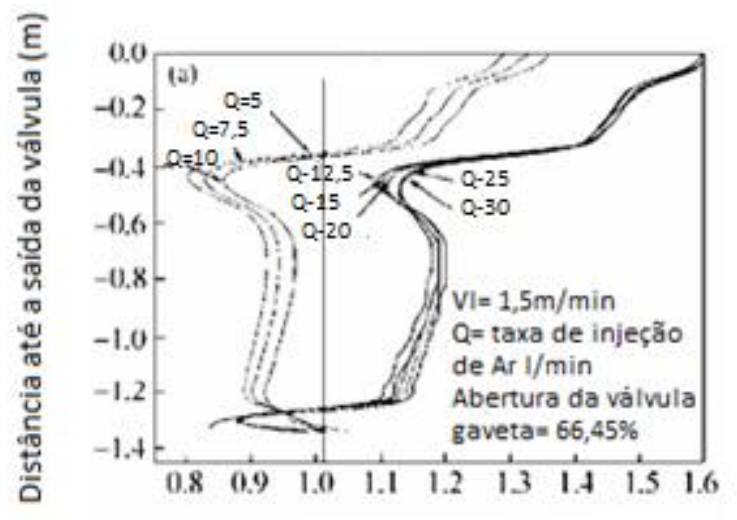

Pressão estática ao longo da linha central do conjunto de válvulas $\left(10^{5} \mathrm{~Pa}\right)$
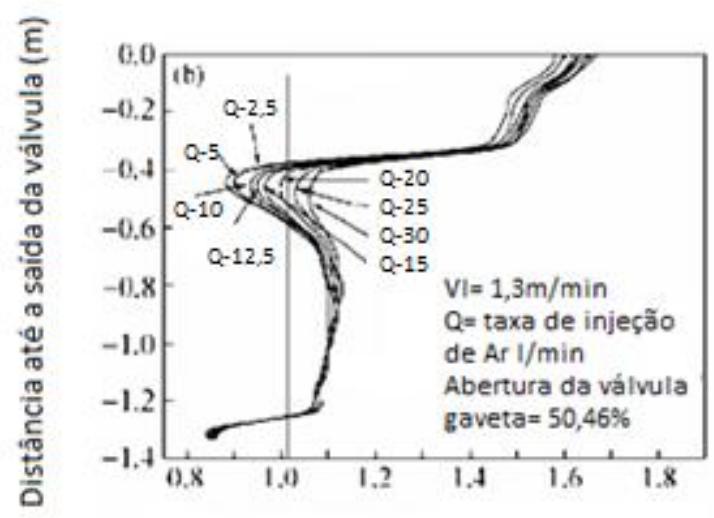

Pressão estática ao longo da linha central do conjunto de válvulas $\left(10^{5} \mathrm{~Pa}\right)$ 


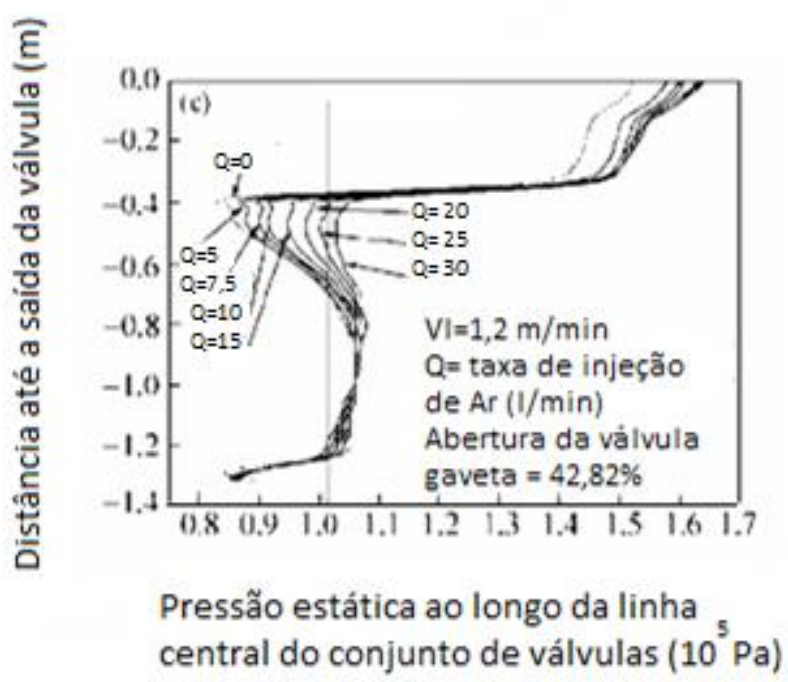

Figura 3.4-2: Efeito da taxa de injeção de argônio sobre a pressão interna ao longo da linha central : (a) $K=66,45 \%$, (b) $K=50,46 \%$ e (c) $K=42,82 \%$ (sendo $K$ o \% de abertura de válvula gaveta).

Para maiores aberturas de válvula gaveta (Figura 3.4-2 a) é possível manter pressões positivas com taxas menores de injeção de Argônio. Com a redução da abertura da válvula gaveta são necessárias maiores taxas de injeção de Ar (Figura 3.4-2 b e c). Por exemplo, para abertura $\mathrm{K}=42,82 \%$ são necessárias taxas de injeção de Ar de 25-30 1/min. O efeito da taxa de injeção de Ar sobre a deposição de alumina é apresentado na Figura 3.4-3. A taxa de injeção de Argônio afeta significativamente a taxa de deposição de alumina, mas o resultado muda com a taxa de abertura da válvula gaveta. Para valores elevados de abertura da válvula gaveta, Figura 3.4-3 (a) e (b), a taxa de deposição tem diferentes mínimos e máximos. Ficando o mínimo na faixa de 5 a 15 para taxa de abertura de 74,71\%, Figura 3.4-3 (a), e 5 a 10 1/min para taxa de abertura de 66,45\%, Figura 3.4-3 (b), respectivamente. Entretanto, para aberturas menores, Figura 3.4-3 (c), a taxa de deposição de alumina se reduz com a elevação da taxa de injeção de Argônio (Yuan, 2008).
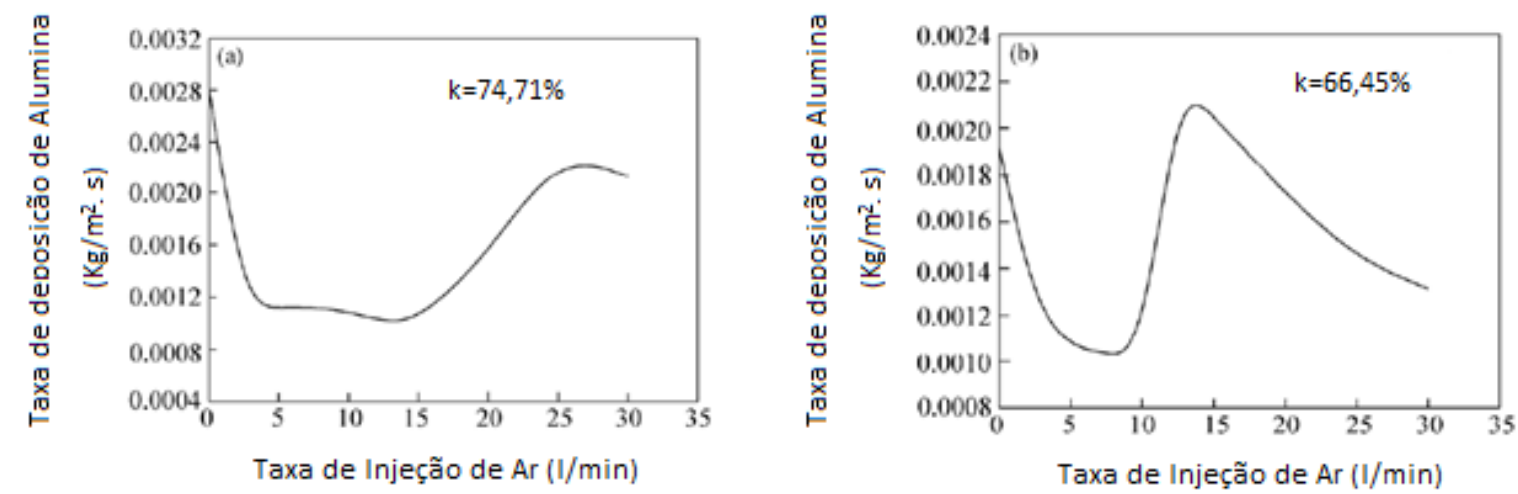


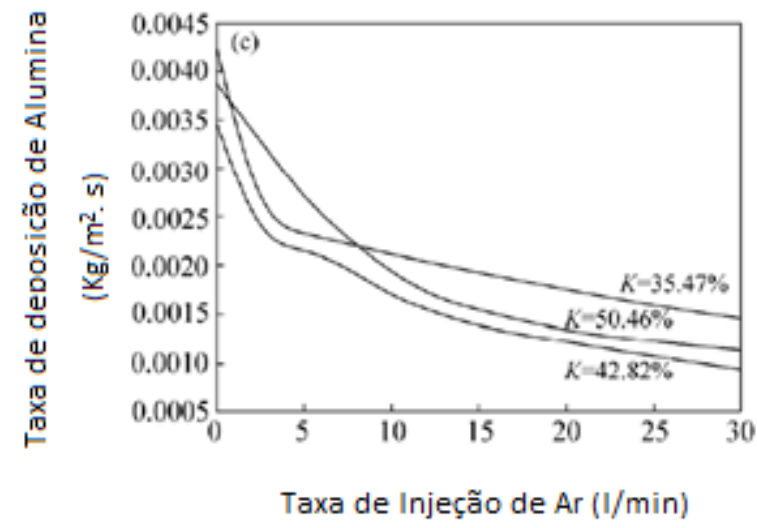

Figura 3.4-3: Influência da taxa de argônio sobre a deposição de alumina.

A Figura 3.4-4 apresenta o cálculo da taxa de deposição de alumina para diferentes percentuais de alumina. Por um lado, a taxa de deposição de alumina tem comportamento linear em relação ao percentual de alumina para taxas de abertura e de injeção de Ar fixas. Por outro lado, com o aumento da velocidade de lingotamento se observa que a inclinação da reta se eleva (Yuan, 2008).
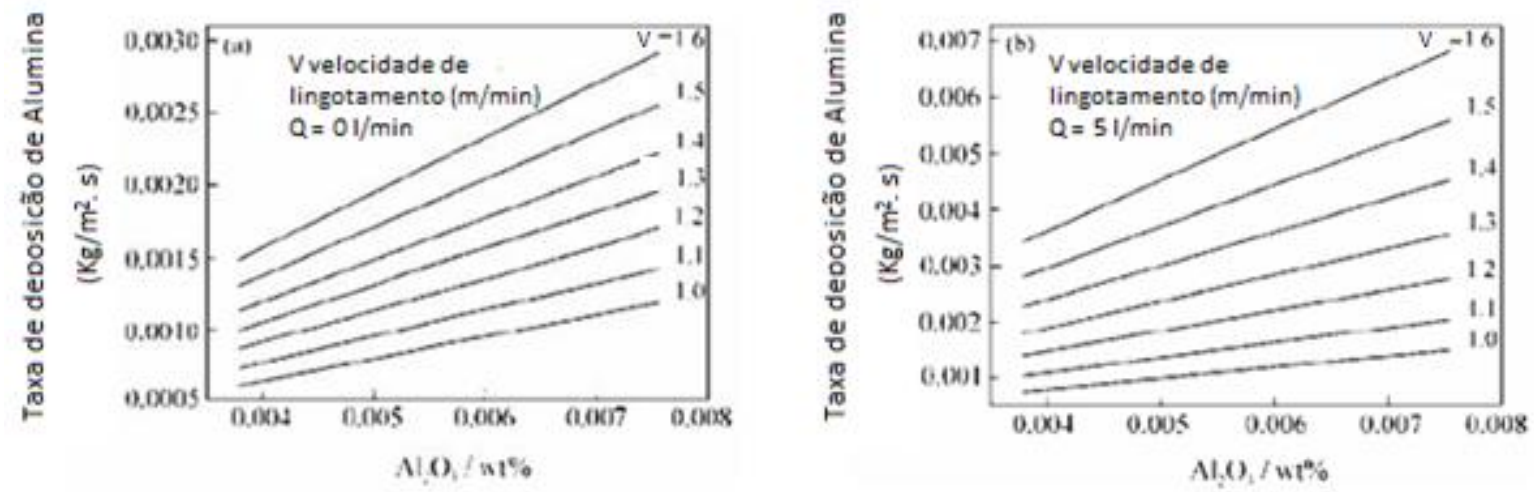

Figura 3.4-4: Taxa de deposição de alumina para diferentes percentuais de alumina no aço em diferentes velocidades.

Borges (2005) realizou simulação matemática para avaliação de resultados das pressões negativas dentro do sistema de refratários com foco na região do sistema de válvula gaveta. De acordo com os resultados da simulação matemática (ver Figura 3.4-5), para as condições definidas na Tabela 3.4-1, foi observado por Borges (2005):

- $\quad$ "Não ocorreu variação significativa no perfil de escoamento do aço no interior das válvulas em função das vazões de argônio e das posições de injeção. 
- A mudança de vazão nos pontos de injeção altera sutilmente a distribuição de argônio no interior da válvula.

- A injeção de gás abaixo da gaveta provocou mudanças mais significativas na distribuição de argônio e na pressão mínima.

- $\quad$ o caso 3 foi o que apresentou menor pressão mínima no interior da válvula.

- Todas as válvulas apresentaram pressão negativa na região da gaveta.

- A principal razão está na alta velocidade de lingotamento empregada, em torno de $2 \mathrm{~m} / \mathrm{min}$ ou 8 t/min de aço."

Tabela 3.4-1: Condições de Injeção de gás na válvula superior e válvula submersa.

\begin{tabular}{|c|l|c|c|c|c|}
\hline \multicolumn{2}{|c|}{ Vazão de argônio } & Caso 1 & Caso 2 & Caso 3 & Caso 4 \\
\hline \multirow{2}{*}{$\begin{array}{c}\text { Válvula } \\
\text { superior }\end{array}$} & $\begin{array}{l}\text { Ponto de injeçao } \\
\text { superior }\end{array}$ & $12 \mathrm{NI} / \mathrm{min}$ & $9 \mathrm{Nl} / \mathrm{min}$ & $3 \mathrm{NI} / \mathrm{min}$ & $6 \mathrm{NI} / \mathrm{min}$ \\
\cline { 2 - 6 } & $\begin{array}{l}\text { Ponto de injeçao } \\
\text { inferior }\end{array}$ & $3 \mathrm{Nl} / \mathrm{min}$ & $6 \mathrm{Nl} / \mathrm{min}$ & $3 \mathrm{NI} / \mathrm{min}$ & $3 \mathrm{NI} / \mathrm{min}$ \\
\hline \multirow{2}{*}{$\begin{array}{c}\text { Válvula } \\
\text { Submersa }\end{array}$} & $\begin{array}{l}\text { Ponto de injeçao } \\
\text { superior }\end{array}$ & - & - & - & $3 \mathrm{NI} / \mathrm{min}$ \\
\cline { 2 - 6 } & $\begin{array}{l}\text { Ponto de injeçao } \\
\text { inferior }\end{array}$ & - & - & $9 \mathrm{NI} / \mathrm{min}$ & $3 \mathrm{NI} / \mathrm{min}$ \\
\hline
\end{tabular}

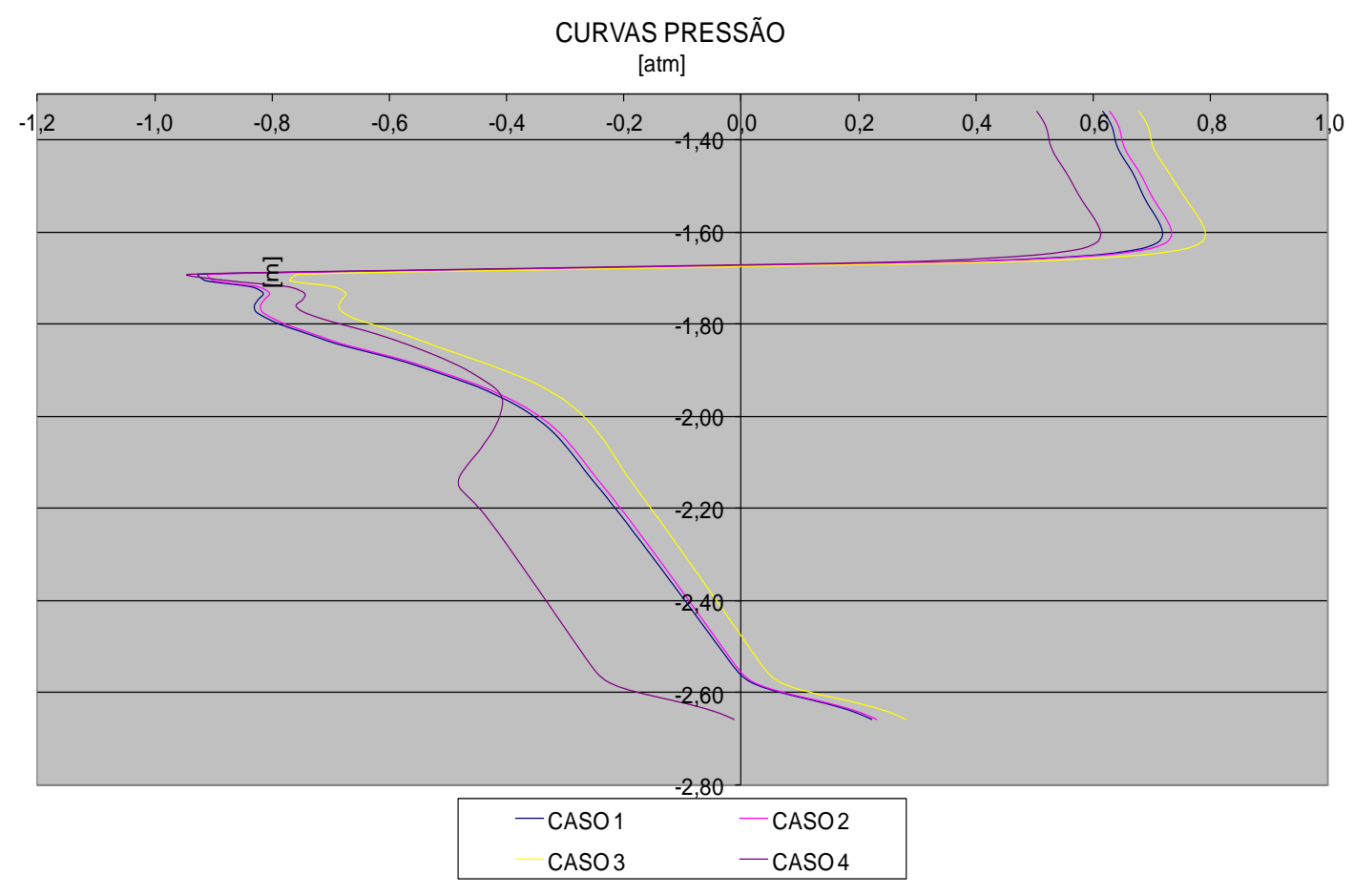

Figura 3.4-5: Efeito da vazão de argônio e pontos de injeção sobre a pressão interna ao longo da linha central do sistema de refratários para casos diversos. 
Borges et al (2005) estudou a redução da formação de obstrução nas Válvulas Superior, Inferior e Submersa pela redução do diâmetro do furo da placa de Válvula Gaveta. Foi avaliado o efeito do diâmetro do furo para uma mesma abertura de válvula gaveta (área útil) com uma mesma condição de injeção de argônio (Figura 3.4-6).

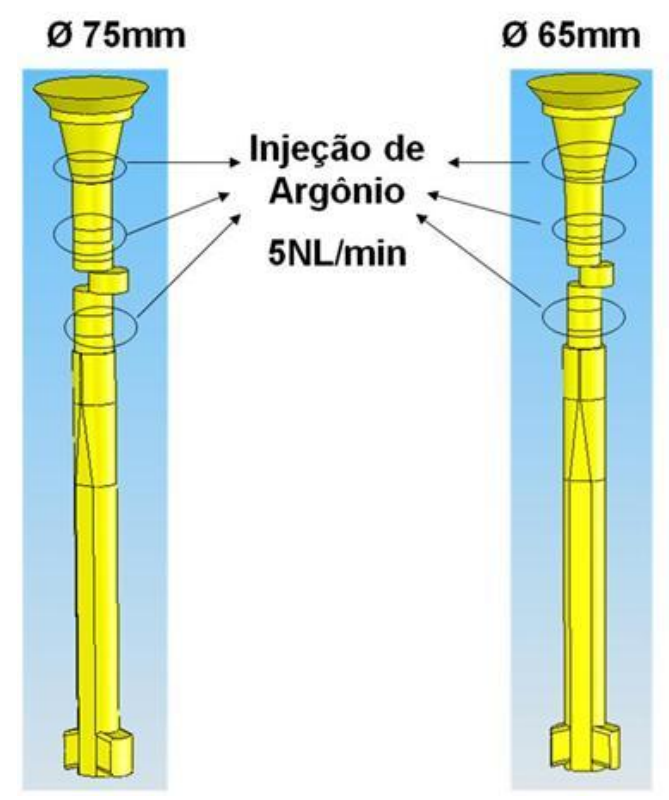

Figura 3.4-6: Pontos de injeção de argônio para diferentes diâmetros do furo das placas do sistema de válvula gaveta.

Borges et al (2005) verificou que a redução do diâmetro do sistema de válvula gaveta proporcionou melhor distribuição do argônio no sistema de refratários (Figura 3.4-7). Este comportamento se deve ao fato de que, a redução do diâmetro do sistema de válvula gaveta (SGV), para se obter uma mesma vazão de aço, implica em uma maior abertura do SVG, ou seja, tem-se um menor estrangulamento da válvula gaveta. 

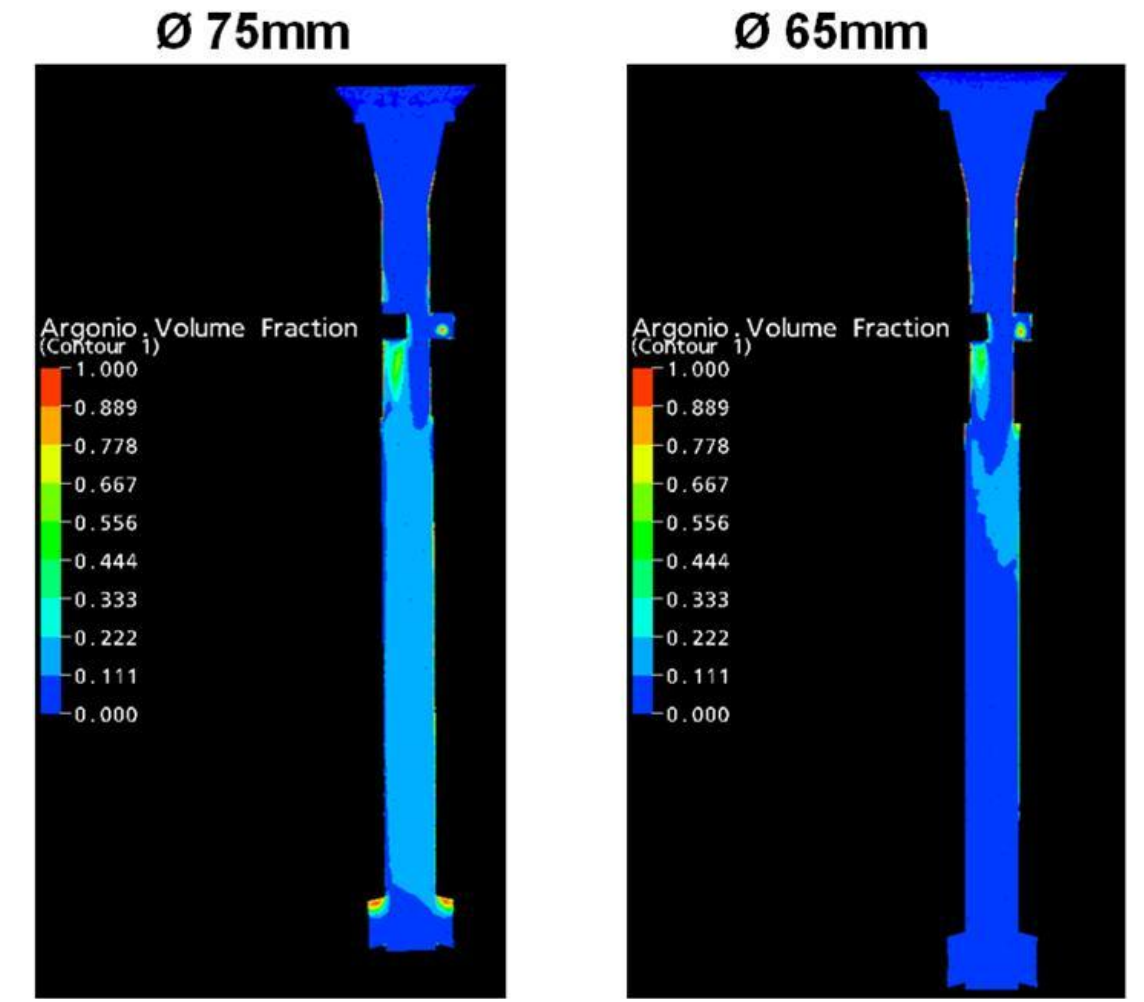

Figura 3.4-7: Fração volumétrica de argônio no sistema de refratários com controle de fluxo tipo válvula gaveta.

Outra vantagem observada por Borges et al (2005) para a redução do diâmetro do sistema de válvula gaveta, é que houve uma redução de quase $50 \%$ da pressão negativa na região de estrangulamento da válvula. Isto conforme Yuan (2008), reduz a probabilidade de arraste de ar e a reoxidação do aço, levando a uma menor obstrução por alumina.

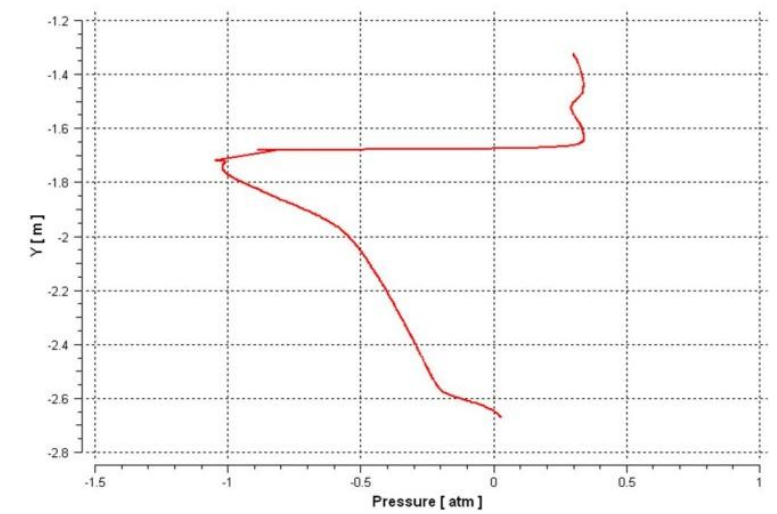

(a)

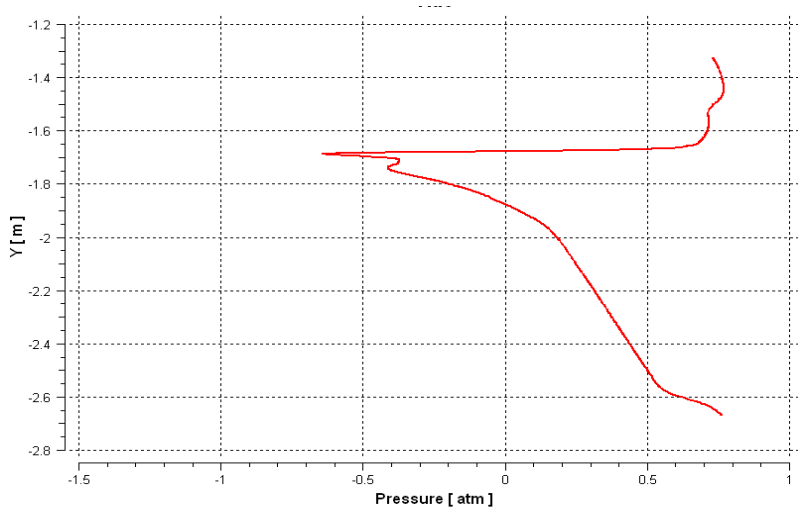

(b)

Figura 3.4-8: Efeito da vazão de argônio sobre a pressão interna ao longo da linha central do sistema de refratários para diâmetro de furo (a) $75 \mathrm{~mm}$ e (b) $65 \mathrm{~mm}$. 


\subsection{Comportamento do gás injetado na válvula superior}

Suzuki (2003) utilizou válvula superior porosa com janela de vidro, para observar o comportamento das bolhas de gás injetadas na válvula superior, em modelo físico em água com sistema de controle de fluxo tipo válvula gaveta (SVG). A Figura 3.5-1 apresenta de maneira esquemática as observações realizadas. Para condições de elevadas vazões as bolhas geradas isoladamente são praticamente arrancadas da superfície refratária diretamente para o fluxo de água. As bolhas descem através da garganta do sistema de válvula gaveta e depois são lançadas no molde através das aberturas da SEN. Enquanto que para baixas vazões e elevadas taxas de injeção de gás, um filme de gás se forma sobre a superfície porosa pela coalescência das bolhas. Algumas vezes, parte deste filme de gás se desprende e forma uma bolha grande que sobe até o distribuidor.

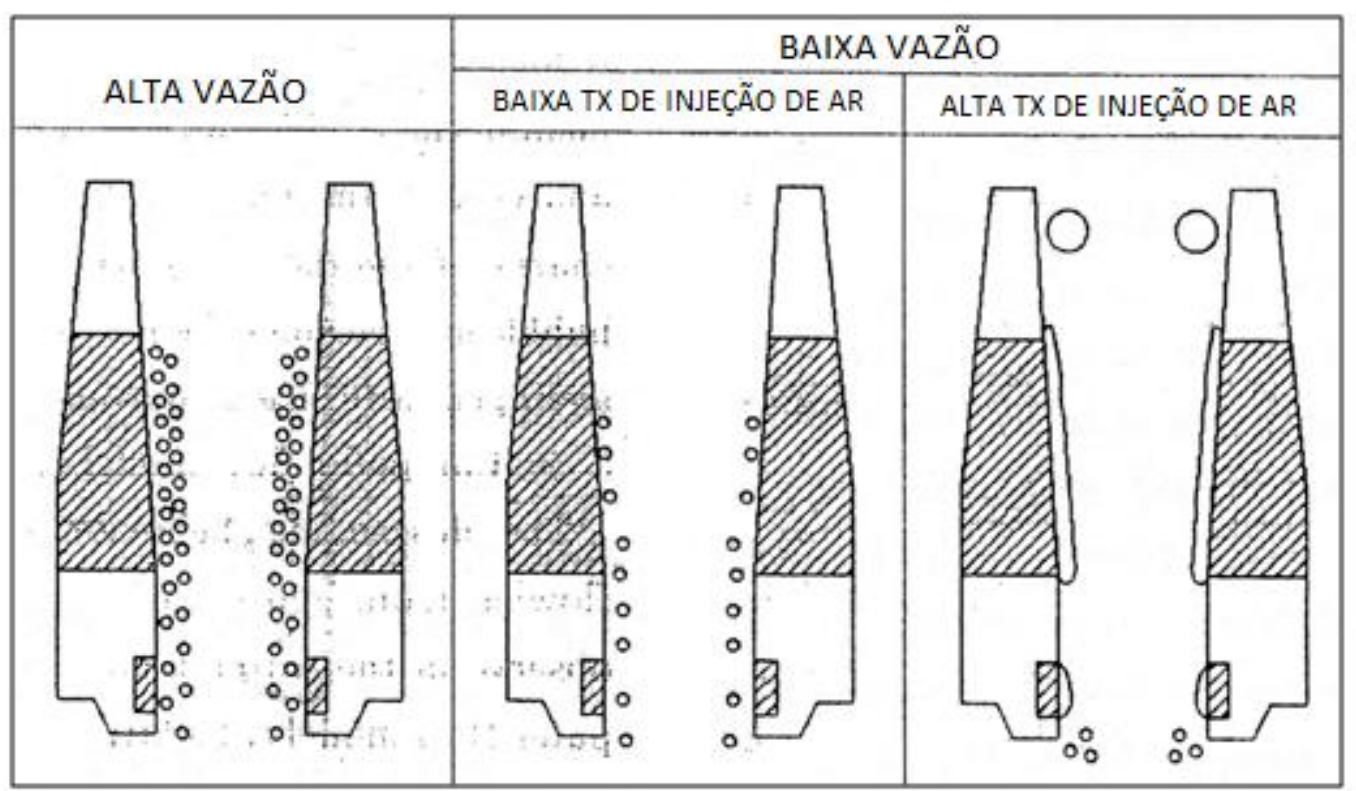

Figura 3.5-1: Desenho esquemático da geração de bolhas no modelo em água.

De acordo com Suzuki (2003) o tamanho das bolhas de gás lançadas pela saída da válvula submersa depende do material poroso, da taxa de injeção de gás, da velocidade do fluído (vazão/ área da seção transversal) e da estrutura da SEN. Por exemplo, em modelo em água, utilizando-se o mesmo material poroso, observa-se que o tamanho da bolha tende a reduzir com a elevação da velocidade do fluido e tende a tornar-se maior com o aumento da taxa de injeção de gás. 
Para Suzuki (2003) a utilização de materiais porosos com variadas distribuições de tamanho de poro permite modificar o tamanho médio da bolha. $\mathrm{O}$ diâmetro da bolha se torna maior com aumento do tamanho médio do poro do material. O tamanho das bolhas foi mensurado por um analisador de imagens através de fotos das bolhas na saída da SEN.

Borges (2004) avaliou o efeito da geometria da válvula superior (ver Figura 3.5-2) para condições limites de lingotamento. Essa mudança na geometria acarreta uma variação no perfil de velocidade, visto que, a válvula padrão apresenta diâmetro de entrada de $100 \mathrm{~mm}$, enquanto a modificada apresenta diâmetro de $120 \mathrm{~mm}$, e consequentemente, no escoamento no interior da válvula.

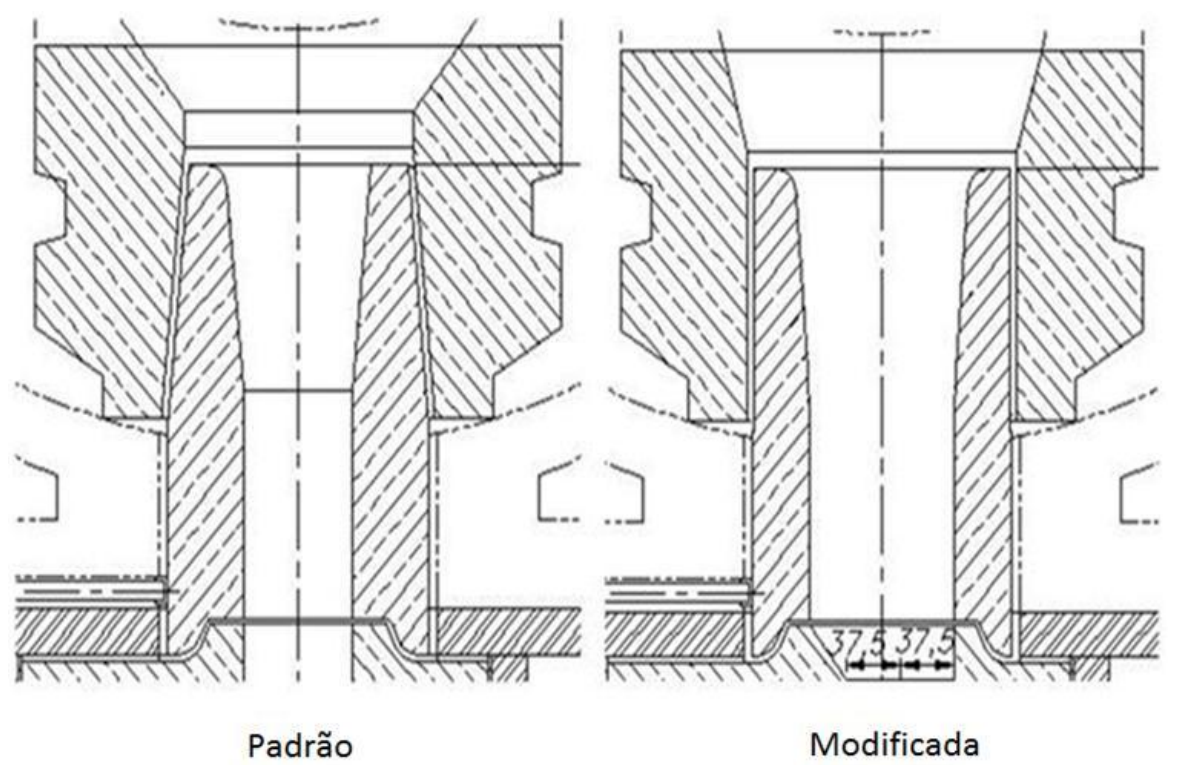

Figura 3.5-2: Projeto válvula superior padrão, utilizada rotineiramente em lingotamento contínuo, e modificada, avaliada em modelo matemático para comparar perfil de velocidade do aço líquido e comportamento da fase gasosa.

Borges (2004) avaliou as condições de fluxo para as duas geometrias de válvulas, que foram simuladas numericamente para duas condições de vazão de aço, 2 e 4t/min.veio, e para duas condições de injeção de gás na válvula superior, ponto superior com $12 \mathrm{Nl} / \mathrm{min}$ e ponto inferior com $3 \mathrm{Nl} / \mathrm{min}$ (caso 1), e ponto superior com $9 \mathrm{Nl} / \mathrm{min}$ e ponto inferior com $6 \mathrm{Nl} / \mathrm{min}$ (caso 2) (Figura 3.5-3). 


\section{Em relação aos resultados obtidos, Borges (2004), afirmou:}

- “As regiões de saída dos distribuidores também eram diferentes, o que justificou a simulação do escoamento nestes. Os perfis de velocidade gerados nas saídas foram usados como condição de contorno nos modelos de válvula.

- Pela análise dos perfis de velocidade na entrada das válvulas, observou-se uma redução de até $19 \%$ na velocidade média para a válvula modificada.

- Essa diferença foi responsável pela diminuição do arraste de argônio que, como consequência, ascendeu mais facilmente, chegando em maior quantidade ao topo da válvula. Esse efeito foi observado somente para a vazão de lingotamento de 2t/min/veio, com um tamanho de bolha de $2 \mathrm{~mm}$ (ver Figura 3.5-4).

- Esse argônio pode ser aquele observado no teste em produção, como bolhas na superfície do distribuidor.

- $\quad$ Para uma vazão de 4 t/min/veio não se observou argônio ascendendo pelas paredes da válvula em nenhuma geometria simulada.

- A fração volumétrica de argônio mostra as principais diferenças entre as válvulas. O argônio fica mais próximo às paredes do modelo Inicial, devido às maiores velocidades (menor área).

- As variações de vazão de argônio entre os casos 1 e 2 não apresentaram efeitos significativos no escoamento.

- O modelo Modificado tende a reter mais argônio na região da gaveta, pois apresenta recirculações maiores nesta região.

- O modelo Modificado apresenta regiões menores de pressão negativa e menos recirculações abaixo da gaveta. Estas recirculações estão relacionadas ao perfil de escoamento de cada válvula." 

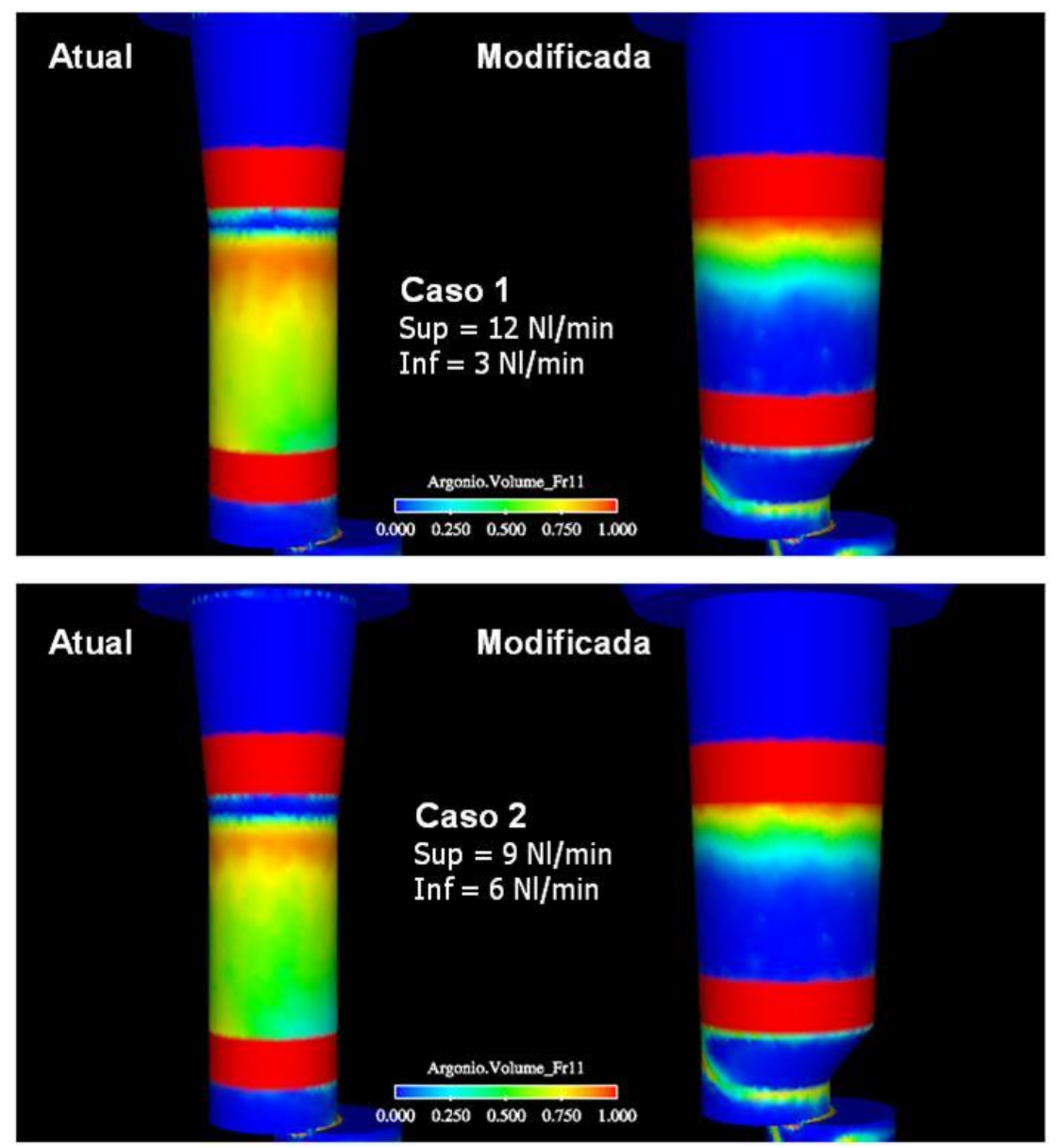

Figura 3.5-3: Fração volumétrica para válvula superior projeto padrão e modificada para injeção de argônio, Caso 1, superior 12Nl/min e inferior 3Nl/min, e Caso 2, superior 9N1/min e inferior $6 \mathrm{~N} l / m i n$

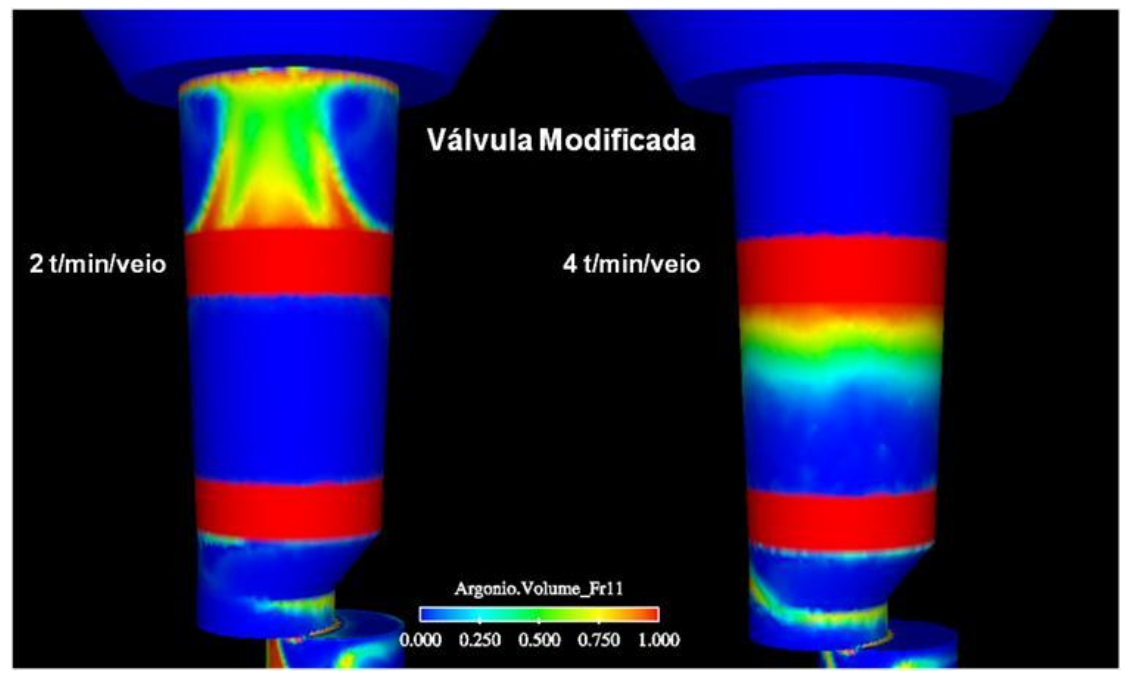

Figura 3.5-4: Fração volumétrica para válvula superior modifica para vazão de aço 2 e 4 t/min.veio.

Lee et al (2009) desenvolveu estudo para investigar o comportamento inicial de bolhas, em modelo em água, utilizando amostras revestidas de refratário de $\mathrm{MgO}$ poroso para simular o 
elevado ângulo de contacto aço-argônio com diferentes permeabilidades. O ar é injetado através do refratário e percorre vários poros através de uma rede de poros interligada até sua saída na superfície do refratário por meio de sítios ativos. O sitio ativo é um poro por onde o gás sai da superfície do refratário. O efeito das propriedades refratárias tem sido investigada tanto em modelo em água estagnada como com fluxo descendente. $\mathrm{O}$ número de sítios ativos aumenta com o aumento da taxa injeção do gás, da permeabilidade, da velocidade do fluxo de água, e menor ângulo de contacto.

A Figura 3.5-5 apresenta um diagrama esquemático do modelo de água. Fluxo de água sai do fundo do distribuidor através de uma válvula superior de distribuidor. O ar é injetado através de uma amostra refratária porosa $(14 \mathrm{~mm}$ de largura x $44 \mathrm{~mm}$ de comprimento x $17 \mathrm{~mm}$ de profundidade) centrada em uma parcela representativa da parede da válvula. O fluxo de água é controlado por um sistema de válvula gaveta de maneira a possibilitar regulagem deste entre 20 a $45 \mathrm{lpm}$, o que corresponde a velocidades médias de água, $\mathrm{V}_{l}$, no interior da válvula de 0,68 a $1.58 \mathrm{~m} / \mathrm{s}$, considerando um quadrado de $22 \times 22 \mathrm{~mm}$ de área de seção transversal. $\mathrm{O}$ formato quadrado da válvula permite a observação clara do comportamento inicial da bolha dentro da válvula, sem distorção por refração.

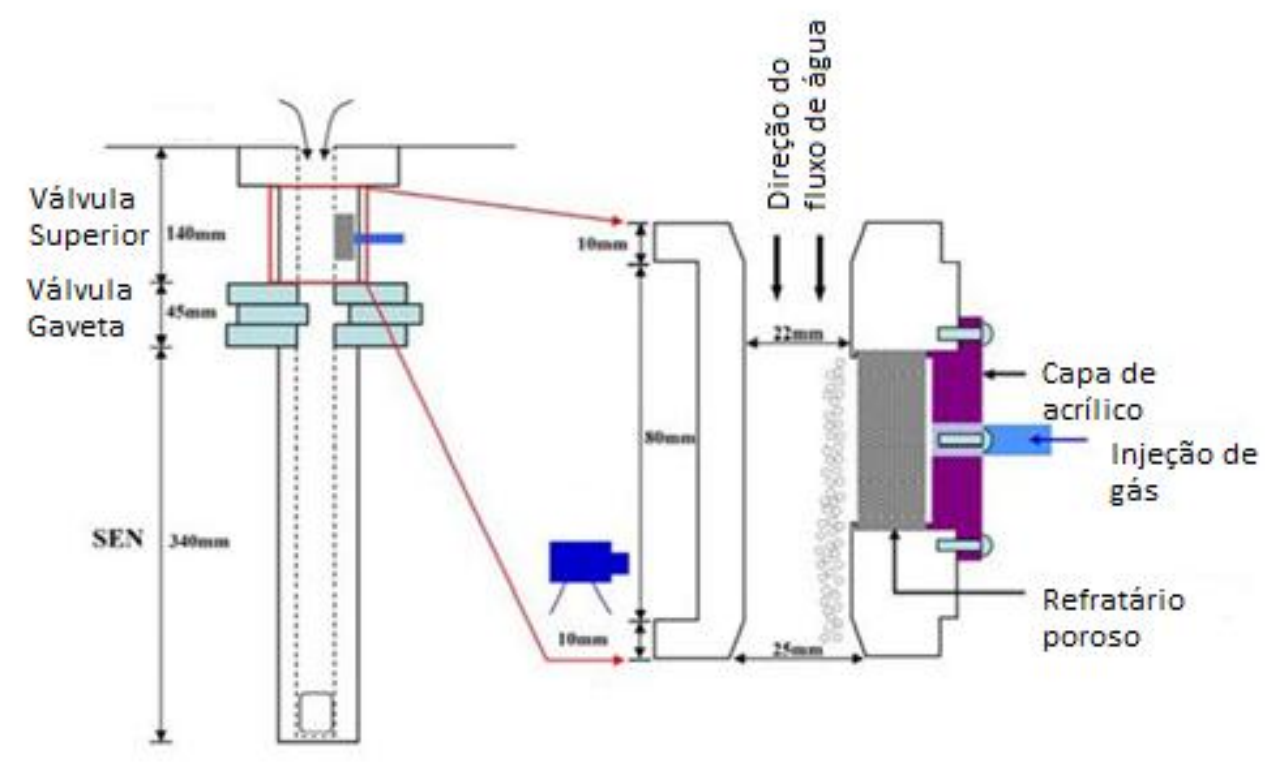

Figura 3.5-5: Injeção de gás através de refratário poroso de MgO.

Lee et al (2009) preparou as amostras porosas de refratário ( $\mathrm{MgO})$ com permeabilidades diferentes. De acordo Lee apud Wang $(1998,1997)$ a molhabilidade entre o aço fundido e o refratário poroso tem grande influência sobre a formação de bolhas na superfície da válvula. 
Para atingir valores semelhantes de baixa molhabilidade (ângulo de contacto elevado), entre a água e o refratário, Lee et al (2009) realizou tratamento especial da superfície do refratário.

A vazão de gás, $\mathrm{Q}_{\mathrm{g}}$, foi ajustada para 0,1 1,0 litro padrão por minuto (LPPM), de maneira a alcançar uma velocidade média de injeção (taxas de fluxo por unidade de área da superfície do refratário) de 0,016 0,162 LPPM/ $/ \mathrm{cm}^{2}$. O gás é injetado em um tubo inserido na parte de trás da peça de refratário poroso. A formação de bolhas inicial foi gravada por uma câmera de alta velocidade (4.000 quadros por segundo), e avaliada posteriormente quadro a quadro. Imagens representativas da filmagem são mostradas na Figura 3.5-6 para três velocidades de água e taxas de injeção de gás. Cada poro por onde as bolhas surgem na superfície refratária é identificada como um "sítio ativo". A contagem dos sítios ativos, do tamanho das bolhas e sua distribuição, foram executadas através de medições diretas realizadas nas imagens individuais de vídeo (Lee et al, 2009).

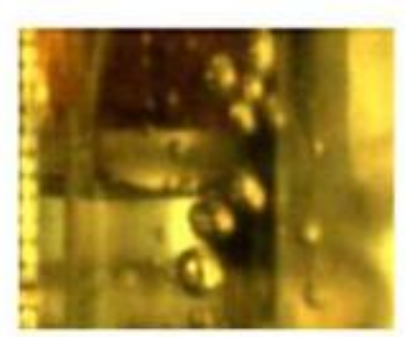

(a)

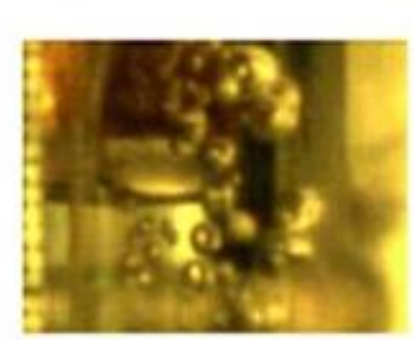

(b)
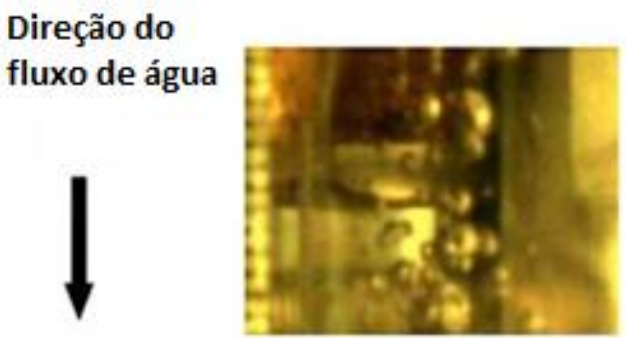

(c)

Figura 3.5-6: Fotos do experimento em água com várias velocidade de água, Vl, e velocidade de gás na válvula, Vg : (a) $\mathrm{Vl}=0,97 \mathrm{~m} / \mathrm{s} ; \mathrm{Vg}=0,0027 \mathrm{~m} / \mathrm{s}$ (b) $\mathrm{Vl}=0,97 \mathrm{~m} / \mathrm{s} ; \mathrm{Vg}=0,0081 \mathrm{~m} / \mathrm{s} ;$ (c) $\mathrm{Vl}=1,27 \mathrm{~m} / \mathrm{s}$;

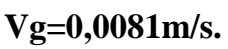

As medições no modelo em água mostram que tanto o tamanho médio da bolha e a variação de sua distribuição aumentam, com o aumento da taxa de injeção de gás, e com a diminuição da velocidade da água, como mostrado na Figura 3.5-7. Reduzindo a velocidade da água abaixo do valor crítico mínimo (como os encontrados nas regiões de recirculação abaixo da válvula gaveta), facilita a formação de bolhas de grandes dimensões. A liberação periódica de tais bolsas de gás pode resultar em flutuações significativas no nível do molde, conduzindo ao aprisionamento de fluxante e defeitos superficiais associados com a instabilidade do menisco (Lee et al, 2009). 

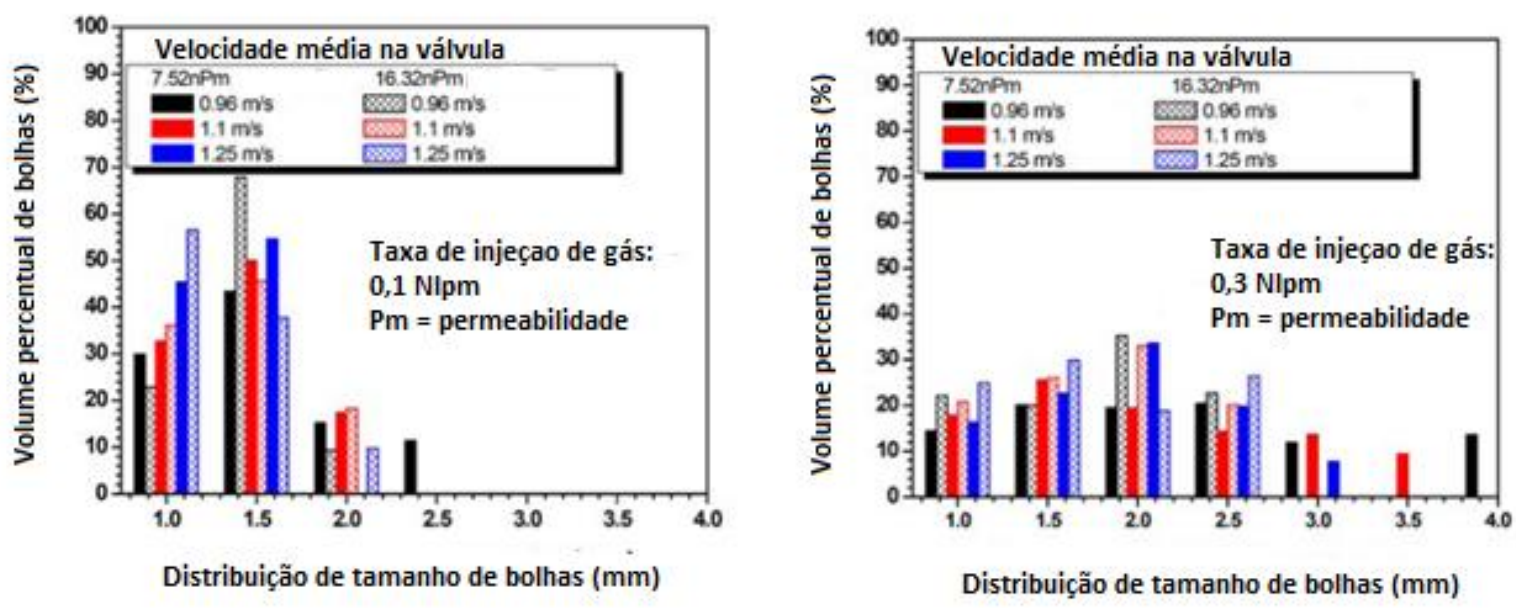

Figura 3.5-7: Distribuição de tamanho de bolhas com diferente velocidade de água e taxa de vazão de gás $\left(6,2 \mathrm{~cm}^{2}\right.$ de área superficial da amostra sem revestimento do refratário).

\subsection{Tipos de configurações da válvula superior do distribuidor}

De maneira a se evitar a adesão da alumina na válvula superior é necessário injeção uniforme de gás, além da prevenção adequada de vazamentos. Para uma injeção uniforme de gás, a otimização da estrutura da válvula superior é necessária, como também, da câmera de gás, do material de selagem, do material denso e da carcaça metálica. A Figura 3.6-1 apresenta estruturas de válvula superior empregadas nas siderúrgicas japonesas produzidas fornecidas pela Shinagawa. A estrutura da válvula superior deve ser ajustada para as condições específicas de cada máquina de lingotamento, tais como operação de distribuidor e as restrições dimensionais do cassete do sistema de válvula gaveta (Suzuki, 2003).

\begin{tabular}{|l|l|l|l|}
\hline $\begin{array}{l}\text { Toda porosa com dois } \\
\text { pontos de injeção }\end{array}$ & Duas camadas & Três camadas & $\begin{array}{c}\text { Três camadas com } \\
\text { dois pontos de injeção }\end{array}$ \\
\hline de gás
\end{tabular}

Figura 3.6-1: Projeto de válvula superior com multicamadas. 


\subsection{Comportamento das bolhas de Argônio no sistema de refratários e no molde}

A movimentação das bolhas de gás desde a válvula superior até a válvula submersa é muito rápida para ser avaliada no modelo físico. Por esta razão Suzuki (2003) desenvolveu um modelo matemático para avaliar o comportamento das bolhas. Devido à dificuldade para modelar a geração e separação das bolhas nas condições de fluxo, foi calculado o comportamento de bolhas, com tamanho fixo, colocadas sobre a válvula superior, as quais são em seguida liberadas no fluxo de aço líquido. Os resultados apresentados na Figura 3.7-1 demonstram que no caso de lingotamento com sistema de válvula gaveta, as bolhas surgem na superfície da válvula superior e são desviadas para o centro, quando passam pela região de redução do SGV, seguindo esta trajetória até a saída da SEN. Este fenômeno é mais significante para bolhas com diâmetros maiores, mantendo-se fixa a abertura do SVG. Este fenômeno também é mais pronunciado para pequenas aberturas do SVG, para um tamanho específico de bolha. Finalmente, a geração de bolhas pequenas através da utilização de material com poros pequenos para maiores aberturas das placas é extremamente vantajosa para prevenção de obstrução na válvula submersa. De acordo com Suzuki (2003) estas observações são consistentes com a experiência pratica de máquinas de lingotamento atuais.

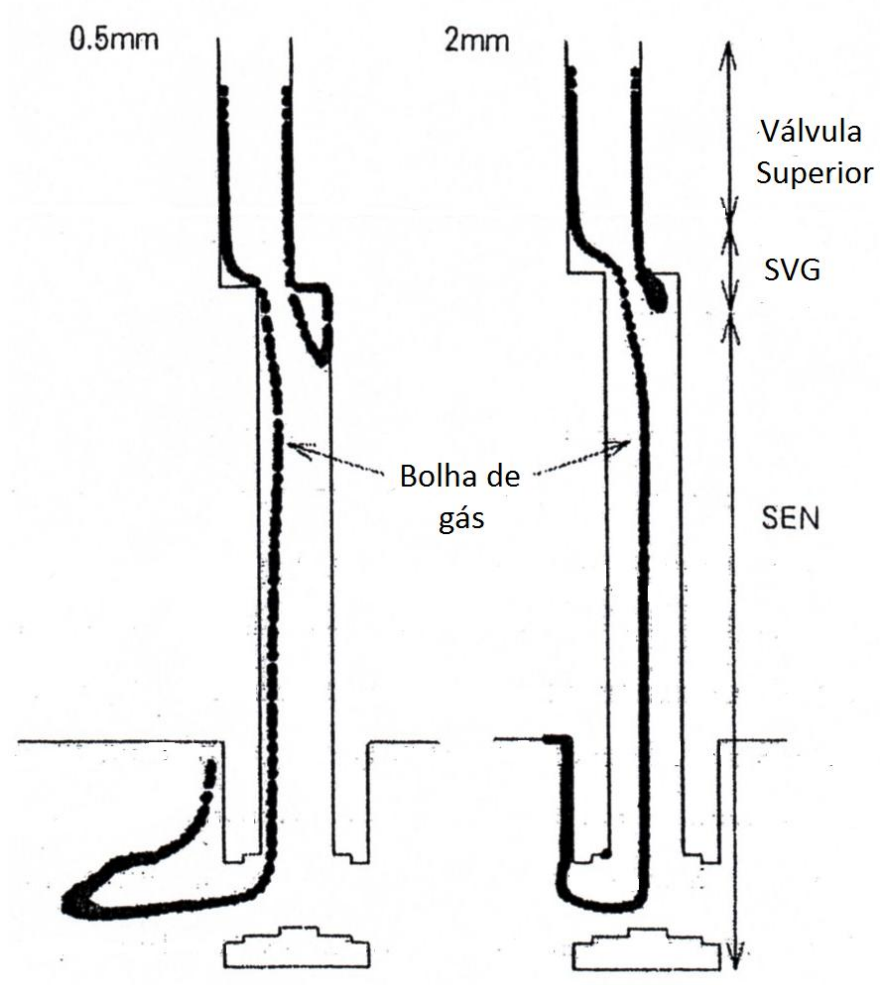

Figura 3.7-1: Trajetória do gás desde a válvula superior até o molde. 
A Figura 3.7-2 apresenta o esquema da montagem experimental realizada por Thomas (1997). O Gás pressurizado (ar, He ou Ar) é injetado através de uma agulha em uma área de $35 \mathrm{~mm}$ x $35 \mathrm{~mm}$ em um tubo vertical de plexiglas com um fluxo de água com condições similares as encontradas nas válvulas de lingotamento contínuo. A saída de gás foi inserida na parede da válvula para simular um furo ou poro na válvula cerâmica. A pressão foi ajustada para obter taxas de fluxo de gás 0,2 a $5 \mathrm{ml} / \mathrm{s}$. A velocidade da água foi variada de 0,9 a $2,5 \mathrm{~m} / \mathrm{s}$ através da mudança de abertura na base da válvula. Três diferentes tamanhos de agulha $(0,3,0,4$ e $0,5 \mathrm{~mm})$ foram utilizadas para examinar o efeito do diâmetro do poro de injeção de gás. A formação das bolhas foi filmada por uma câmera de alta velocidade de 4500 quadros por segundo. O comportamento da injeção das bolhas foi realizado pela avaliação das imagens de vídeo frame por frame. O diâmetro das bolhas foi medido diretamente através das imagens individuais de vídeo e checado pela contagem do número de bolhas na saída da agulha, sabendo-se a taxa de injeção de gás (Thomas, 1997).

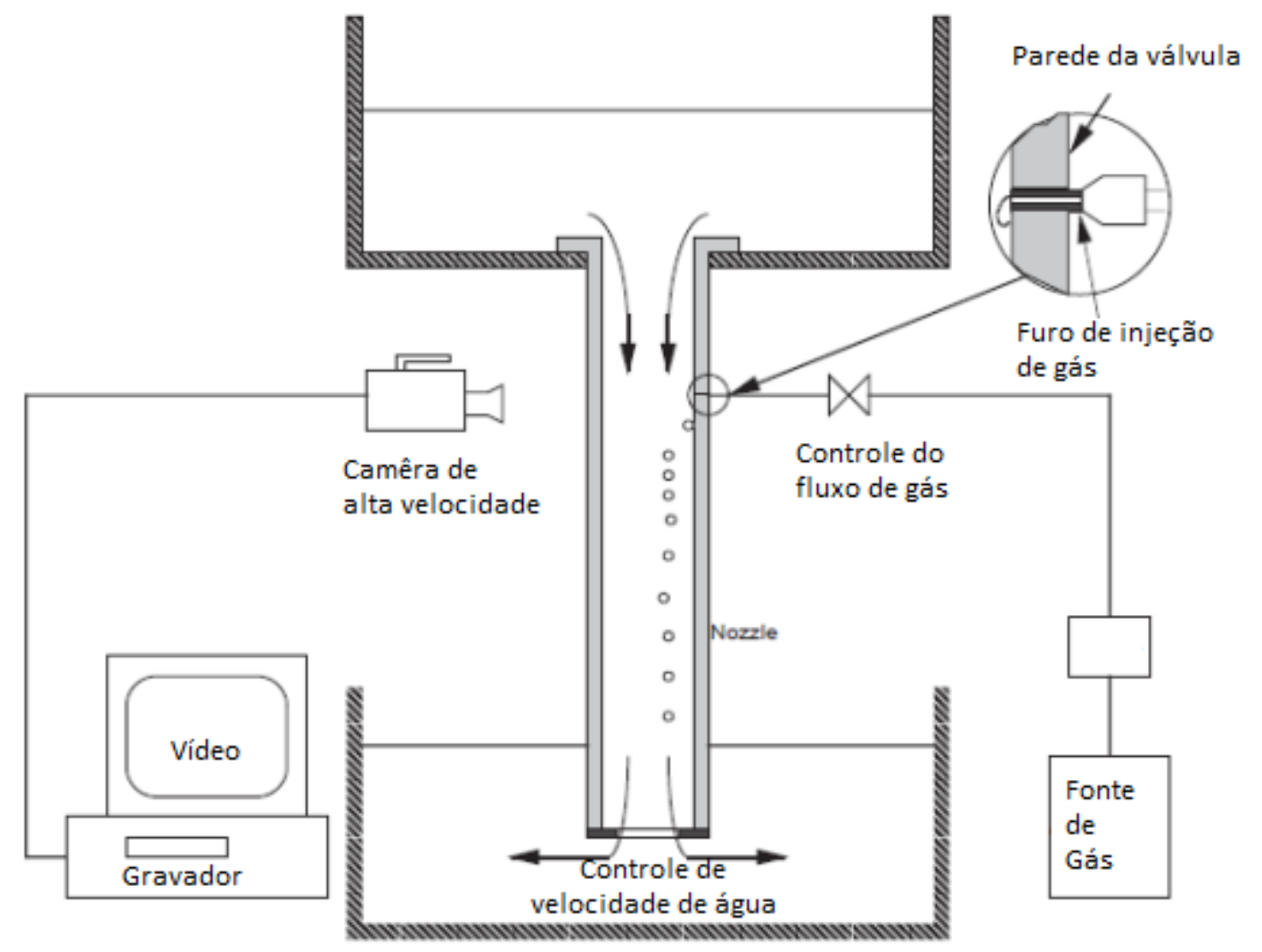

Figura 3.7-2: Esquema modelo físico para avaliação comportamento das bolhas de gás.

Thomas (1997) observou que inicialmente o gás injetado pelo poro apresentava diferentes formatos de bolha e comportamentos em função da velocidade do fluxo de água e da taxa de 
injeção de gás (Figura 3.7 3). Para baixas velocidades do fluxo de água (incluindo o estagnado) e baixas taxas de injeção de gás, Modo I, se observa a formação uniforme de bolhas esféricas à partir da saída do poro, que depois suavemente se soltam e acompanham o fluxo do líquido. Para o Modo IV, altas velocidades de fluxo e altas taxas de injeção de gás, se observa um alongamento das bolhas para baixo ao longo da parede formando um filme gasoso. Este filme eventualmente se rompe em diferentes tamanhos de bolhas, variando entre algumas muito grandes e outras muito pequenas. O Modo II é uma condição de transição entre o Modo I e IV na qual o gás injetado se solta da parede, mas permanece próximo desta. As bolhas normalmente são alongadas próximo da saída, mas são relativamente uniformes quando comparadas com as formadas no Modo III e IV. O Modo III é similar ao Modo IV, exceto pelo fato de que o fluxo de gás é insuficiente para manter uma camada uniforme de gás na parede, então se formam vazios.

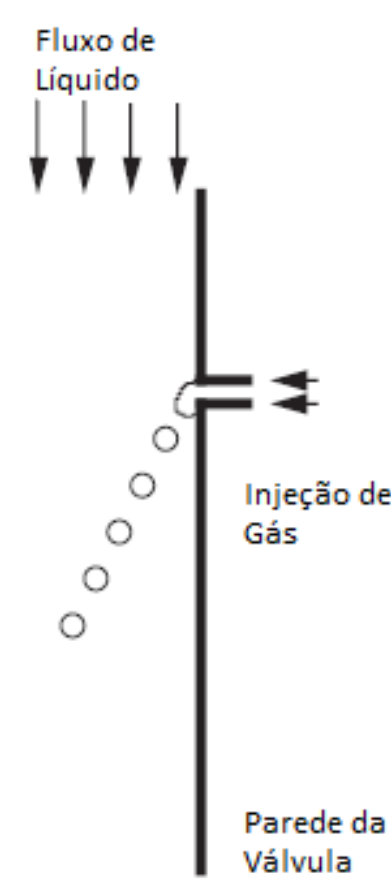

Modo I

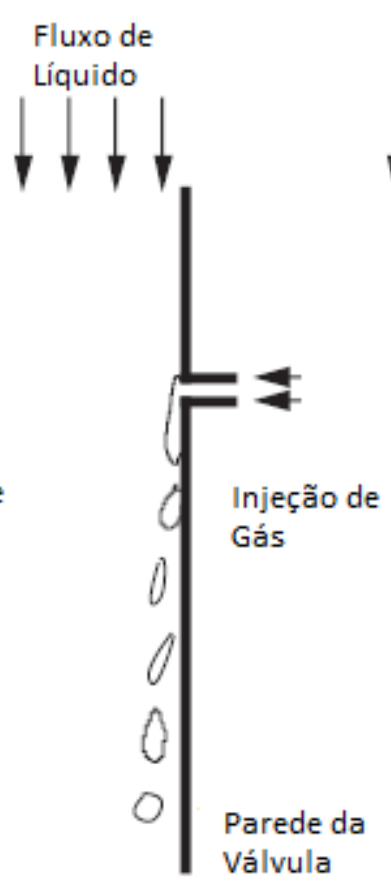

Modo II

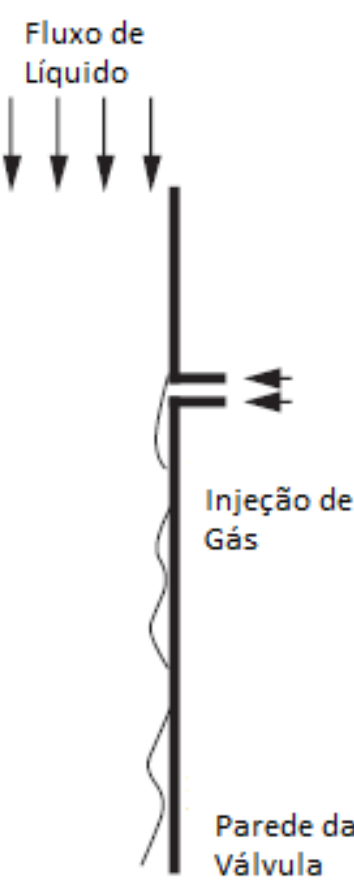

Modo III

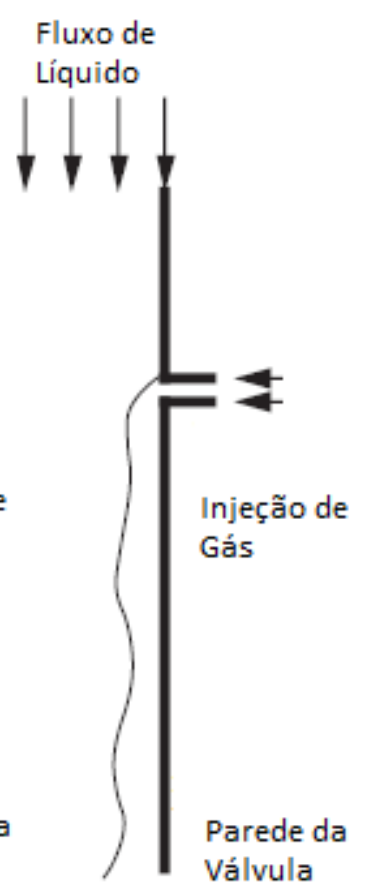

Modo IV

Figura 3.7-3: Quatro modos de injeção de gás.

Observa-se que o comportamento do gás é governado principalmente pela quantidade de movimento do gás e a quantidade de movimento transversal do líquido. Este fenômeno é apresentado na Figura 3.7-4, onde os quatro modos estão claramente relacionados ao número 
de Reynolds para a taxa de injeção de gás e fluxo transversal de água. Estes números foram definidos pelas seguintes equações, de acordo com Thomas, (1997):

$$
\begin{aligned}
& R e_{g a s}=\frac{4 Q \rho_{\text {gas }}}{\pi d u_{\text {gas }}} \\
& R e_{l i q}=\frac{\rho_{l i q} U D}{u_{l i q}}
\end{aligned}
$$

Onde $\rho_{\text {gas }}$ é a densidade do gás, $\rho_{\text {liq }}$ é a densidade do líquido; $u_{g a s}$ é a viscosidade do gás, $u_{\text {liq }}$ é a viscosidade do líquido; d é diâmetro do poro de injeção de gás, $\mathrm{D}$ é a medida do diâmetro da bolha, Q é a taxa de injeção de gás e U a é velocidade média do líquido. Por exemplo, para bolhas injetadas em furo de $2 \mathrm{~mm}$ para taxas de injeção de $1 \mathrm{ml} / \mathrm{s}$ e velocidade de $0,9 \mathrm{~m} / \mathrm{s}, \operatorname{Re}_{\mathrm{gas}}=242, \mathrm{Re}_{\mathrm{liq}}=2000$, e a taxa $\operatorname{Re}_{\mathrm{gas}} / \mathrm{Re}_{\mathrm{liq}}=0,121$. Este exemplo é semelhante ao Modo I.

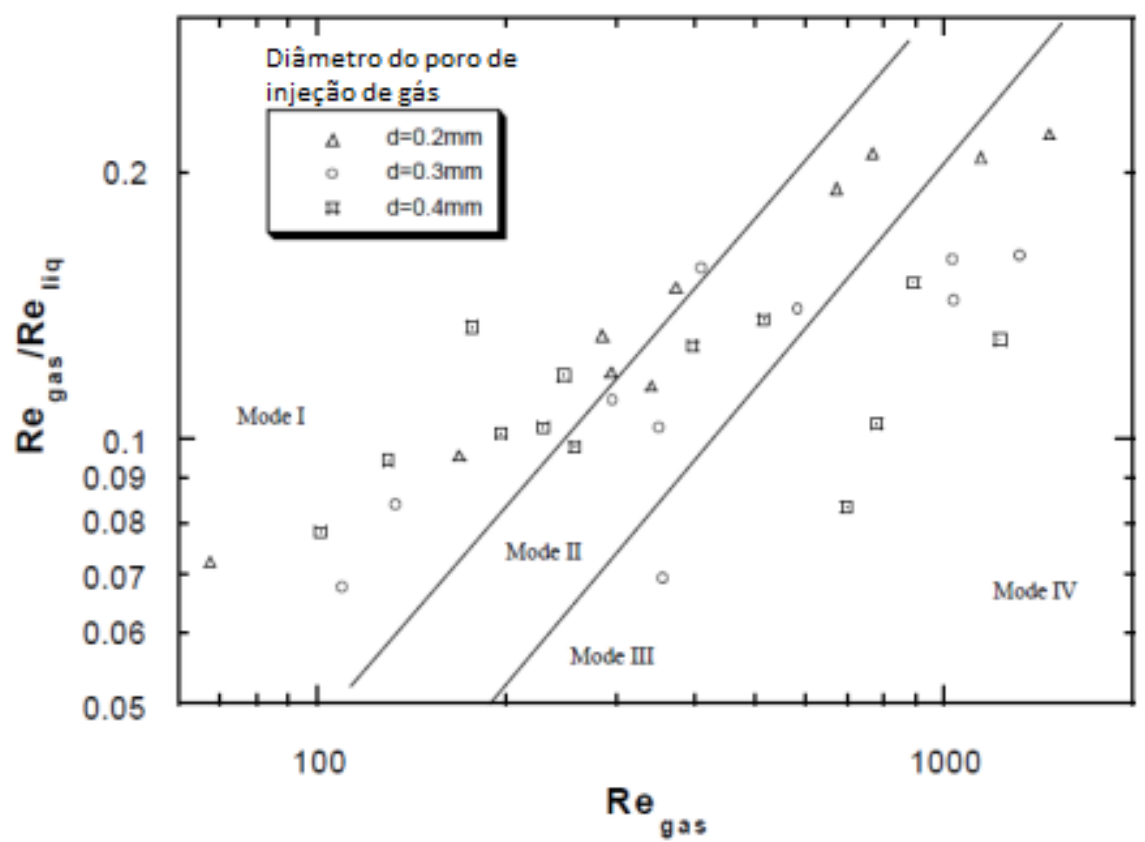

Figura 3.7-4: Modos de injeção de gás e sua relação com o número de Reynolds para gás e líquido.

Thomas (1997) observou que a medida do diâmetro varia de 1 a $5 \mathrm{~mm}$ dependendo da velocidade transversal da água e da taxa de injeção de gás. A Figura 3.7-5 apresenta a medida do diâmetro das bolhas para diferentes taxas de injeção de gás e diferentes velocidades transversais de água. $\mathrm{O}$ tamanho das bolhas aumenta significativamente com o aumento da 
injeção de gás e a redução da velocidade da água. A Figura 3.7-6 apresenta os resultados das medidas do diâmetro das bolhas para três diferentes diâmetros de poros de injeção de gás para uma mesma velocidade da água. Este gráfico demonstra que em princípio o tamanho da bolha é independente do diâmetro do poro de injeção. Esta observação é diferente da realizada para injeção de gases em líquidos estagnados, onde o tamanho de bolhas aumenta suavemente com o aumento do diâmetro do poro para elevadas taxas de injeção de gás, Thomas (1997).

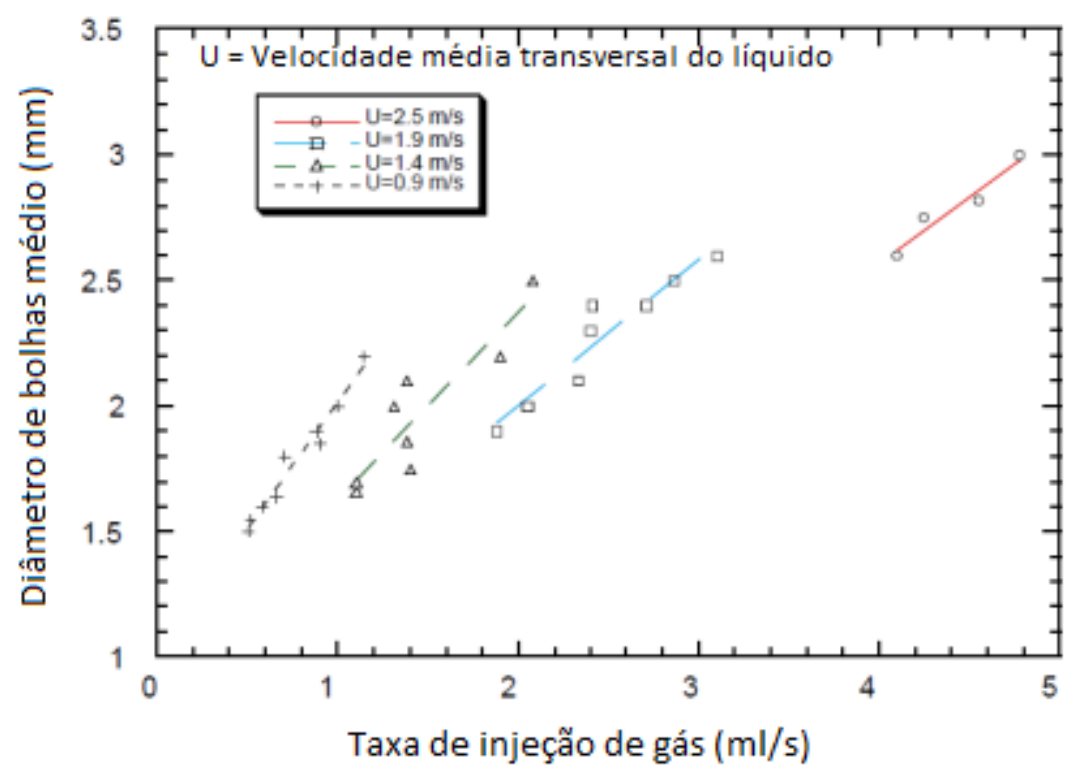

Figura 3.7-5: Medida do tamanho da bolha em fluxo transversal de água para diâmetro de poro de injeção igual a $0,4 \mathrm{~mm}$. 


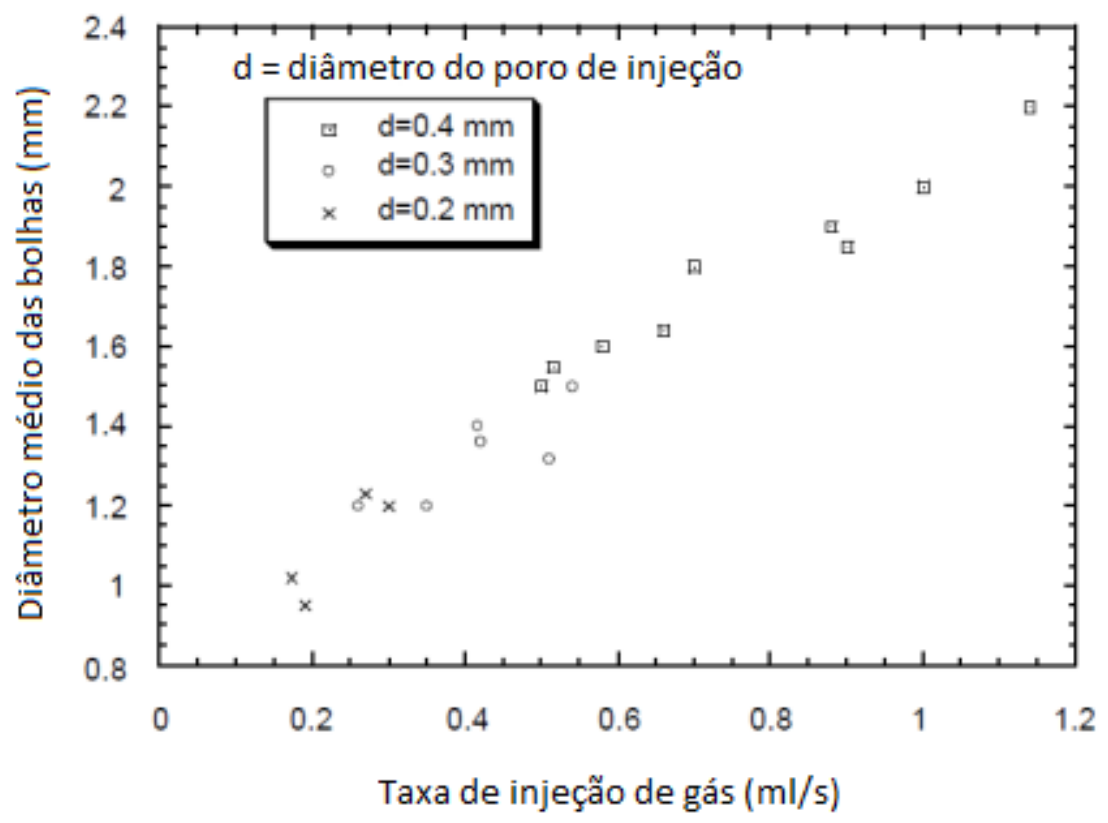

Figura 3.7-6: Efeito do tamanho do poro de injeção do gás no tamanho das bolhas para velocidade transversal da água de $0,9 \mathrm{~m} / \mathrm{s}$.

Thomas et al (2001) investigou o efeito do tamanho da bolha através do aumento do diâmetro da bolha de $1 \mathrm{~mm}$ para $3 \mathrm{~mm}$ e $5 \mathrm{~mm}$ para uma válvula padrão. Importantes características do fluxo são comparadas na Figura 3.7-7.

Para Thomas et al (Parte II - 2001) bolhas maiores acarretam uma redução do ângulo do jato. Isto seria devido à sua maior flutuabilidade, apesar de serem em menor número para uma dada fração volumétrica de gás. Este efeito se torna mais significativo para maiores taxas de injeção de argônio. Como resultado deste efeito, as variações de tamanho de bolha podem facilmente causar variações do fluxo no molde. O ângulo horizontal do jato aumenta suavemente com o aumento do diâmetro da bolha, enquanto que o ângulo vertical é fortemente afetado pelo diâmetro das bolhas (ver Figura 3.7-7). Thomas et al (Parte I - 2001) valida o modelo matemático através de um modelo físico escala 0,4 (ver Figura 3.7-8). Thomas et al (Parte II - 2001) também observa que bolhas maiores tendem a reduzir o tamanho da zona de recirculação na saída da válvula, mas aumentam a turbulência, especialmente para altas taxas de vazão de gás.

Thomas (1997) demonstrou que o tamanho médio da bolha depende principalmente da taxa de injeção de gás, do tamanho do poro na parede interna da válvula e da velocidade descendente do líquido. O tamanho da bolha aumenta e a distribuição de tamanhos torna-se 
menos uniforme à medida que a velocidade do líquido diminui e a taxa de injeção de gás aumenta. Thomas (1994) comprova através de modelo matemático de fluxo com duas fases que o tamanho da bolha afeta o padrão de fluxo no molde.

Thomas (Parte II - 2001) observou que bolhas grandes tendem a subir imediatamente para a superfície livre, mas bolhas pequenas tendem a seguir o fluxo do líquido e alcançando regiões mais profundas do lingote, onde elas podem ser aprisionadas pela frente de solidificação, liderando as ocorrências de esfoliação e outros defeitos.

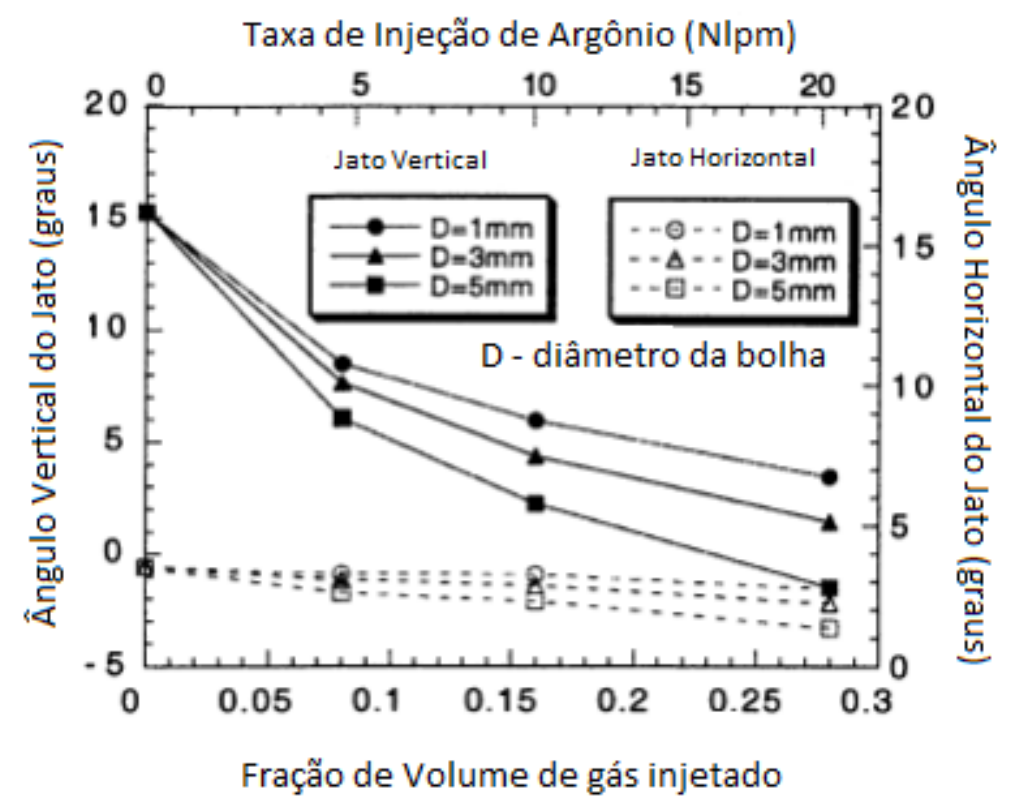

Figura 3.7-7: Efeito do tamanho da bolha de argônio e a injeção de gás no ângulo horizontal e vertical jato (Thomas, Parte II - 2001).

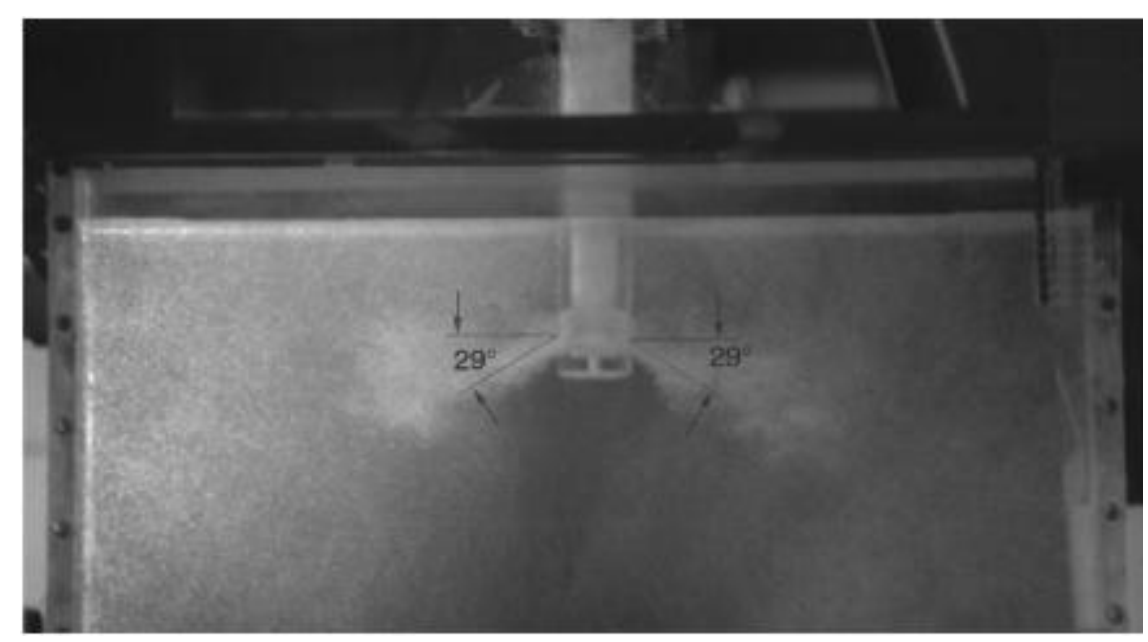

Figura 3.7-8: Modelo em água em escala 0,4 apresenta o padrão de fluxo e ângulo vertical do jato com a válvula de validação (Thomas, Parte I - 2001). 
Sengupta et al (2010) avaliou o efeito do argônio no molde através do uso de equipamento de medição da velocidade do submenisco (Sub-meniscus Velocity Control - SVC) para uma largura de 1600mm para várias taxas de injeção de Argônio. A profundidade da SEN e a velocidade da máquina de lingotamento foram mantidas aproximadamente constantes. A velocidade estabelecida foi de $1,3 \mathrm{~m} / \mathrm{min}$.

Como pode ser observado na Figura 3.7-9 (a) a redução do argônio total de 6lpm para 4lpm aumentou significantemente a velocidade do menisco. A velocidade do menisco foi reduzida assim que o argônio foi elevado novamente para 6lpm. Este fenômeno pode ser explicado através do modelo físico em água para condições similares de largura e velocidade de lingotamento. A estrutura do fluxo do fluido próximo a SEN foi avaliada e filmada utilizando equipamento para determinação a laser das velocidades das partículas (Particle Velocimetry Image - PIV), como apresentado na Figura 3.7-9 (b). Fica claro que o forte fluxo ascendente próximo à válvula submersa se reduz quando diminui a vazão de argônio, acarretando no aumento da quantidade de movimento do fluxo de aço no rolo superior (Sengupta et al, 2010).

Desta maneira, além de outros fatores, como velocidade de lingotamento e a mudança desta, a taxa de injeção de argônio é outro fator crítico que afeta o padrão de fluxo no molde e a velocidade do menisco. Note-se que embora a vazão de argônio permaneça a mesma para diferentes velocidades de lingotamento, a fração de volume varia com a vazão de aço. Como o gás se expande em altas temperaturas, a taxa de injeção de gás será maior no molde do que na temperatura ambiente. Sengupta calculou a fração do volume de gás através da lei dos gases ideais, utilizando a pressão ferrostática e as temperaturas de saída da válvula. Os resultados são apresentados na Figura 3.7-10. A redução da velocidade do menisco com o aumento da fração de volume de gás foi confirmada novamente (Sengupta et al, 2010). 

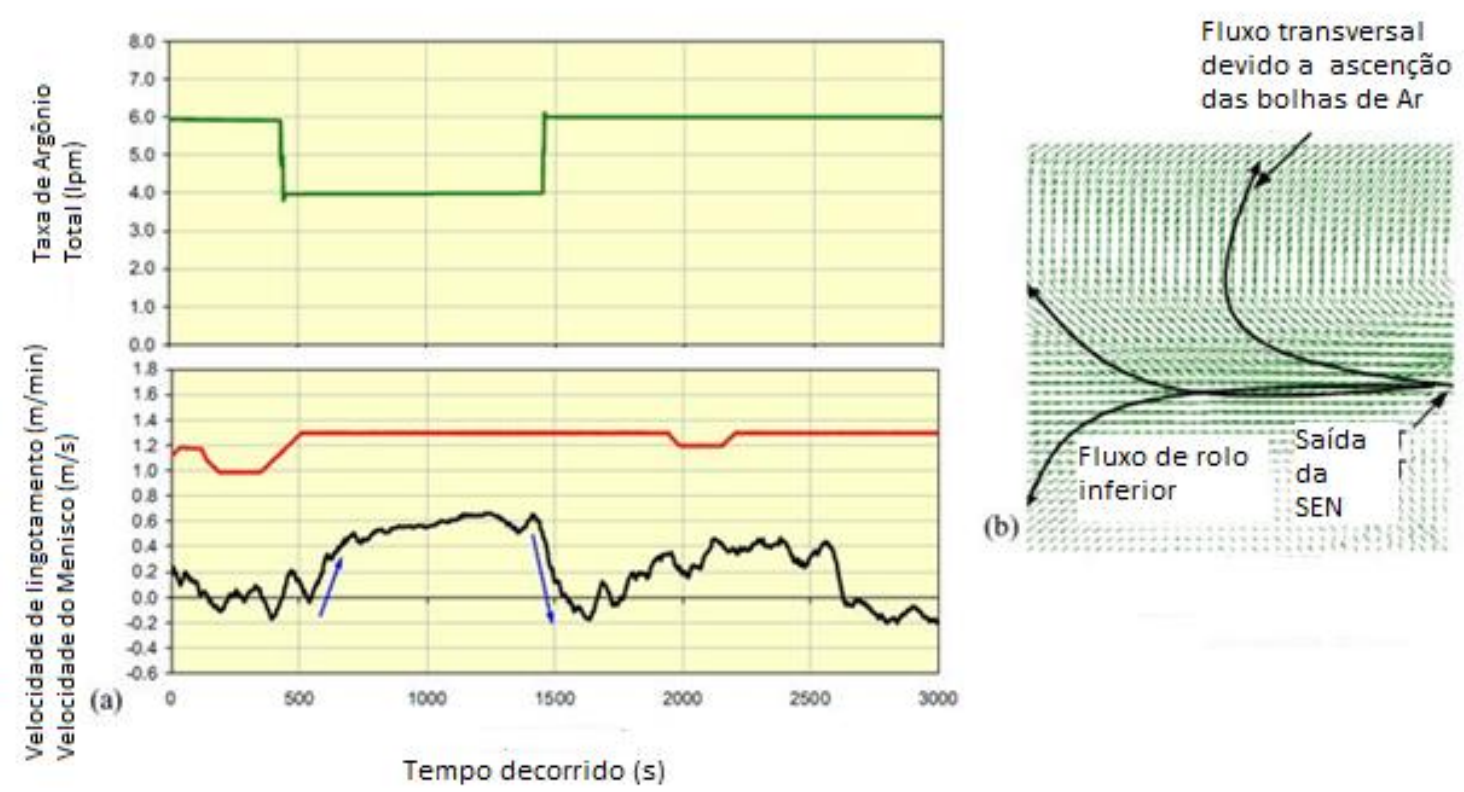

(b)

Figura 3.7-9: (a) Dados da variação da velocidade de lingotamento e vazão de argônio, e evolução da medida da velocidade do menisco na Máquina 1 (veio 1). (b) Imagem PIV do modelo em água.

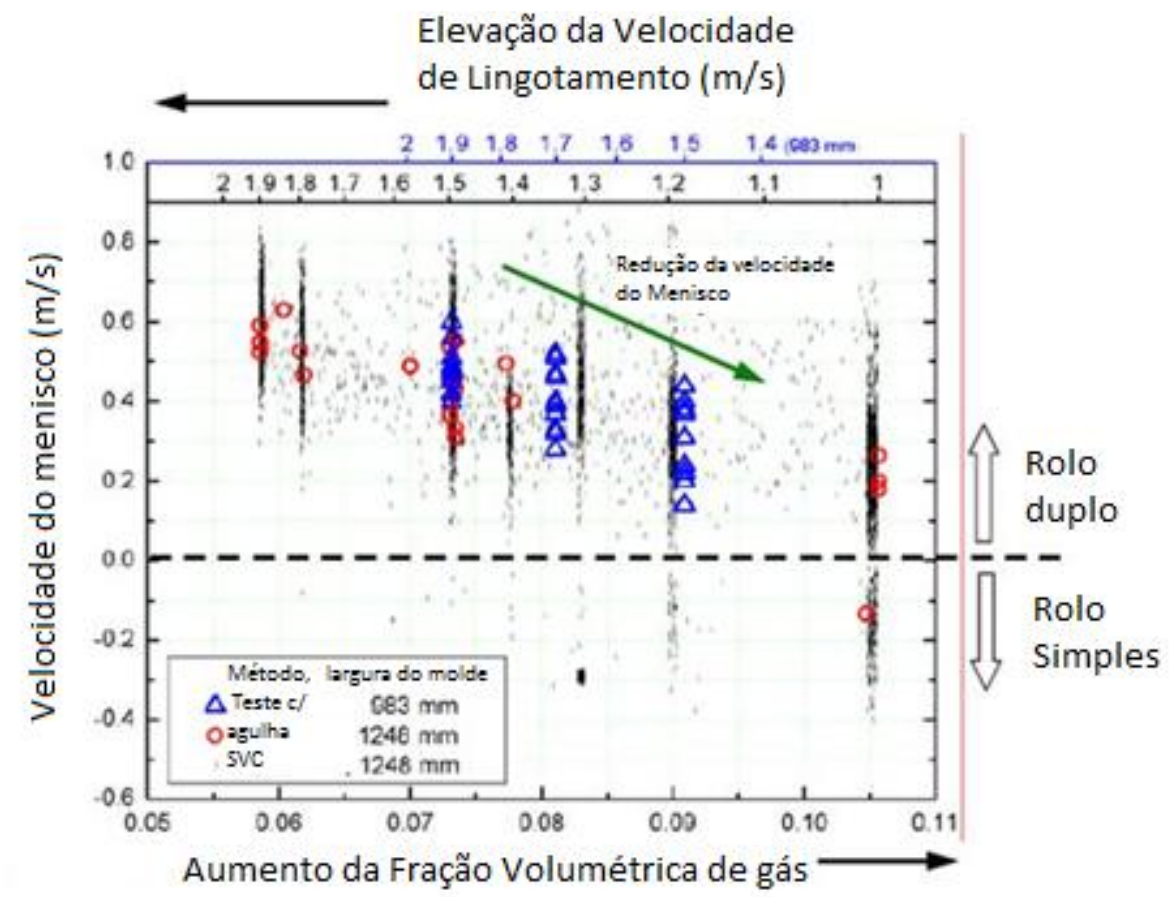

Figura 3.7-10: Fração volumétrica de gás (calculada para condição a quente) e seu efeito sobre a velocidade do menisco.

\subsection{Distribuição das bolhas em tubo e no molde}

Banderas et al (2005) estudou o fluxo bifásico gás-líquido dentro da válvula submersa (SEN) e no molde para placas e a sua influência na região superior do molde. Utilizou um modelo 
físico (escala 1:2 do molde IMEXSA Steel), gravação de vídeo, simulações matemáticas e analisador de velocidade de partículas por imagens (Particle Image Velocimetry - PIV). Grandes quantidades de gás (razão entre vazões de gás e de líquido) e elevadas velocidades no lingotamento levam ao aumento da quantidade de bolhas e do tamanho destas devido a velocidade do processo de coalescência ser superior ao de ruptura das bolhas. Bolhas acumuladas no fundo da válvula submersa sofrem cisalhamento e ruptura pelas bordas do poço e da saída da válvula e posteriormente são lançadas no molde. Uma vez no molde as bolhas então sofrem um processo de coalescência e ruptura que tem sua cinética definida pela vazão de gás e provavelmente pela distribuição de tamanhos das bolhas na saída da válvula submersa. Neste ponto é necessário salientar que o fenômeno de coalescência mencionado, pode ser na verdade coalescência ou aglomeração de bolhas, ou ambos, uma vez que o analisador de imagem não faz uma clara distinção entre estes. Da mesma forma, quando se trata de processos de ruptura das bolhas, provavelmente, o que é interpretado como tal pode ser também relacionado com a rápida ascendência das bolhas grandes, deixando apenas as bolhas pequenas no campo de visão do "Charged Couple Device" (CCD). Consequentemente, os termos coalescência e rompimento de bolhas devem ser entendidos com cautela (Banderas et al, 2005).

Banderas et al (2005) comenta que embora não tenha sido determinada quantitativamente a transição borbulhante-anular no interior da SEN, esta foi estimada por meio de observação visual. Naturalmente, esta transição muda radicalmente o padrão de fluxo no molde. O fluxo anular na SEN implica em fluxo estruturalmente acoplado no molde. Sob estas condições, toda a seção transversal da porta se encontra preenchida por uma mistura de duas fases (gáslíquido) que é lançada para dentro do molde. Bolhas de grandes dimensões são formadas e ascendem rapidamente para a superfície do banho e um grande número de pequenas bolhas são formadas, as quais vão estar sujeitas ao processo de coalescência-ruptura durante seu deslocamento, a partir da saída da SEN, até a superfície do banho ou até a face estreita e depois até a superfície do molde. Estas condições correspondem a um fluxo estruturalmente ajustado (Coupled - C) onde ambas as fases, gás e líquido, seguem um caminho similar no molde.

Para avaliar melhor o fenômeno de coalescência e ruptura das bolhas Banderas et al (2005) dividiu uma das seções do molde, arbitrariamente, em quatro zonas como apresentado na 
Figura 3.8-1. A primeira zona é adjacente à saída da SEN e a quarta próxima da face estreita do molde.

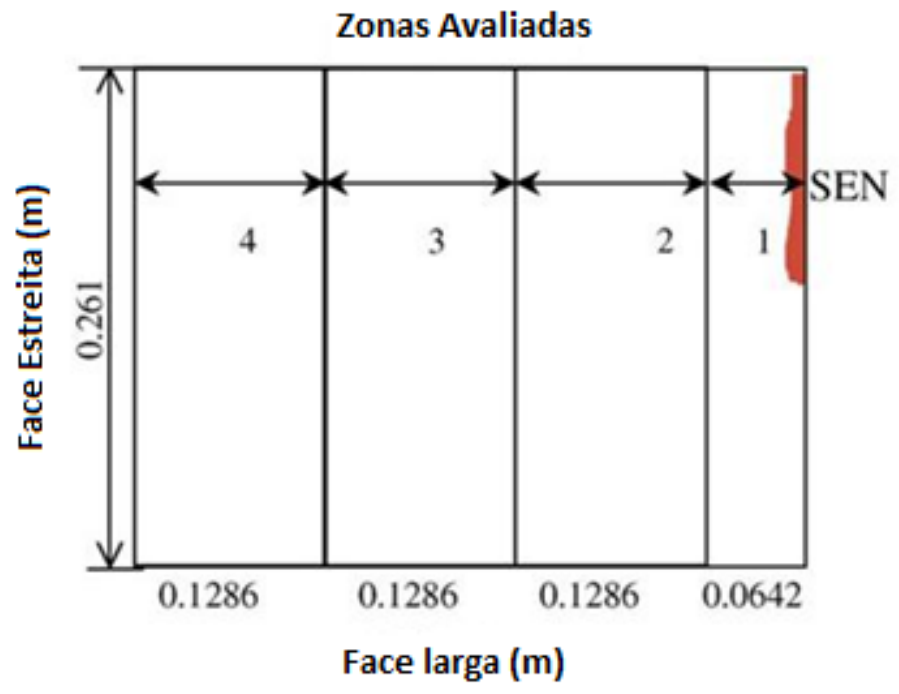

Figura 3.8-1: Esquema das quatro regiões avaliadas.

O efeito do gás injetado nas quatro zonas para velocidades de lingotamento de 0,8, 1,2 e 1,8 $\mathrm{m} / \mathrm{min}$ sobre a população das bolhas (calculada pela divisão do número médio de bolhas por frame e a área de cada região) é apresentado nas Figura 3.8-2 (a-c), respectivamente.

Para baixa vazão de gás e baixa velocidade de lingotamento, Figura 3.8-2 (a), a população de bolhas é máxima para zonas 1 e se reduz para as zonas 2,3 e 4 . O fluxo é essencialmente desacoplado (NC) ou de transição $(\mathrm{T})$. A população de bolhas permanece praticamente constante, o que indica que elas não sofrem ruptura significativa, uma vez que a quantidade de energia necessária para sua ruptura é maior que a fornecida pela energia cinética da fase líquida. Outro ponto, é que o tamanho das bolhas é muito similar desde a saída da válvula até face estreita do molde. Para vazões mais elevadas de gás o fluxo torna-se estruturalmente acoplado (C). O aumento da quantidade de bolhas pode ser entendido pela condição de ruptura das mesmas durante seu movimento. Desta maneira para baixa velocidade de lingotamento e elevadas vazões de gás, tem-se fluxos mais acoplados com aumento da quantidade de bolhas, enquanto que para baixas vazões de gás tem-se fluxos desacoplados com quantidade de bolhas quase constante.

Para velocidades elevadas de lingotamento, independentemente da taxa de injeção de gás, a quantidade de bolhas aumenta da porta da SEN até a face estreita do molde (Figura 3.8-2 (b) 
e (c)). Como seria de se esperar, o aumento da quantidade de bolhas é maior para os fluxos estruturalmente acoplados do que estruturalmente desacoplados ou fluxos de transição. Velocidades de lingotamento elevadas irão sempre aumentar a quantidade de bolhas a partir da zona 1 para a zona 4 (Banderas et al, 2005).
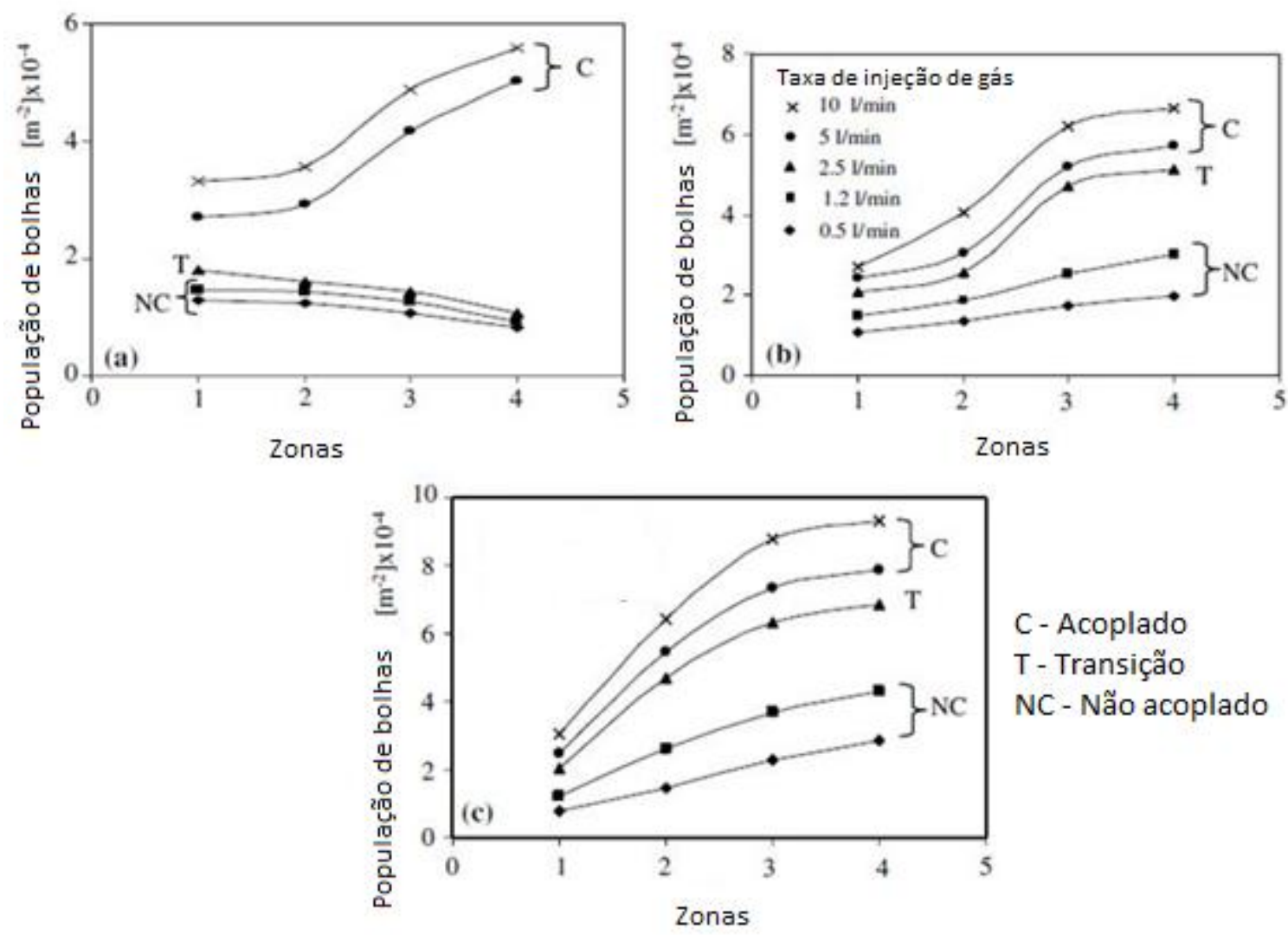

Figura 3.8-2: Quantidade de bolhas por área para velocidades de lingotamento de (a) 0,8, (b) 1,2 e (c) 1,8 $\mathbf{m} / \mathbf{m i n}$.

O tamanho das bolhas segue um comportamento complexo para baixas vazões de gás e baixas velocidades lingotamento, como apresentado na Figura 3.8-3(a), para uma velocidade de lingotamento de $0,8 \mathrm{~m} / \mathrm{s}$, o que corresponde a fluxos desacoplados. O tamanho máximo de bolha é observado na zona 2, devido ao processo de coalescimento das bolhas da zona 1 , enquanto que na zona 3 e 4 se observa a redução do diâmetro das bolhas devido ao processo dominante ser o de ruptura destas. Para baixas velocidades de lingotamento, o tamanho da bolha aumenta nas zonas 1 e 2, devido ao processo de coalescência, como resultado natural do fluxo de duas fases na SEN. Isto é, a fase gasosa se acumula no fundo da SEN e flui junto com o líquido formando um fluxo tipo torrente com bolhas de grandes dimensões próximas da porta. Entretanto, logo dentro do molde, as forças de arraste rompem estas bolhas de 
grandes dimensões ou separam os aglomerados de bolhas. Este mecanismo também pode ser aplicado a fluxos de transição com baixa velocidade de lingotamento.
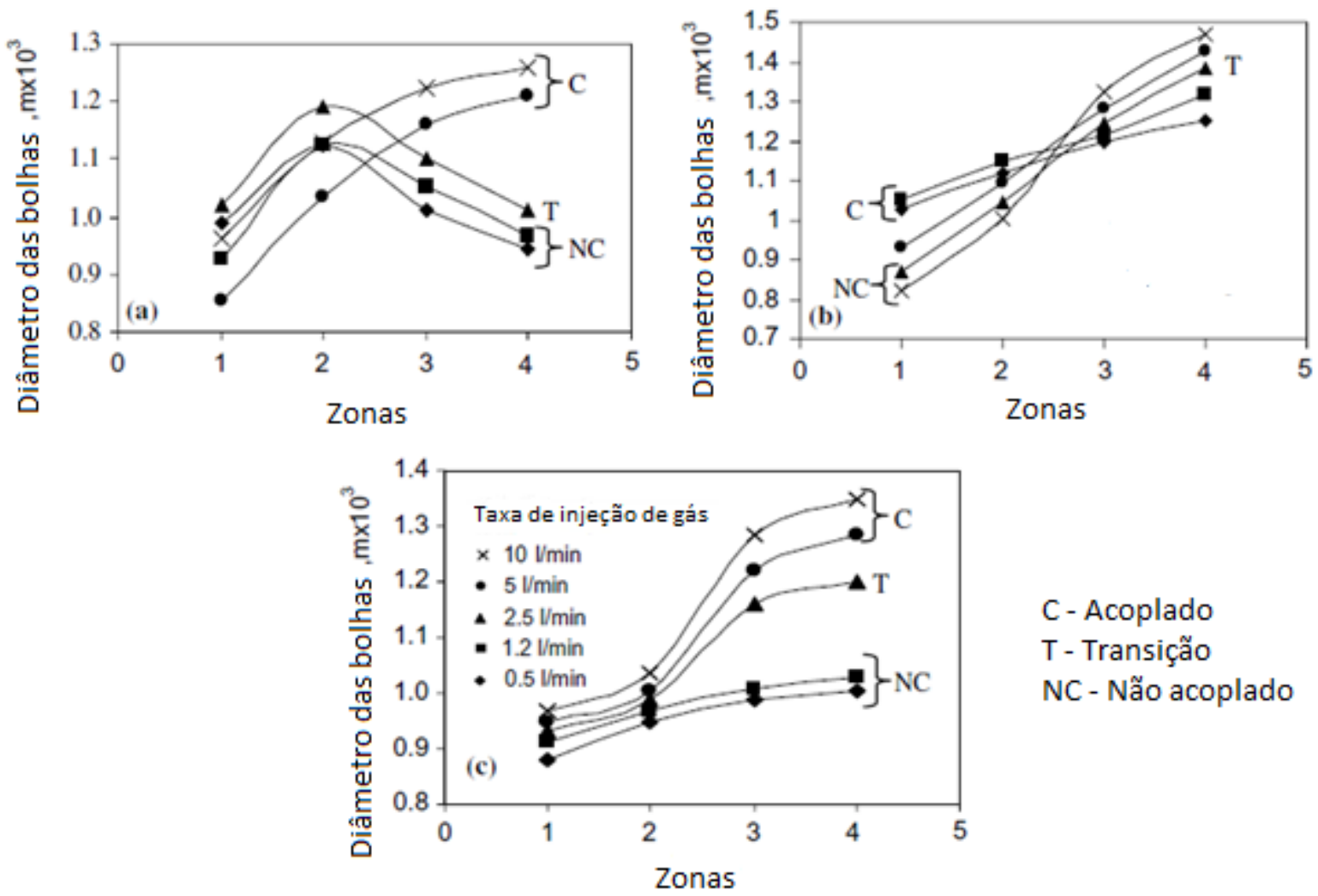

C - Acoplado

T - Transição

NC - Não acoplado

Figura 3.8-3: Diâmetro de bolhas para velocidades de lingotamento de (a) 0,8, (b) 1,2 e (c) 1,8 m/min.

Para altas velocidades e baixas vazões de gás a mistura (água e gás) sai da válvula em um jato de duas fases intermitente como pode ser observado na Figura 3.8-4 (a). Ainda no molde, mais perto das paredes estreitas a concentração das bolhas diminui e se reduz a interação entre estas, cessando o mecanismo de coalescimento.

Já para altas velocidades de lingotamento com elevadas taxas de injeção de gás a mistura sai da válvula em um jato contínuo de duas fases como se pode ver na Figura 3.8-4 (b). Um processo contínuo de coalescência das bolhas, desde a saída da válvula até a face estreita do molde, é observado devido ao aumento significativo da concentração de bolhas no molde, o que promove uma interação intensa entre as bolhas, favorecendo consequentemente este processo.

Para elevada velocidade de lingotamento com elevadas taxas de injeção de gás (estruturalmente desacoplado - NC) a população de bolhas no molde possui pequeno 
diâmetro próximo à saída da válvula (ver Figura 3.8-3 b e c), onde a interação entre as bolhas, é menos frequente. O crescimento inicial das bolhas é reduzido mas se incrementa firmemente desde a saída da SEN até a face estreita do molde onde se tem a população de bolhas com maiores diâmetros.
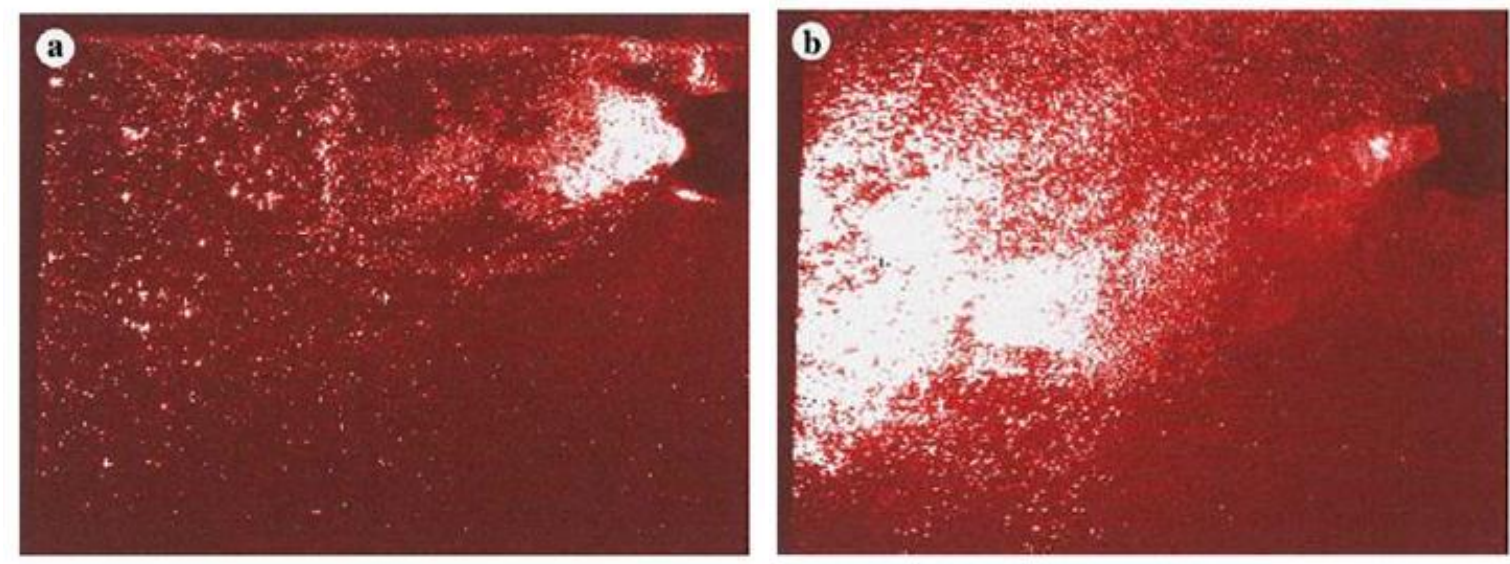

Figura 3.8-4: Padrão de fluxo para injeção de $1,67 \times 10^{-3} \mathrm{~m}^{3} / \mathrm{s} \mathrm{com} \mathrm{velocidade} \mathrm{de} \mathrm{lingotamento} \mathrm{(a)} \mathrm{de} 0,8 \mathrm{~m} / \mathrm{s}$ (fluxo estruturalmente ajustado) e (b) $1,8 \mathrm{~m} / \mathrm{min}$ (fluxo estruturalmente ajustado).

Fluxos anulares na SEN ou fluxos estruturalmente acoplados no molde, conduzem a oscilações elevadas do nível de aço no molde, com uma grande quantidade de bolhas sendo arrastadas junto com o líquido e grandes volumes de água sendo arrastadas por bolhas em direção à superfície do banho com formação de uma camada de espuma. Estas condições não são adequadas para uma operação estável e segura. Para velocidades elevadas de lingotamento é obvio a existência do processo de coalescência de bolhas, mesmo para fluxos de transição e estruturalmente desacoplados. Naturalmente fluxos estruturalmente acoplados, devido às razões explicadas acima, sempre produzem bolhas maiores próximas à face estreita do que os fluxos estruturalmente desacoplados.

A presença de gás afeta radicalmente o fluxo da fase líquida, como pode ser visto na Figura 3.8-5, de vetores de campo de velocidade, determinados por medições de PIV através da média 100 imagens, para um fluxo monofásico de água com vazão de 160 1/min, e para fluxo com duas fases, estruturalmente desacoplado, com a mesma vazão de água e com taxa de injeção de gás de 1,2 Nl min. Na Figura 3.8-5 (a) um vórtice é observado na zona superior da porta da SEN (1), outro vórtice localizado na superfície do banho perto da SEN (2) e um terceiro (3), com menores dimensões, perto da face estreita na parte superior canto esquerdo. 
Em um fluxo de duas fases (Figura 3.8-5 (b)) observa-se que uma baixa taxa de injeção de gás é suficiente para eliminar a presença de vórtices na superfície e próximo do canto e que se reduz o vórtice acima da porta, devido à presença de elevadas forças de flutuação promovida pelas bolhas ascendentes. Trata-se de um resultado positivo devido aos vórtices serem os responsáveis por promover o arrastamento inclusões para o interior do líquido. Este importante resultado conduz a conclusão de que o fluxo estruturalmente desacoplado e de transição pode ser útil, não só para evitar o entupimento, mas também para eliminar vórtices.
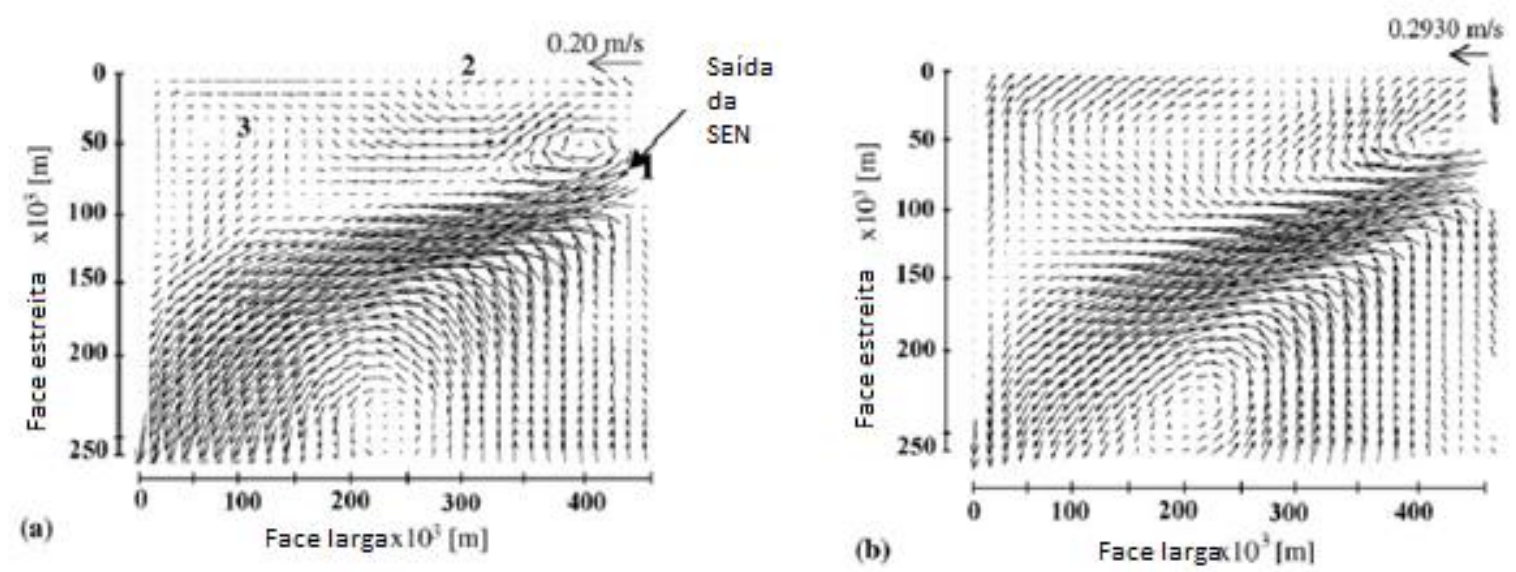

Figura 3.8-5: Vetores de velocidade determinados via PIV de (a) fluxo monofásico de água (b) fluxo bifásico com taxa de injeção de gás de 1,2Nl/min com velocidade de lingotamento de 1,8m/min.

Prasser et al (2002) utilizou sensor de malha de arame o qual produz sequências instantâneas de distribuição da fração de gás na seção transversal com uma resolução 1200 quadros por segundo e resolução espacial de 2 a $3 \mathrm{~mm}$. Para velocidades de fluxo moderadas $(1-2 \mathrm{~m} / \mathrm{s})$, a distribuição das bolhas pode ser determinada, desde que cada bolha individualmente é mapeada em várias distribuições sucessivas. O método foi usado para estudar a evolução da distribuição do tamanho de bolha em fluxo vertical de duas fases. Para este propósito, o sensor foi posicionado após o ponto de injeção em posições variadas (Figura 3.1-1Figura 3.8-6). 


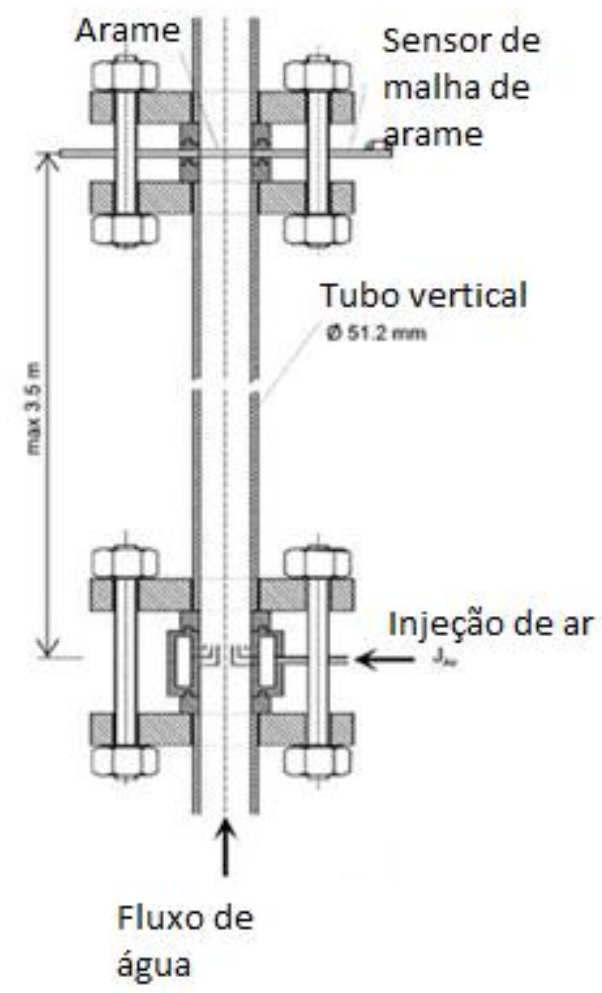

Figura 3.8-6: Teste da seção vertical equipado com injeção de ar e sensor de malha de arame

Na Figura 3.8-7 são apresentados os resultados das medições para baixa vazão de ar, onde a coalescência das bolhas não é um fenômeno significativo. Para este caso o uso exclusivo do dispositivo $\mathrm{A}$ com $\mathrm{D}=0,08 \mathrm{~mm}$ leva a obtenção de bolhas com diâmetros menores que 5,5 $\mathrm{mm}$, enquanto todas as bolhas serão maiores que $5,5 \mathrm{~mm}$ quando se utiliza o dispositivo B onde o gás é injetado através de orifícios de 4 mm (Figura 3.8-7 (a)). No caso de distribuição equidistante dos capilares as bolhas primárias são geradas em toda a seção transversal. No entanto, para uma distância relativa de L/D aproximada de 0,6 observa-se um pico pronunciado de fração de gás próximo à parede. Isto é causado pela força de empuxo agindo em direção à parede. No caso do sistema $\mathrm{B}$ de injeção forma-se um pico próximo à parede $\mathrm{o}$ qual é formado devido à injeção periférica de ar. Neste caso todas as bolhas são maiores que 5,5 $\mathrm{mm}$ e a força de empuxo reversa ocasiona um movimento das bolhas para a direção central do tubo. Para L/D aproximadamente de 60 um pico central é estabelecido (Prasser et al, 2002). 


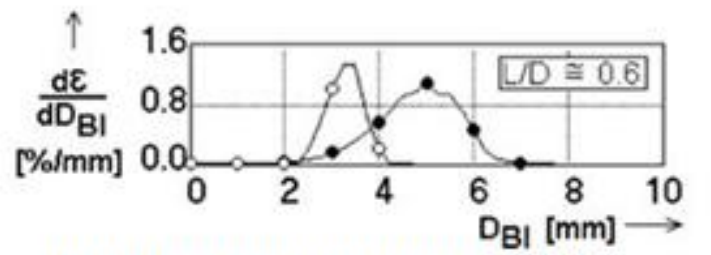

a) Distribuição primária do tamanho de bolha

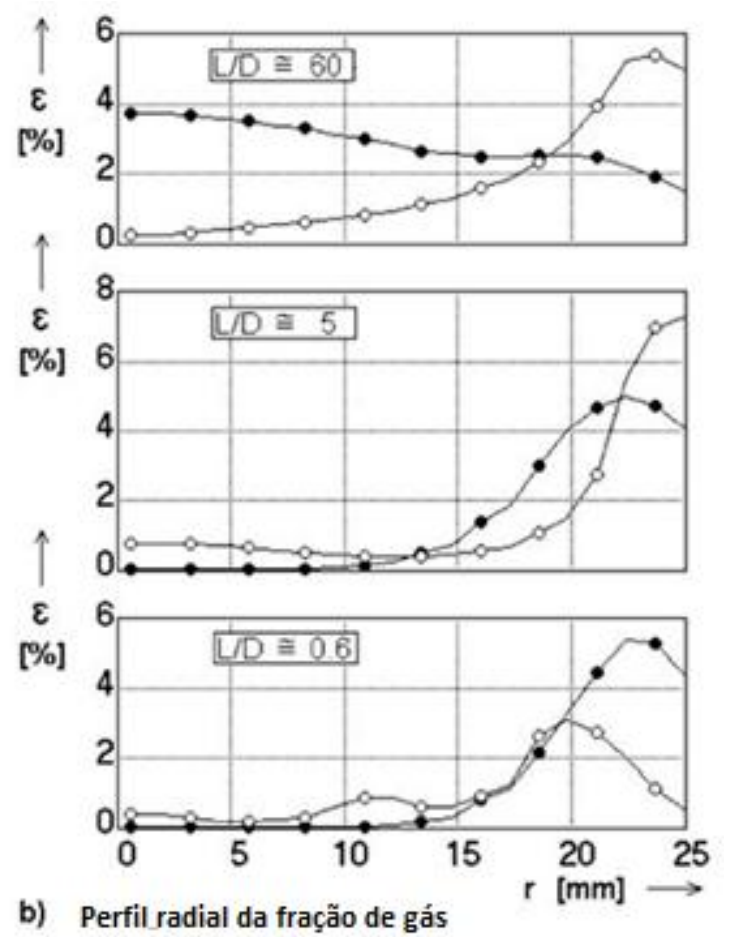

b) Perfil radial da fração de gás

- Injeção de gás $A-19$ caplilares, $D=0,8 \mathrm{~mm}$

$\rightarrow$ Injeção de gás $\mathrm{B}-8$ orifícios, $\mathrm{D}=0,8 \mathrm{~mm}$

Figura 3.8-7: Distribuição primária de gás e evolução dos perfis da fração de gás radial para velocidades superficiais de água $=1 \mathrm{~m} / \mathrm{s}$ e ar $=0,02 \mathrm{~m} / \mathrm{s}$ (abstendo do fenômeno de coalescência)

\subsection{Comportamento do fluxo em função da geometria da válvula submersa}

Para Forman et al (2010) a maioria da SENs apresenta instabilidade no fluxo na saída da válvula, ou seja, ocorre uma diferença de fluxo entre uma porta em relação a outra em um movimento quase periódico. A utilização do fundo da SEN em formato de taça tende a estabilizar estas influências, enquanto o fundo em formato de telhado tende a promover esta instabilidade (Figura 3.9-1). Utilizando uma válvula com fundo do tipo telhado, Forman verificou que na porta com um fluxo mais elevado, o ângulo do jato poderia ser de até 19 graus para baixo, enquanto a outra saída, com redução de fluxo, apresentaria um ângulo de até 15 graus para cima. Esta mudança periódica do fluxo nas portas modifica instantaneamente o padrão do fluxo do molde de duplo rolo para rolo simples, como apresentado na Figura 3.9-2. Cada ciclo se completava a cada 28 segundos e continuava repetindo periodicamente. Estes resultados foram obtidos e validados através de estudos realizados em modelo físico em água em escala 1:1 de um lingotamento contínuo e Simulação Numérica - CFD (Forman et al, 2010). 


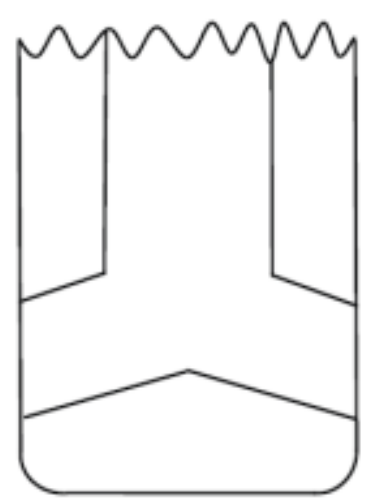

Telhado

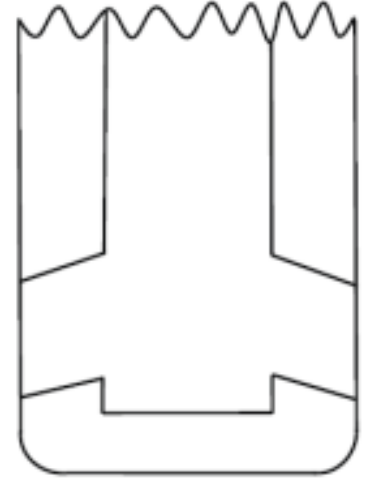

Plano

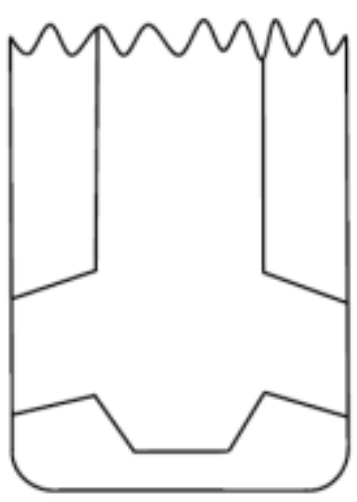

Taça

Figura 3.9-1: Projetos do fundo da Válvula Submersa.

Forman et al (2010) acredita que o fluxo de rolo simples é menos eficiente para retirada de inclusões que o fluxo de duplo rolo, pois apresenta menos recirculação de aço no menisco que o fluxo de duplo rolo.

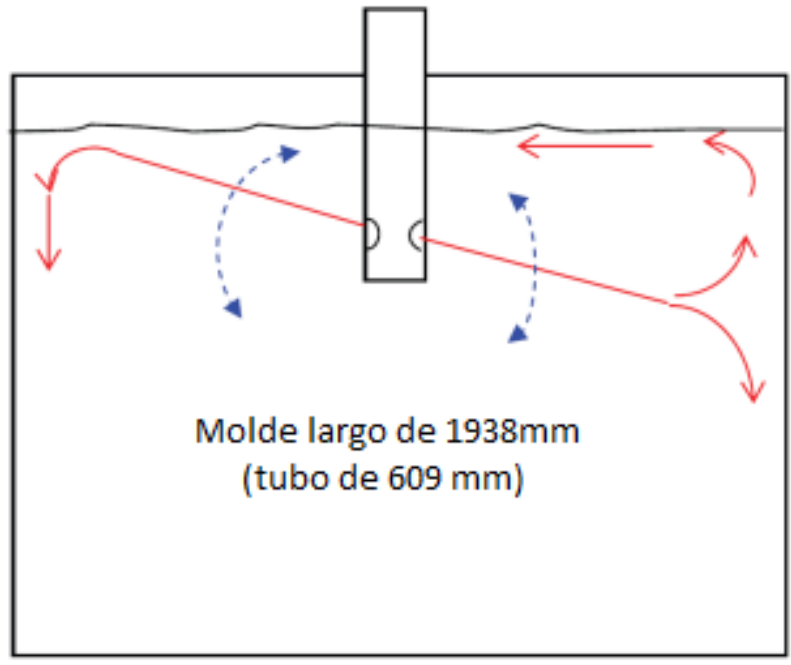

Figura 3.9-2: Fluxo do molde para molde largo. 


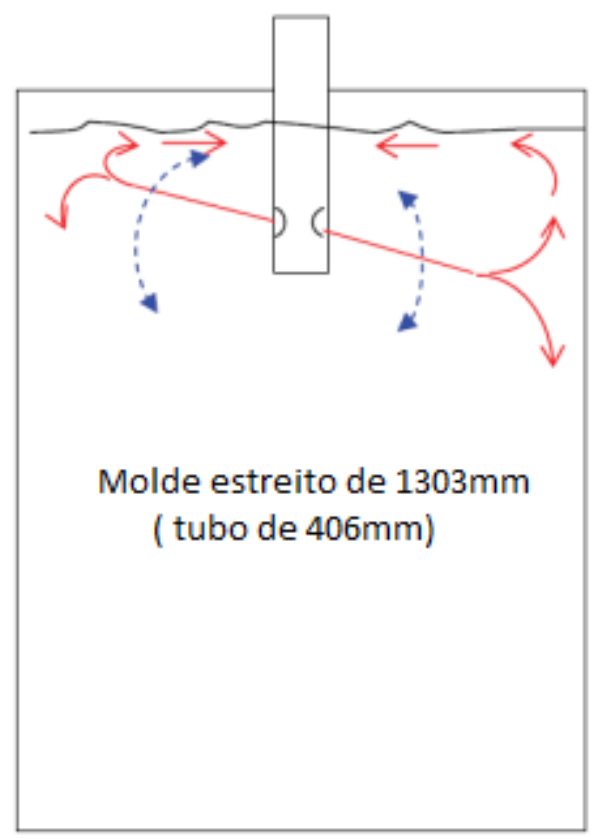

Figura 3.9-3: Fluxo do molde para molde estreito

Outro ponto observado é que os ângulos dos jatos e a periodicidade do ciclo independem da largura do molde. Contudo, para uma largura estreita de molde, por exemplo, $1303 \mathrm{~mm}$, o jato oscilante não alcança o menisco (ver Figura 3.9-3), como para larguras maiores onde se forma o fluxo de rolo simples. Desta maneira em molde estreito, largura de $1303 \mathrm{~mm}$, o fluxo de duplo rolo é mais presente de maneira geral. Este mesmo comportamento foi observado com o modelo CFD (Figura 3.9-4), mas diante ao fato do modelo matemático ser o resultado médio para o momento de 200 segundos, não se evidencia o movimento do jato na saída da SEN (Forman et al, 2010). 

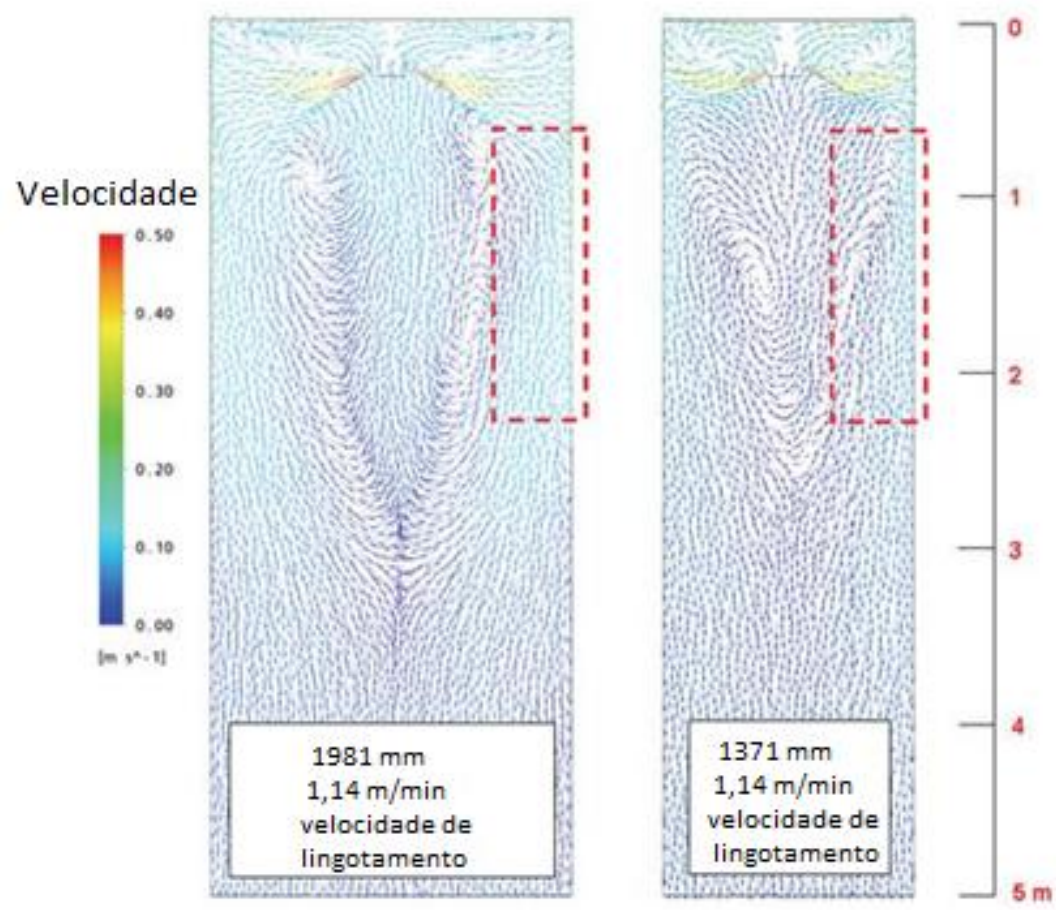

Figura 3.9-4: Resultado do modelo matemático CFD para fluxo no molde utilizando válvula formato tipo telhado para molde com largura estreita e larga.

Forman et al (2010) observou que a medida da velocidade máxima do submenisco através da largura do molde é um importante parâmetro na definição da qualidade da placa. Velocidades elevadas de submenisco podem causar arrastamento de pó do menisco. A velocidade do submenisco foi medida no modelo em água em escala real utilizando um anemômetro tipo hélice colocado a $50 \mathrm{~mm}$ abaixo da superfície do menisco. As medições foram feitas para metade da espessura do molde em paralelo com a face larga da SEN até a parede estreita do molde em incrementos de $50 \mathrm{~mm}$. Para este estudo de velocidade as medições foram realizadas em quatro velocidades de lingotamento e três larguras de molde para o fundo da SEN tipo telhado, copo plano, e copo cônico (tipo taça).

A Figura 3.9-5 mostra a velocidade máxima do submenisco medida em cada uma das condições de lingotamento no modelo em água para SEN com projeto tipo telhado. Esta é condição mais critica de velocidade máxima de menisco entre as válvulas a valiadas, devido à variação periódica do fluxo nas saídas da SEN. Conforme observado na Figura 3.9-5 as velocidades são semelhantes para todas as três larguras de molde e estão dentro da faixa recomendada de 0,15 a $0,35 \mathrm{~m} / \mathrm{s}$ para lingotamento de placa (Forman et al, 2010). 


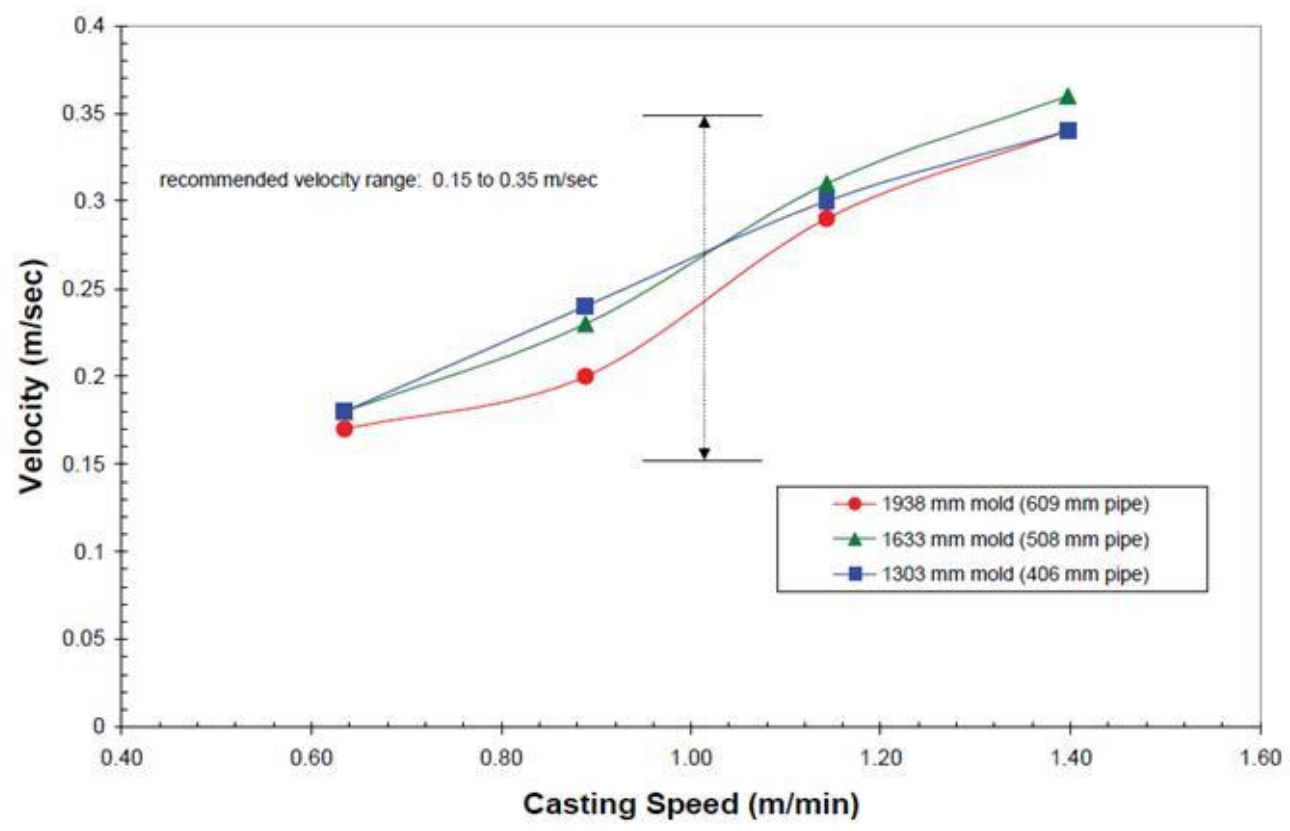

Figura 3.9-5: Relação entre a velocidade máxima de submenisco, velocidade de lingotamento e largura do molde para válvula submersa tipo telhado.

Yavuz (2010) desenvolveu modelos computacionais fluido dinâmicos e de transferência de calor para simular o fluxo de fluido e os padrões de temperatura no molde em função da vazão de aço para larguras de molde de 900 e 1600mm. Foram utilizadas válvulas submersas tipo copo plano, usada rotineiramente na máquina de lingotamento continuo $\mathrm{n}^{\mathrm{o}} 1$ (Arcelor Mittal Dofasco), e válvulas tipo telhado, testadas para avaliar novas geometrias (ver Figura 3.9-1), com o objetivo de se avaliar os riscos de aprisionamento de partículas em placas e minimizar os defeitos de esfoliação em bobinas. Baseado nestes modelos as condições de fluxo que contribuem para o aprisionamento de alumina e pó-fluxante foram identificadas para condições limites de taxas de vazão de aço, como descrito abaixo:

"Molde: (a) velocidade de meniscos maiores que $0,35 \mathrm{~m} / \mathrm{s}$ em molde com larguras de $900 \mathrm{~mm}$ para taxas de vazão elevada resultam em excessiva atividade no menisco, contribuindo para o aprisionamento de inclusões de pó-fluxante, e (b) velocidade de meniscos inferiores a $0,20 \mathrm{~m} / \mathrm{s}$ em molde com larguras de $1600 \mathrm{~mm}$ para taxas de vazão baixas resultam em atividade mínima do menisco, formação de ganchos e marcas de oscilação, contribuindo para o aprisionamento de inclusões de alumina (ver Figura 3.9-6)." 


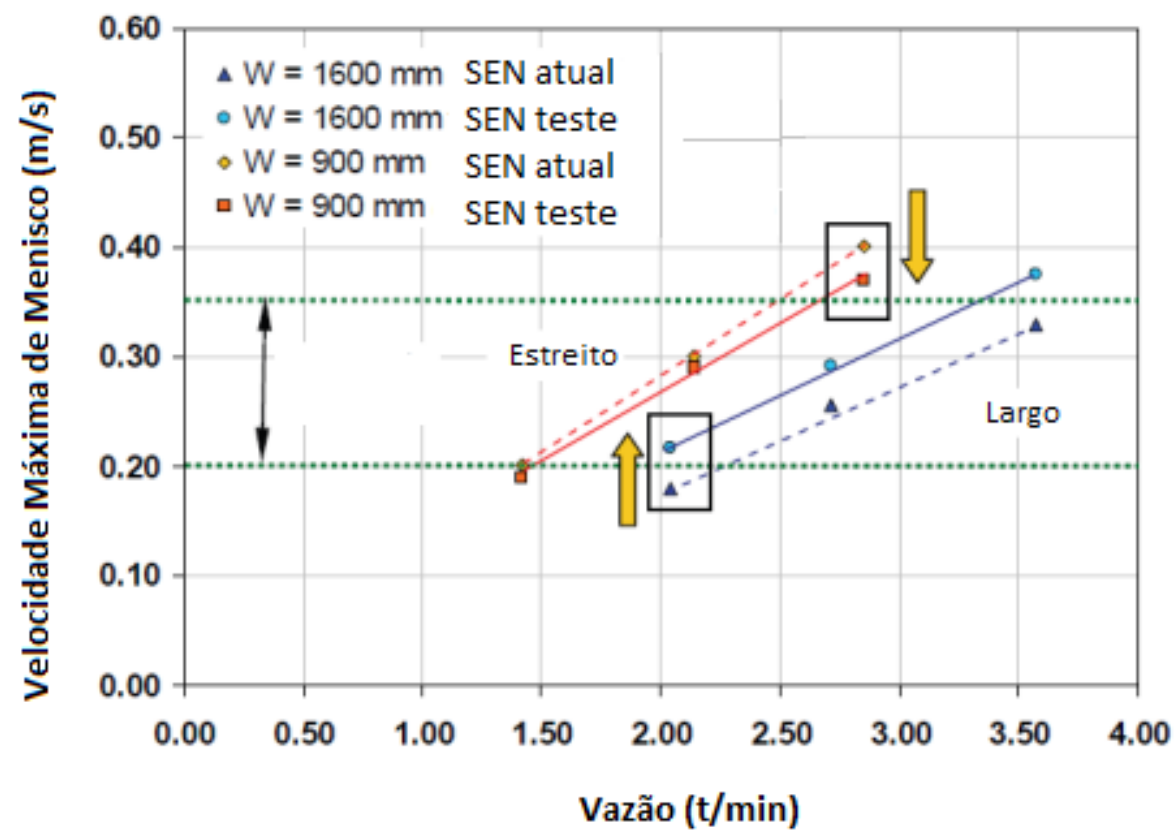

Figura 3.9-6: Gráfico comparativo da velocidade de menisco e das condições limites da vazão de aço para válvulas tipo copo e telhado para largura de molde estreita e larga.

Estas contribuições salientam a importância do gás injetado no sistema de lingotamento, no sentido de determinar o padrão de fluxo no interior do molde. Daí a conveniência deste trabalho. 


\section{CAPÍTULO 4: PARTE EXPERIMETAL}

\subsection{Modelo Físico}

Utilizou-se modelo de molde em escala 1:1 com largura de $1260 \mathrm{~mm}$ e espessura de $200 \mathrm{~mm}$. O líquido utilizado na simulação foi água a $25^{\circ} \mathrm{C}$. Foi construída uma réplica em acrílico da válvula submersa (Submerged Entry Nozzle - SEN), conforme apresentado na Figura 4.1-1 (a). As dimensões internas da peça em acrílico são idênticas às apresentadas na Figura 4.1-1 (b). De maneira a se obter uma condição similar de lingotamento a válvula em acrílico tem também as dimensões da base (região que permanece submersa) idênticas ao projeto (Figura 4.1-1 a).

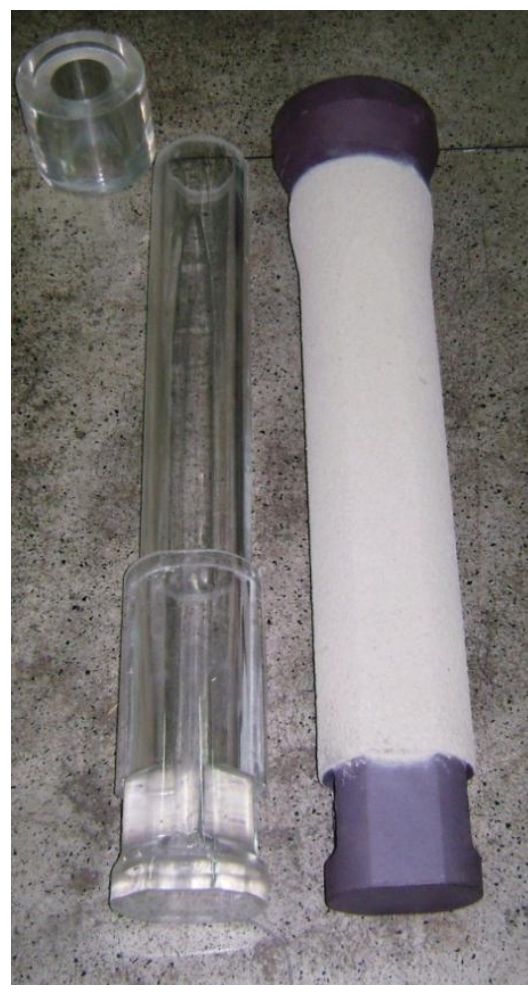

(a)

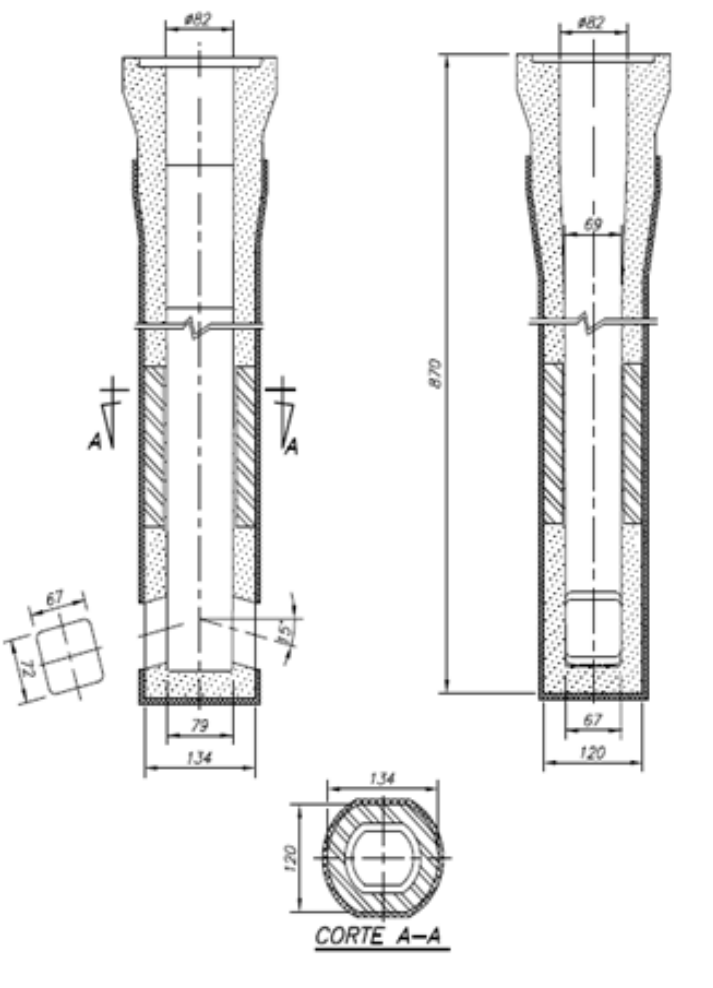

(b)

Figura 4.1-1: SEN Construída em Acrílico ao lado da SEN Refratária (a) e Desenho da SEN (b).

Foram testadas duas válvulas superiores com configurações refratárias diferentes. A válvula mostrada na Figura 4.1-2 (a) tem dois pontos de injeção de gases, porém todo o material refratário apresenta permeabilidade ao gás (porosidade), enquanto que à válvula apresentada na Figura 4.1-2 (b) possui material denso (inserto não poroso) entre as duas áreas de injeção de gases. 


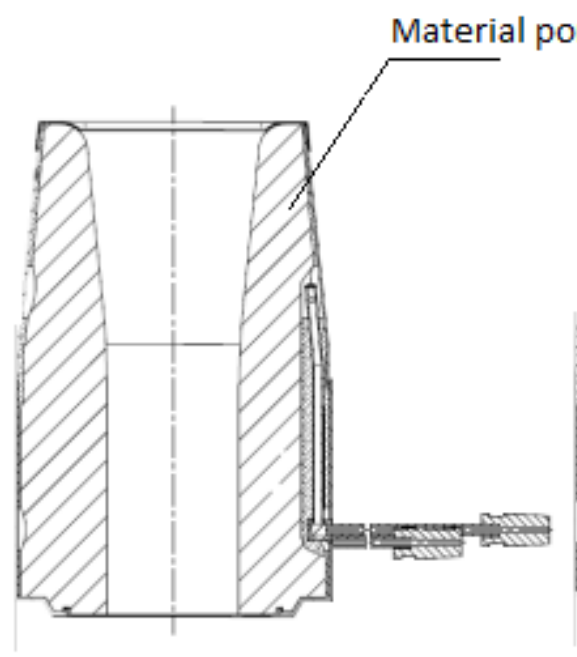

(a)

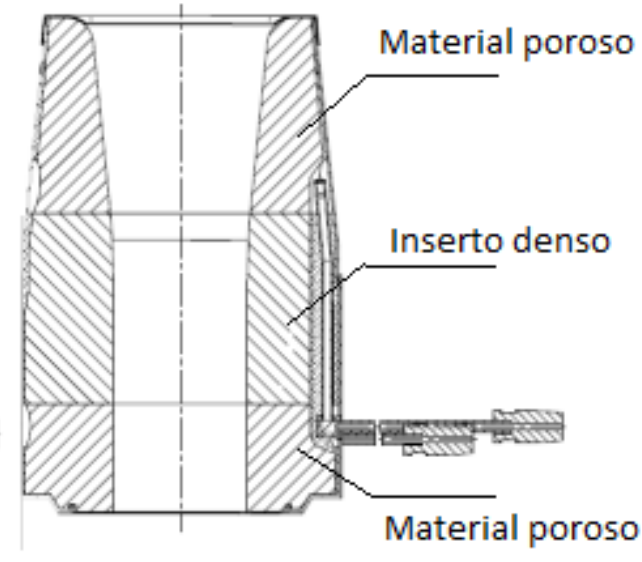

(b)

Figura 4.1-2: Desenho válvula superior porosa (a) e desenho válvula superior com material denso (b).

A válvula superior e a válvula em acrílico foram montadas seguindo uma configuração similar à utilizada na montagem do sistema de refratários (ver Figura 4.1-3 a). Contudo, alguns ajustes foram realizados, tais como: a válvula em acrílico foi construída com duas peças, uma representando a válvula submersa e outro o monobloco (ver foto Figura 4.1-1 a), o controle de fluxo é realizado por uma válvula entre o reservatório de água e a válvula superior (ver foto Figura 4.1-3 a) e não por um sistema com válvula deslizante (ver desenho Figura 4.1-2 b). O gás utilizado na simulação em água em substituição ao argônio (Ar) foi ar e Hélio (He) injetado nos dois pontos de injeção da válvula superior (Figura 4.1-3). O controle de vazão de gás foi realizado utilizando-se reguladores de pressão e medidor de vazão mássica OMEGA da série FMA; a vazão de água foi ajustada com o auxílio de um medidor do tipo palheta (previamente calibrado para a tubulação de alimentação) e inversor de frequência para controle de rotação da bomba. 


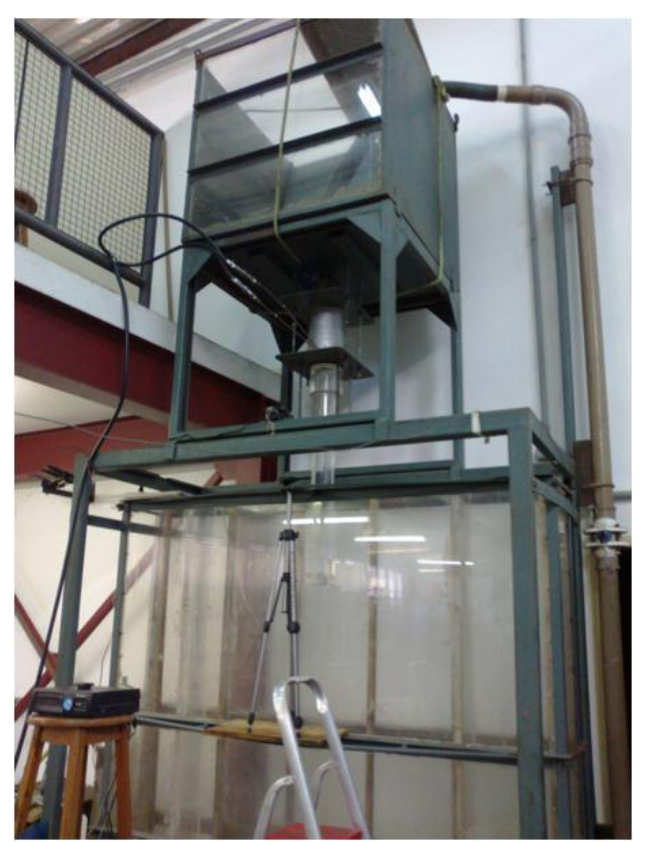

(a)

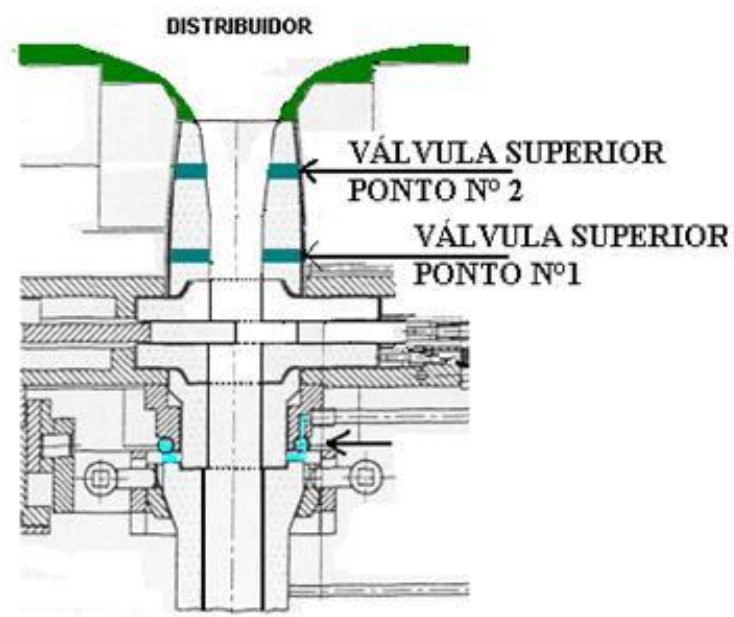

(b)

Figura 4.1-3: Montagem modelo em escala 1:1 (a) e esquema de montagem dos refratários para lingotamento contínuo (b).

Inicialmente empregaram-se duas vazões de água, a $336 \mathrm{l} / \mathrm{min}$ e $400 \mathrm{l} / \mathrm{min}$, equivalentes a $2,35 \mathrm{t} / \mathrm{min}$ e $2,8 \mathrm{t} / \mathrm{min}$ de aço, respectivamente, enquanto as vazões de ar/ He foram fixadas em 4, 8, 12 e $16 \mathrm{Nl} / \mathrm{min}$; e estas vazões foram determinadas com base em critério de similaridade (ver item 4.3). Posteriormente, utilizou-se as vazões de 336 1/min e 360 1/min, com vazões variando de 2 a $10 \mathrm{Nl} / \mathrm{min}$ e 2 a $16 \mathrm{Nl} / \mathrm{min}$, respectivamente. Sugere-se que a similaridade é atingida se a razão entre vazões de líquido e gás se mantiverem, comparandose máquina industrial e modelo. A profundidade de imersão da SEN, medida entre a parte superior da porta de saída e o nível de líquido foi fixada em $120 \mathrm{~mm}$.

Foram realizadas filmagens da metade do molde com utilização de laser (laser sheet visualization) para determinação do comportamento das bolhas de ar e do fluxo de água no molde. Em alguns experimentos foram adicionadas partículas de SG6 de mesma densidade da água para explicitar o movimento da água na região do menisco e nas regiões com poucas bolhas de ar. Posteriormente avaliou-se o comportamento do fluxo de água e das bolhas através do software PIVVIEW para geração dos vetores de movimento.

Para determinação do tamanho de bolha, no interior da SEN, foram realizadas filmagens a 150 fps, sob luz estroboscópica, utilizando-se uma escala de referência junto à válvula em 
acrílico (Figura 4.1-4). Posteriormente utilizou-se um software comercial para separação da filmagem em quadros, VirtualDub, e outro software, QUANTIKOV, para determinação do tamanho médio das bolhas.
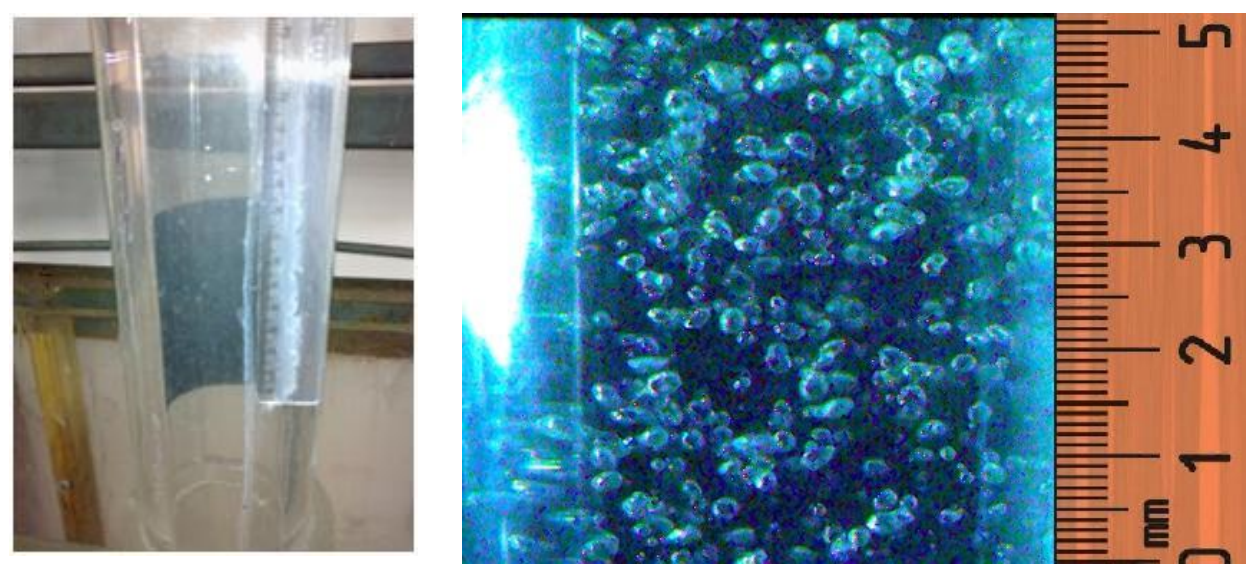

Figura 4.1-4: Válvula em acrílico com escala de referência; exemplo de foto para 336 lpm e 2 lpm de ar, válvula superior completamente porosa.

\subsection{Modelo Matemático}

O modelo matemático foi elaborado de maneira a representar as condições físicas do modelo em água com observância das dimensões reais do mesmo (ver Figura 4.2-1). O software utilizado foi o CFX em módulo transiente permanente. A fase contínua definida foi água a $25^{\circ} \mathrm{C}$ e 1 atm e a fase dispersa o ar na condição de gás ideal. A vazão de água utilizada foi de 336L/min e 400L/min com a vazão de ar variando entre 4 e $12 \mathrm{Nl} / \mathrm{min}$. Também avaliou-se o efeito do diâmetro da bolha no modelo, valores de 2 e $3 \mathrm{~mm}$. A malha foi construída com 35.400 nós, sendo mais refinada na saída da válvula submersa e na região do jato (ver Figura 4.2-2). Tomou-se a tensão interfacial entre gás e água como igual a 0,7N/m. Verificou-se também a influência de opções de fase dispersa desconsiderando e considerando a força de empuxo. 


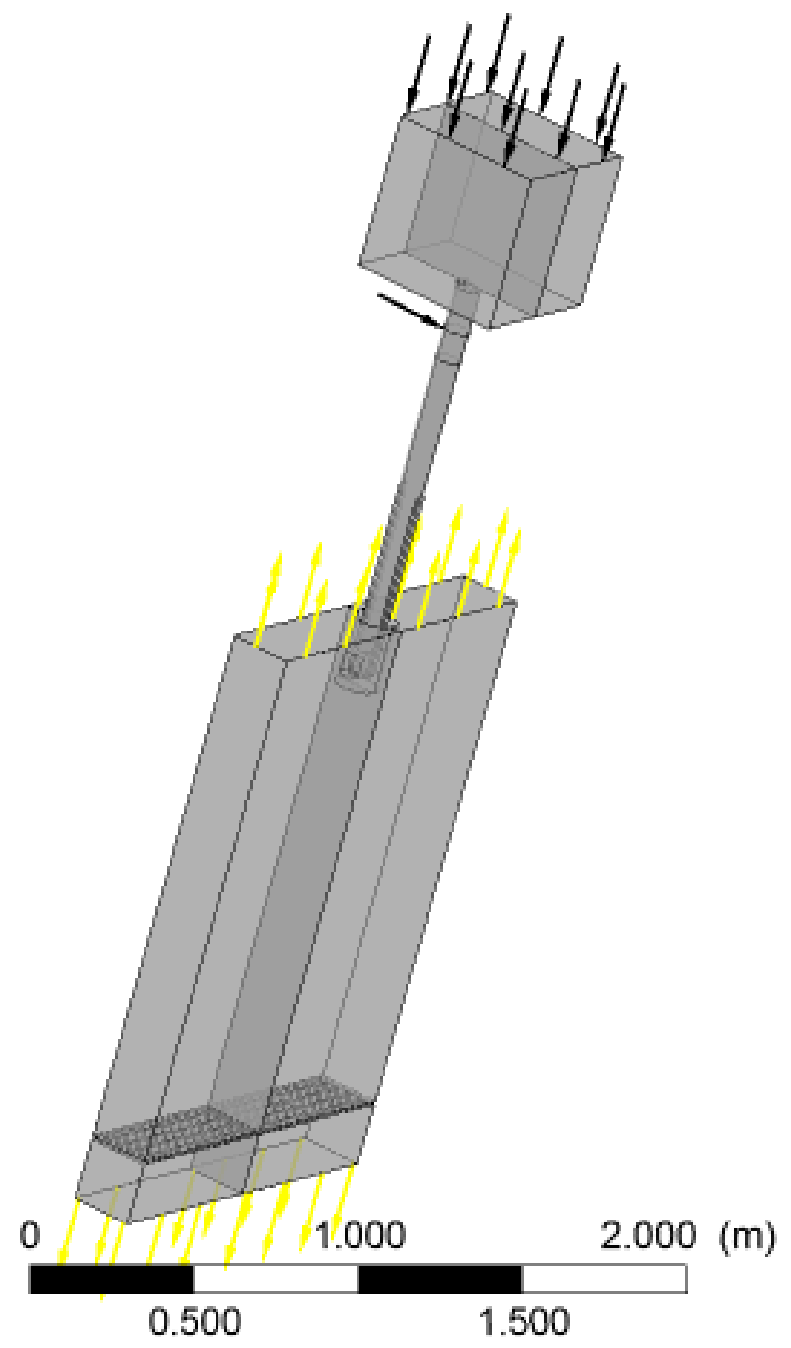

Figura 4.2-1: Imagem em 3-D do modelo físico gerada pelo software CFX.

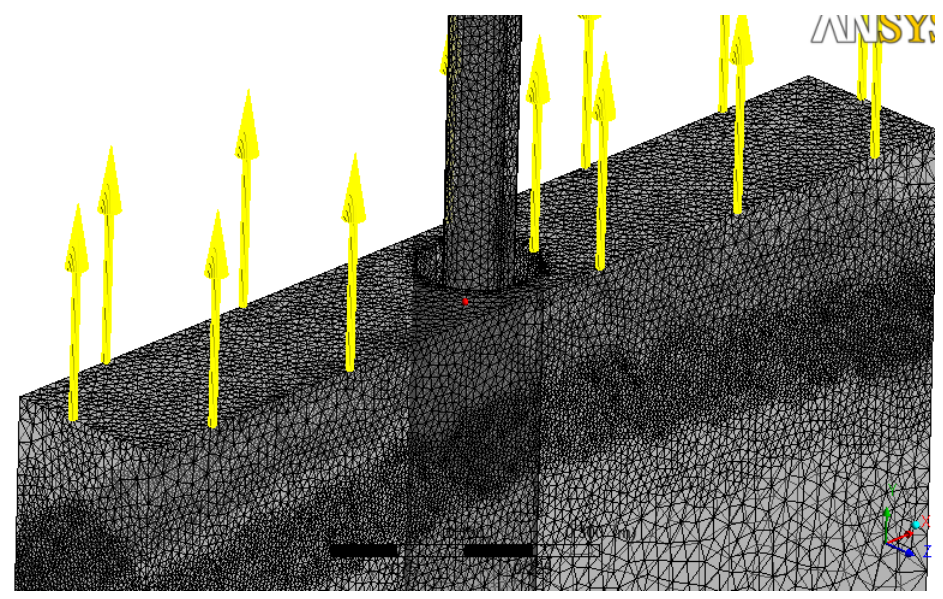

Figura 4.2-2: Imagem gerada pelo software CFX do molde e da válvula submersa com ênfase na malha. 
Para a descrição do campo de velocidades utilizou-se o modelo k-epsilon $-\mathbf{k}-\boldsymbol{\varepsilon}$ de turbulência, embutido no ANSYS ${ }^{\circledR}$. Neste modelo, $\boldsymbol{k}$ representa a energia cinética de turbulência, definida pelas flutuações de velocidade; $\varepsilon$ é taxa de dissipação de energia. $\mathrm{O}$ modelo $\boldsymbol{k}-\boldsymbol{\varepsilon}$ introduz duas variáveis no sistema de equações, que passa a ser:

\section{Continuidade:}

$\frac{\partial \rho}{\partial t}+\nabla \cdot(\rho U)=0$

\section{Navier Stokes:}

$$
\frac{\partial \rho U}{\partial t}+\nabla \cdot(\rho U \otimes U)-\nabla \cdot\left(\mu_{e f f} \nabla U\right)=-\nabla p+\nabla \cdot\left(\mu_{e f f} \nabla U\right)^{T}+B
$$

\section{Viscosidade efetiva:}

$\mu_{e f f}=\mu+\mu_{t}$

\section{Equações auxiliares, $\boldsymbol{k}-\varepsilon$}

$$
\begin{aligned}
& \frac{\partial \rho k}{\partial t}+\nabla \cdot(\rho U k)=\nabla \cdot\left[\left(\mu+\frac{\mu_{t}}{\sigma_{K}}\right) \nabla k\right]+P_{k}-\rho \varepsilon \\
& \frac{\partial \rho \varepsilon}{\partial t}+\nabla \cdot(\rho U \varepsilon)=\nabla \cdot\left[\left(\mu+\frac{\mu_{t}}{\sigma_{\varepsilon}}\right) \nabla \varepsilon\right]+\frac{\varepsilon}{k}\left(C_{\varepsilon 1} P_{k}-C_{\varepsilon 2} \rho \varepsilon\right)
\end{aligned}
$$

\section{Viscosidade turbulenta}

$\mu_{t}=C_{\mu} \rho \frac{k^{2}}{\varepsilon}$

Estas equações são resolvidas interativamente, até a convergência, considerando-se condições de contorno características do sistema (Figura 4.2-3). A energia cinética de turbulência e a taxa de dissipação de energia na entrada da SEN são determinadas a partir da velocidade média no corpo da válvula, isto é, pela vazão e área de seção reta de fluxo. Nas paredes onde (do molde, do corpo da válvula) emprega-se condição de não deslizamento, a qual implica em energia cinética de turbulência, taxa de dissipação de energia e velocidade nulas. No topo do molde, interface metal-atmosfera, a componente vertical de velocidade é assinalado um valor 
nulo; e as outras componentes são livres para o sistema. Os valores de variáveis na base do molde não são especificados, sendo portanto determinados pelo programa.

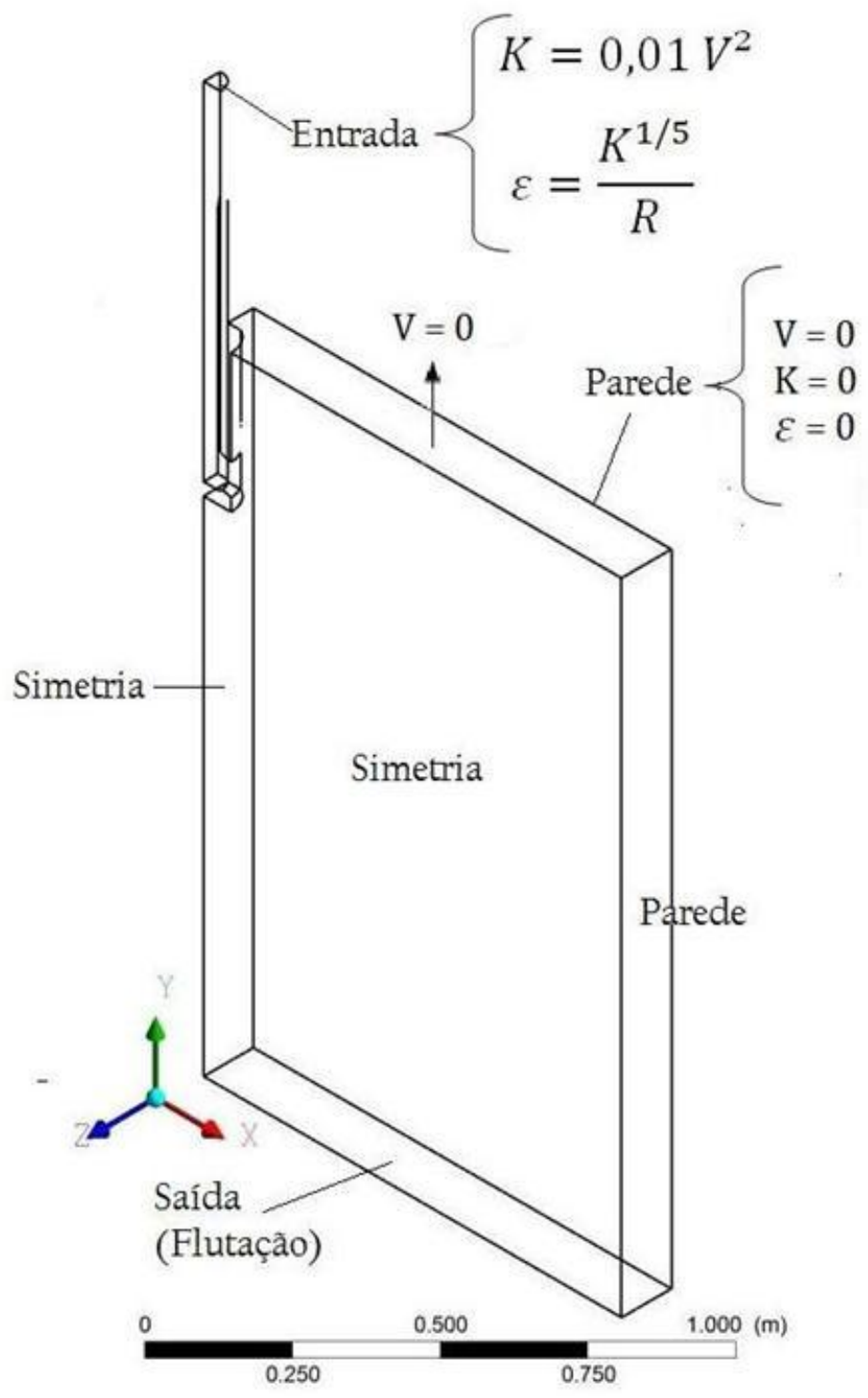

Figura 4.2-3: Representação da geometria de 1/4 de um molde de lingotamento contínuo de placas e condições de contorno típicas aplicáveis ao sistema em estudo.

\subsection{Critério de Similaridade}

A fim de estabelecer o critério de similaridade para injeção de gás no molde pode ser considerada primeiramente a equação de Continuidade, para um fluido incompressível, após a aplicação do Operador Média (BIRD, 1960). Mostra-se que a equação da continuidade em termos de valores médios mantém a mesma forma da equação original, 
$0=\frac{\partial}{\partial x} \bar{V}_{x}+\frac{\partial}{\partial y} \bar{V}_{y}+\frac{\partial}{\partial z} \bar{V}_{z}$

Por outro lado a equação de conservação de quantidade de movimento, após a introdução do conceito de viscosidade turbulenta fica (componente OX, a título de exemplo),

$$
\begin{aligned}
& \frac{\partial}{\partial t} \rho \bar{V}_{x}=-\frac{\partial}{\partial x} \bar{p}-\rho\left\{\frac{\partial}{\partial x} \bar{V}_{x} \bar{V}_{x}+\frac{\partial}{\partial y} \bar{V}_{x} \bar{V}_{y}+\frac{\partial}{\partial z} \bar{V}_{x} \bar{V}_{z}\right\}+ \\
& \left(\eta^{\text {la } \min a r}+\eta^{\text {turbulenta }}\right) \nabla^{2} \bar{V}_{x}+\rho g_{x}
\end{aligned}
$$

Num dado volume de controle, no qual a fração ocupada pelo gás é dada por $\alpha$, a massa específica média pode ser aproximada como:

$$
\rho_{m}=\alpha \rho_{\text {gas }}+(1-\alpha) \rho_{\text {liquido }}
$$

Desta forma, a equação anterior de conservação de quantidade de movimento, fica:

$$
\begin{aligned}
& \frac{\partial}{\partial t} \rho \bar{V}_{x}=-\frac{\partial}{\partial x} \bar{p}-\rho\left\{\frac{\partial}{\partial x} \bar{V}_{x} \bar{V}_{x}+\frac{\partial}{\partial y} \bar{V}_{x} \bar{V}_{y}+\frac{\partial}{\partial z} \bar{V}_{x} \bar{V}_{z}\right\}+ \\
& \left(\eta^{\text {laminar }}+\eta^{\text {turbulenta }}\right) \nabla^{2} \bar{V}_{x}+\rho_{m} g_{x}
\end{aligned}
$$

Os critérios de semelhança podem agora ser identificados, reescrevendo-se a equação de conservação a partir de números adimensionais (SZEKELY, 1989). Após combinação com a equação de continuidade a equação de conservação de quantidade de movimento seria,

$$
\begin{aligned}
& \rho \frac{D}{D t} \bar{V}=-\nabla \bar{p}+\left(\eta^{\text {laminar }}+\eta^{\text {turbulenta }}\right) \nabla^{2} \bar{V}+\rho_{m} g \\
& \rho \frac{D}{D t} \bar{V}=-\nabla \bar{p}+\eta^{\text {efetiva }} \nabla^{2} \bar{V}+\rho_{m} g
\end{aligned}
$$

Aqui, para fins de simplificação empregam-se os operadores:

$$
\begin{aligned}
& \text { 1- Gradiente, } \nabla=\frac{\partial}{\partial x} i+\frac{\partial}{\partial y} j+\frac{\partial}{\partial z} k \\
& \text { 2- Laplace, } \nabla^{2}=\frac{\partial^{2}}{\partial x^{2}}+\frac{\partial^{2}}{\partial y^{2}}+\frac{\partial^{2}}{\partial z^{2}}
\end{aligned}
$$


3- Stokes, $\frac{D}{D t}=\frac{\partial}{\partial t}+\left\{\bar{V}_{x} \frac{\partial}{\partial x}+\bar{V}_{y} \frac{\partial}{\partial y}+\bar{V}_{z} \frac{\partial}{\partial z}\right\}$.

A introdução das variáveis adimensionais, abaixo, nas equações 1, 2 e 3, levam as equações 4,5 e 6 :

$\overline{V^{*}}=\frac{\bar{V}}{V_{o}} ; \overline{p^{*}}=\frac{\bar{p}-\overline{p_{o}}}{\rho_{m} V_{o}^{2}} ; t^{*}=\frac{t V_{o}}{L} ; x^{*}=\frac{x}{L} ; y^{*}=\frac{y}{L} ; z^{*}=\frac{z}{L}$

4- Gradiente, $\left.\nabla^{*}=L \nabla=\frac{\partial}{\partial x^{*}} i+\frac{\partial}{\partial y^{*}} j+\frac{\partial}{\partial z^{*}} k\right\}$

5- Laplace, $\nabla^{* 2}=L^{2} \nabla^{2}=\left\{\frac{\partial^{2}}{\partial x^{* 2}}+\frac{\partial^{2}}{\partial y^{* 2}}+\frac{\partial^{2}}{\partial z^{* 2}}\right.$

6- Stokes, $\frac{D}{D t^{*}}=\frac{L}{V_{o}} \frac{D}{D t}=\frac{\partial}{\partial t^{*}}+\left\{\bar{V}_{x}^{*} \frac{\partial}{\partial x^{*}}+\bar{V}_{y}^{*} \frac{\partial}{\partial y^{*}}+\bar{V}_{z}^{*} \frac{\partial}{\partial z^{*}}\right\}$

Isto permite, identificar os critérios de semelhança (para que a mesma equação de movimento seja aplicada ao modelo e protótipo os coeficientes da mesma devem ser iguais):

$$
\frac{D}{D t^{*}} \bar{V}^{*}=-\nabla^{*} \overline{p^{*}}+\frac{\eta^{\text {efetiva }}}{L V_{o} \rho_{m}} \nabla^{* 2} \overline{V^{*}}+\frac{g L}{V_{o}^{2}}
$$

Então devem ser iguais, no modelo quando comparado com a máquina industrial:

$$
F r=\frac{V_{o}^{2}}{g L} \quad \text { e } \quad \operatorname{Re}=\frac{L V_{o} \rho_{m}}{\eta^{\text {efetiva }}}
$$

As Figura 4.3-1 e Figura 4.3-2 mostram mapas de distribuição da Fração Volumétrica de gás e de Velocidades do Líquido, para simulações no modelo em escala natural, empregando água como fluido de trabalho, e no molde real. Em ambos os casos emprega-se vazão de líquido igual a $400 \mathrm{lpm}$ (2,80 toneladas/min) e tamanho de bolha igual a $3 \mathrm{~mm}$. Os resultados sugerem que se deve manter a mesma razão entre vazões de líquido e gás, para se alcançar comportamento similar. 


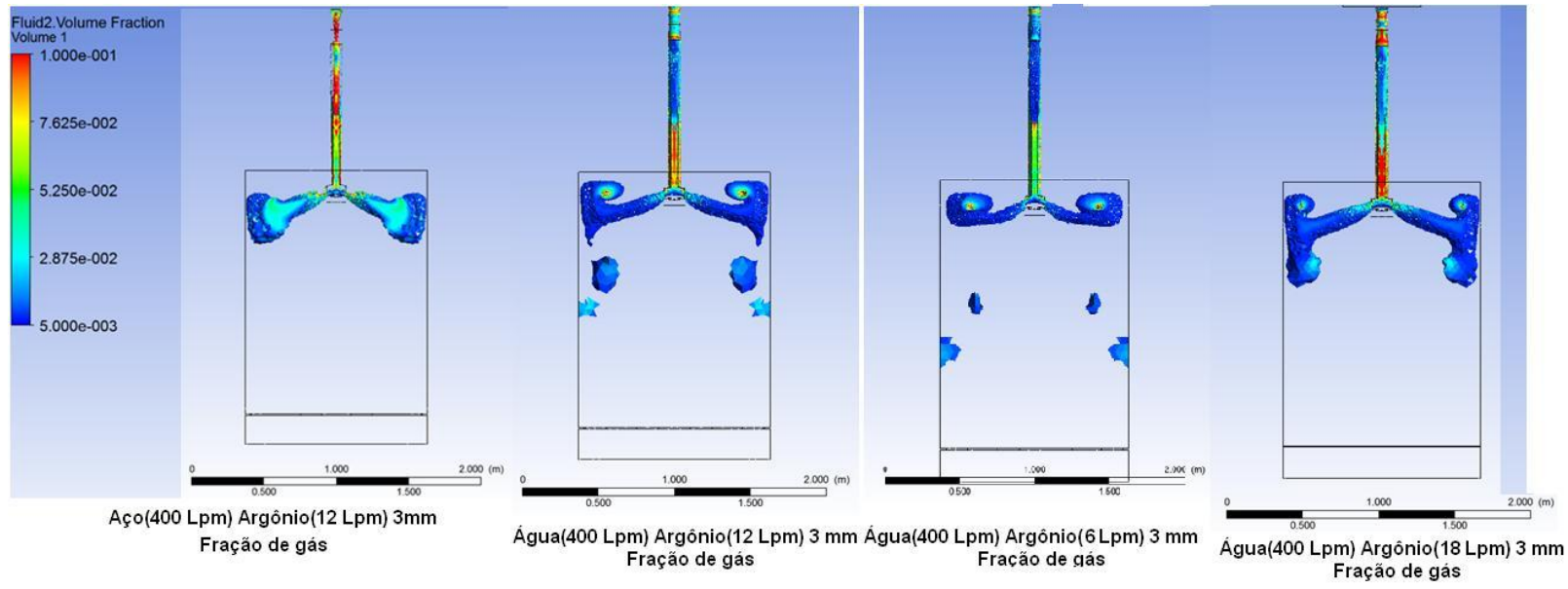

Figura 4.3-1: Mapas de distribuição de fração volumétrica de gás, modelo e na máquina industrial.

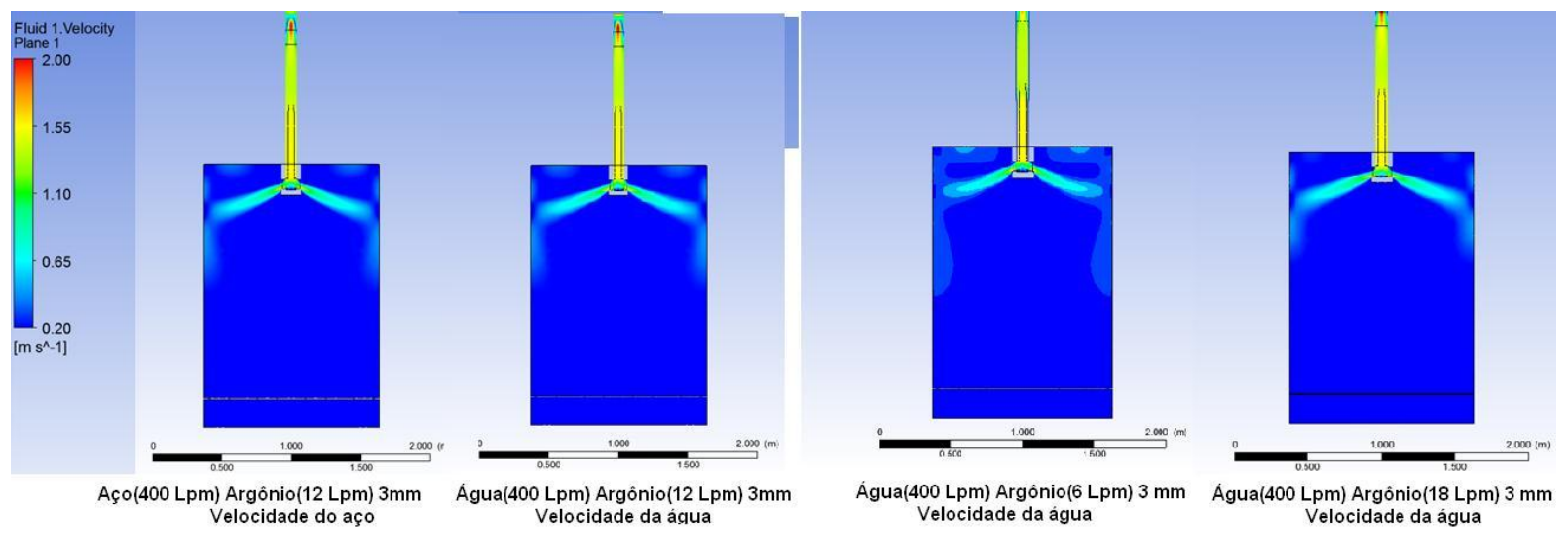

Figura 4.3-2: Mapas de distribuição de velocidades do líquido, no modelo e na máquina industrial. 


\section{CAPÍTULO 5: RESULTADOS E DISCUSSÃO}

\subsection{Diâmetro médio das bolhas dentro da SEN}

Como citado neste estudo foram utilizadas dois tipos de válvula superior porosa: todo o corpo poroso e duas seções porosas com inserto denso entre elas (Figura 4.1-2). As filmagens com luz estroboscópica tiveram por objetivo investigar se, em função das diferentes geometrias de injeção, haveria diferença significativa entre os tamanhos médios e distribuição de tamanhos das bolhas dentro da SEN, portanto, abaixo das seções de injeção. A evidência experimental não permite identificar a formação de filmes gasosos junto às paredes da SEN e a identificação individual de bolhas só se torna possível em baixas vazões de gás (2 e 4 $\mathrm{Nl} / \mathrm{min}$ ), (Figura 5.1-1). Para esta faixa de vazões foram realizadas contagens manuais em 10 quadros, com auxílio do software Quantikov, com os resultados apresentados na Tabela 5.1-1.

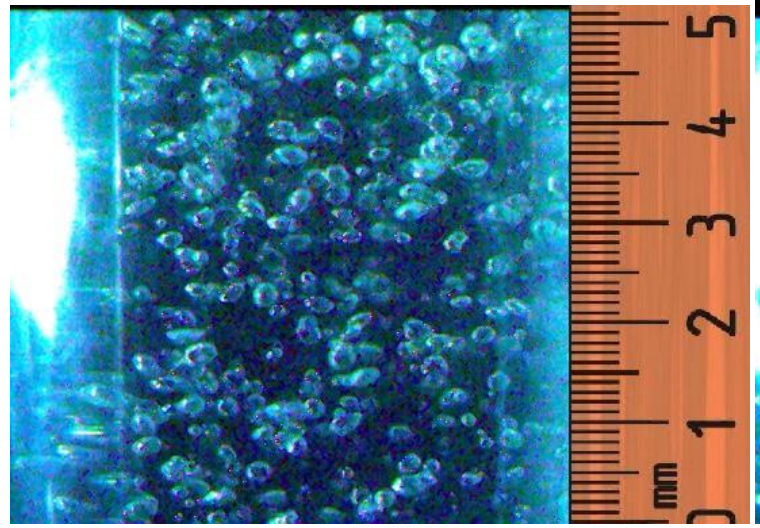

(a)

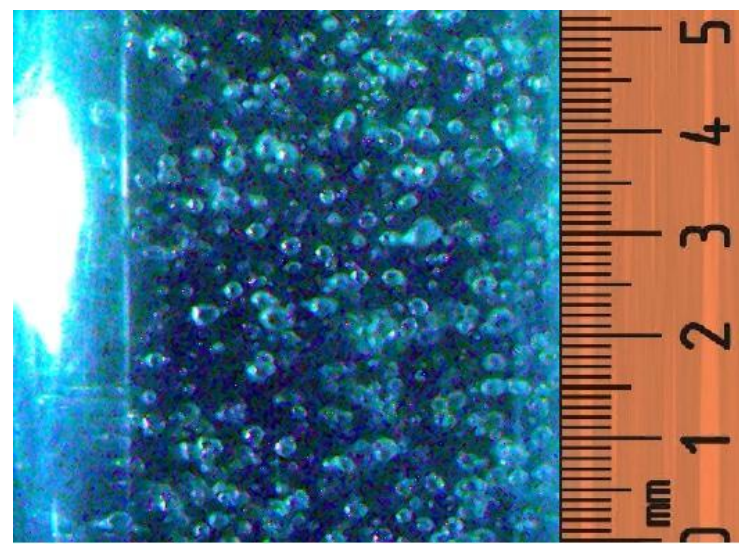

(c)

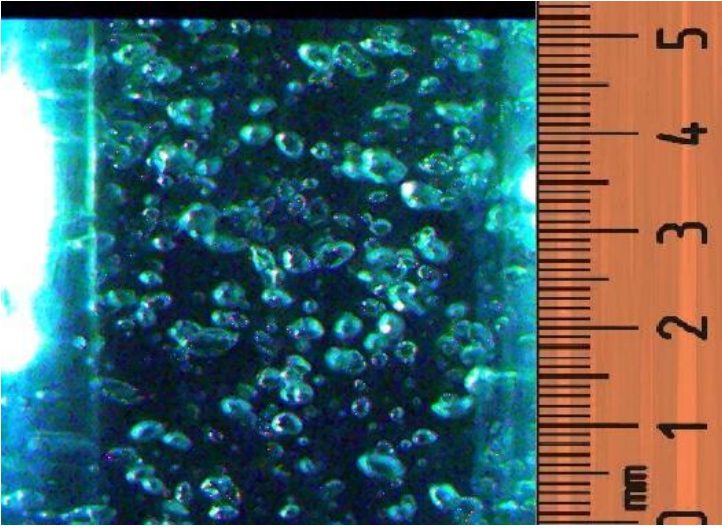

(b)

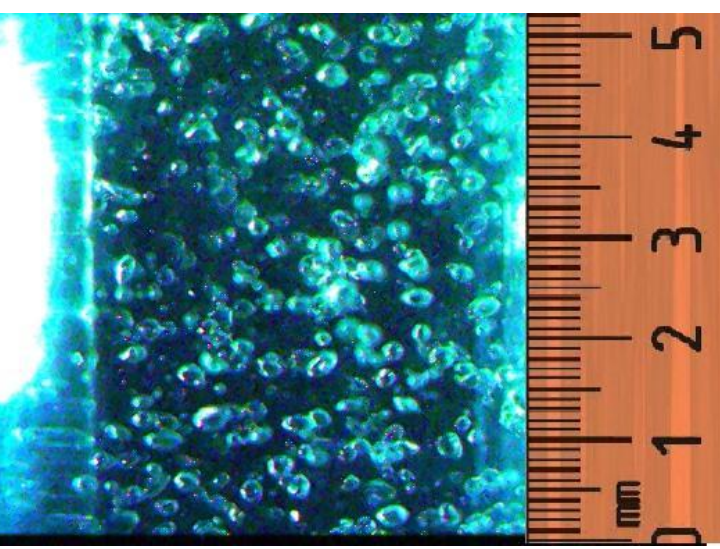

(d)

Figura 5.1-1: Válvula bloco superior com porosidade uniforme a) foto frame 336lpm com $21 \mathrm{lpm}$ de ar, b) foto frame $336 \mathrm{lpm}$ com $2 \mathrm{lpm}$ de $\mathrm{He}$, c) foto frame $4001 \mathrm{pm}$ com $21 \mathrm{lpm}$ de ar e d) foto frame $4001 \mathrm{pm}$ com 2lpm de He. 
Tabela 5.1-1: Tamanho médio das bolhas de acordo com as condições de injeção para válvula toda porosa.

\begin{tabular}{|l|l|l|l|l|}
\hline LPM Liq & LPM gas & $\begin{array}{l}\text { Fator } \\
\mathrm{Ar} / \mathrm{He}\end{array}$ & Gás & $\begin{array}{l}\text { Dmédio } \\
(\mathrm{mm})\end{array}$ \\
\hline 336 & 2 & 0 & $\mathrm{Ar}$ & 2,22867 \\
\hline 336 & 2 & 1 & $\mathrm{He}$ & 2,33692 \\
\hline 336 & 4 & 0 & $\mathrm{Ar}$ & 2,34824 \\
\hline 336 & 4 & 1 & $\mathrm{He}$ & 2,34988 \\
\hline 400 & 2 & 0 & $\mathrm{Ar}$ & 1,89258 \\
\hline 400 & 2 & 1 & $\mathrm{He}$ & 2,05748 \\
\hline 400 & 4 & 0 & $\mathrm{Ar}$ & 1,94441 \\
\hline 400 & 4 & 1 & $\mathrm{He}$ & 2,19058 \\
\hline
\end{tabular}

Regressão "stepwise" dos dados apresentados na Tabela 5.1-1 sugerem que as variáveis significativas são a vazão de líquido, vazão de gás e o tipo de gás, com fórmula de regressão:

$d(m m)=3,863-0,00460 x$ Vazão de água $(L P M)+0,0397 x$ Vazão de gás $(L P M)+0,130 x$ Tipo de gás $(\mathrm{Ar}=0 ; \mathrm{He}=1)$, com $\mathrm{r} 2=88 \%$;

O que indica pela equação serem as bolhas de Hélio ligeiramente maiores, 0,13 mm.

Experimentos semelhantes, conduzidos para a válvula com duas seções porosas de injeção (ver Figura 4.1-2b e Tabela 5.1-2) sugerem, que a equação de regressão, para diâmetros de bolha é:

$$
d(m m)=3,494-0,00381 x \text { Vazão de água }(L P M)+0,079 x \text { Vazão tde gás }(L P M), \text { com r2=74\%; }
$$

O que demonstra, pela avaliação das equações acima, que não existem diferenças perceptíveis de tamanhos de bolha, para as condições avaliadas, entre os dos dois tipos de válvula superior. 
Tabela 5.1-2: Tamanho médio das bolhas de acordo com as condições de injeção para válvula com duas seções porosas.

\begin{tabular}{|c|c|c|c|c|}
\hline LPM Liq & LPM gas & $\begin{array}{c}\text { Fator } \\
\mathrm{Ar} / \mathrm{He}\end{array}$ & Gás & $\begin{array}{c}\text { Dmédio } \\
(\mathrm{mm})\end{array}$ \\
\hline 336 & 2 & 0 & $\mathrm{Ar}$ & 2,1533420 \\
\hline 336 & 4 & 0 & $\mathrm{Ar}$ & 2,2711224 \\
\hline 400 & 2 & 0 & $\mathrm{Ar}$ & 1,8693324 \\
\hline 400 & 4 & 0 & $\mathrm{Ar}$ & 2,0669574 \\
\hline
\end{tabular}

Como base nos dados apresentados, não parece haver diferença significativa entre estas condições, o que provavelmente se deve aos altos valores de número de Reynolds, da ordem de 100.000, o que assegura ser o fluxo turbulento. Desta forma, após curto trajeto, as condições de formação de bolhas (condição local de porosidade) não seriam determinantes, mas sim o processo de desintegração e coalescimento dominado pela turbulência. $\mathrm{O}$ valor médio do diâmetro das bolhas é normalmente um dado de entrada em modelagem matemática em sistemas gás-líquido como o abordado nesta contribuição.

Ainda de acordo com as Tabela 5.1-1 e 5.1-2, e respectivas equações de regressão, se pode perceber, que para ambos os gases, o diâmetro das bolhas são maiores para vazões de água menores e para vazões de ar ou He maiores. Este comportamento foi apresentado e discutido por SUZUKI (2003) e THOMAS (1997).

\subsection{Distribuição de gás no interior do molde para válvula superior totalmente porosa}

O padrão de fluxo no molde (distribuição e trajetória das bolhas; movimentação do líquido) se mostra fortemente influenciado pela combinação entre vazão de líquido e de gás. O fluxo de duplo rolo com velocidade de menisco adequada $(0,2$ a $0,4 \mathrm{~m} / \mathrm{s})$ é considerada a melhor condição para qualidade interna do aço em todas as larguras de placas ${ }^{[4]}$. É possível se observar a formação do fluxo de duplo rolo bem definido no modelo físico para as vazões de 3361/min e 4001/min sem injeção de gás (Figura 5.2-1 e Figura 5.2-2). Estas linhas de fluxo foram visualizadas através da adição de partículas de SG6 (Goodyear) e iluminação com plano de laser. 


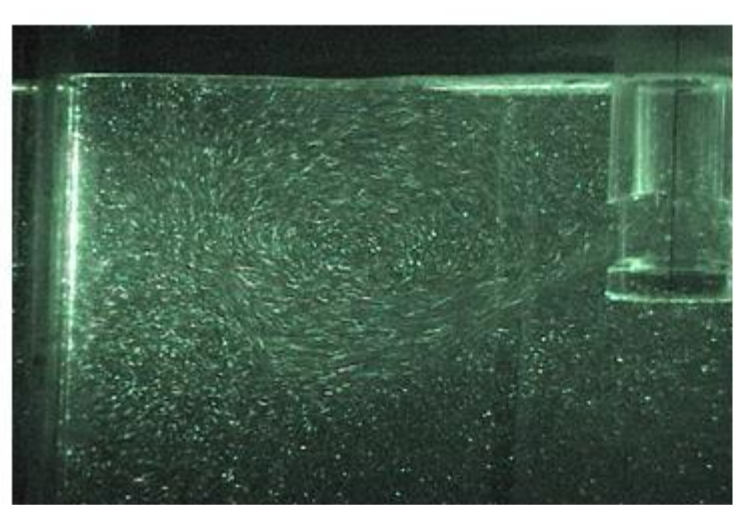

(a)

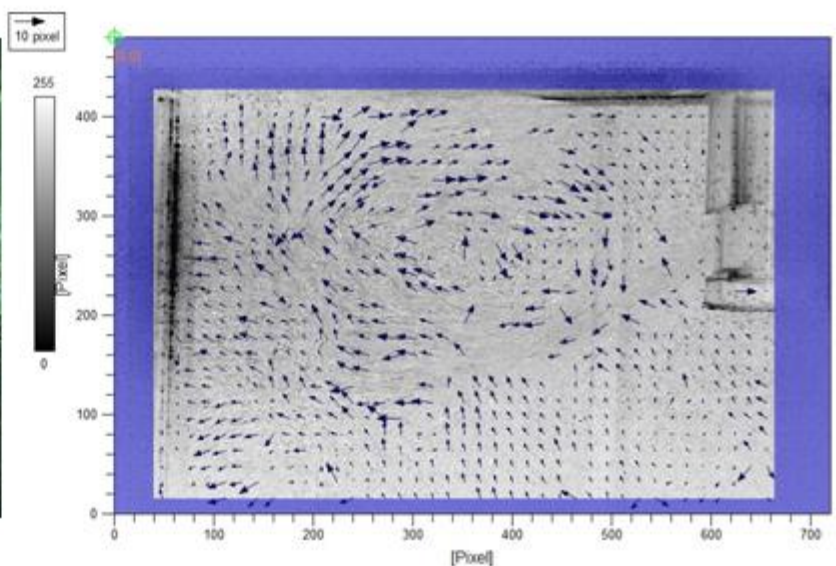

(b)

Figura 5.2-1: Foto modelo físico em funcionamento duplo rolo bem definido com a) 3361/min de água sem gás b) Imagem vetores gerados pelo software PIVVIEW para o caso de 3361/min de água sem gás.
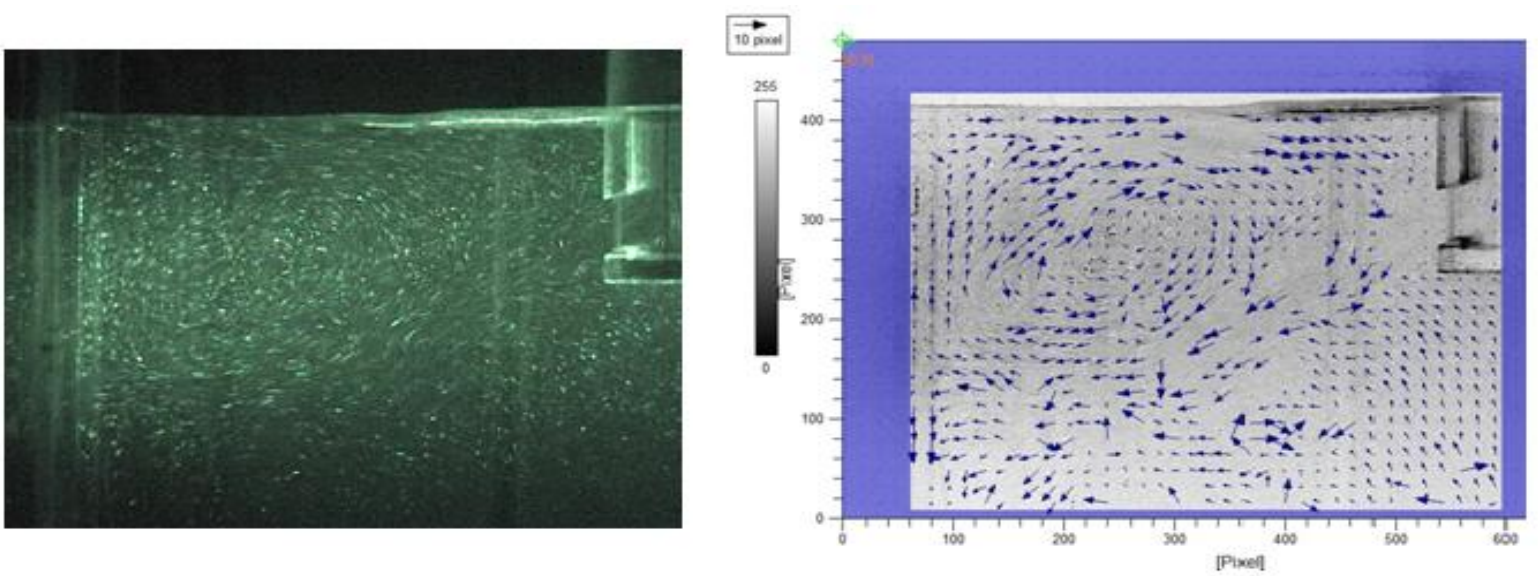

Figura 5.2-2: Foto modelo físico em funcionamento duplo rolo bem definido com a) 4001/min de água sem gás b) Imagem vetores gerados pelo software PIVVIEW para o caso de 4001/min de água sem gás.

Para a vazão de 3361/min com vazão de ar de 4N1/min pode-se observar a existência do fluxo duplo rolo (Figura 5.2-3). Contudo, para as vazões de ar de 8, 12 e 16 Nl/min (Figura 5.2-4,Figura 5.2-5 e Figura 5.2-6), se observa que o fluxo duplo rolo fica prejudicado pelo fluxo de ar, que tende a determinar um fluxo ascendente próximo a saída da válvula, sendo este mais intenso e mais próximo da válvula para as vazões mais elevadas de ar, 12 e 16Nl/min. Conforme já mencionado o padrão de fluxo no molde se mostra fortemente influenciado pela combinação entre vazão de líquido e de gás (Thomas, 1997). 


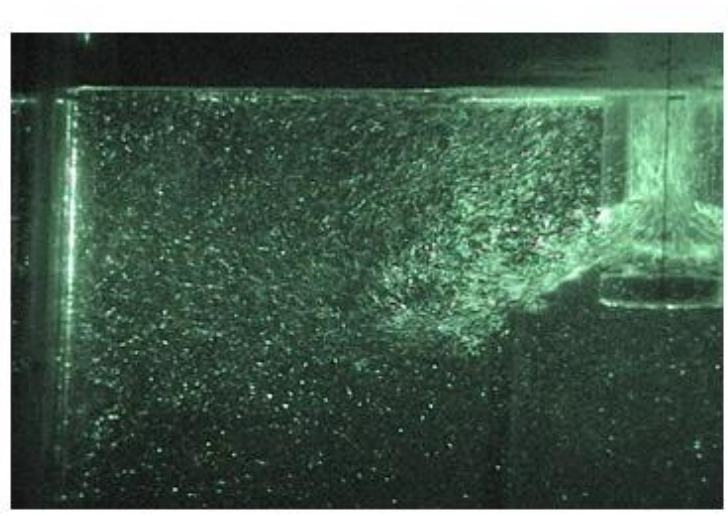

(a)

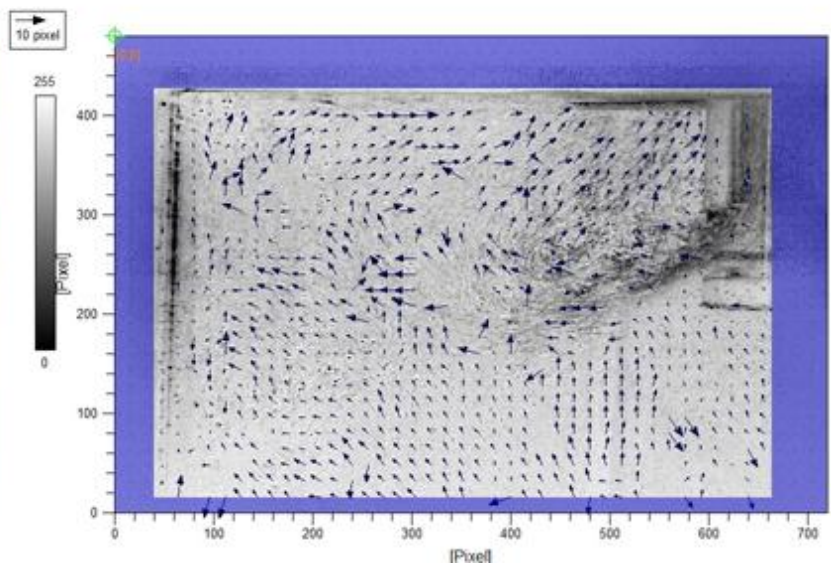

(b)

Figura 5.2-3: Foto modelo físico em funcionamento duplo rolo bem definido com a) 336l/min de água e 4N1/min de ar b) Imagem vetores gerados pelo software PIVVIEW para o caso de 336l/min de água e $4 \mathrm{Nl} / \mathrm{min}$ de ar.

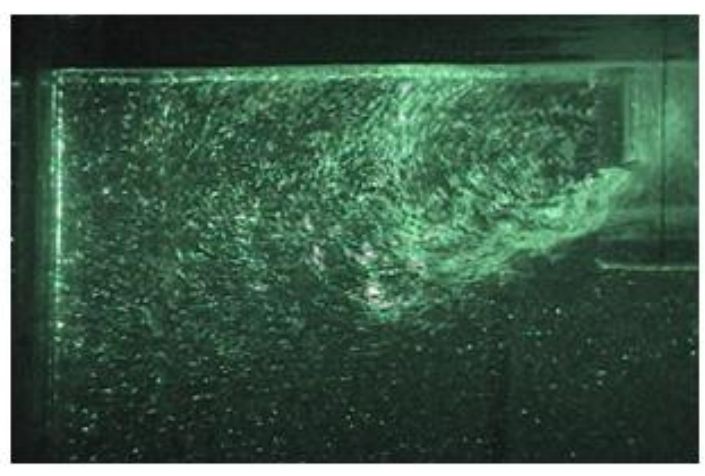

(a)

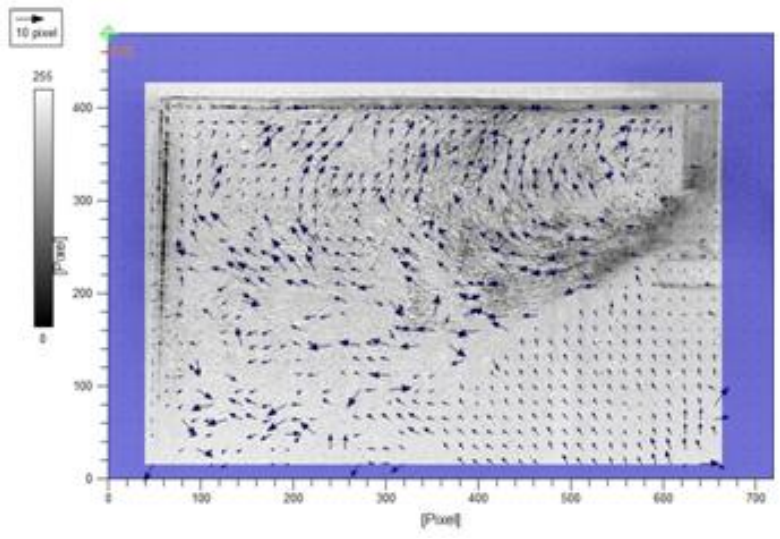

(b)

Figura 5.2-4: Foto modelo físico em funcionamento duplo rolo prejudicado com a) $3361 / \mathrm{min}$ de água e $8 \mathrm{Nl} / \mathrm{min}$ de ar b) Imagem vetores gerados pelo software PIVVIEW para o caso de 3361/min de água e $8 \mathrm{Nl} / \mathrm{min}$ de ar. 


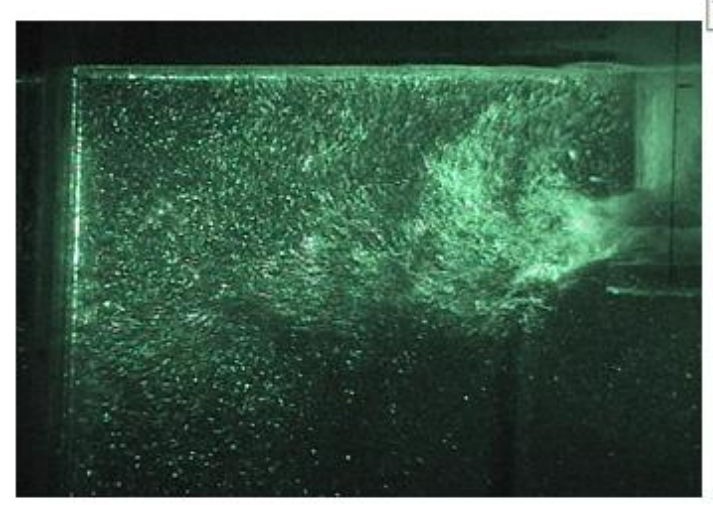

(a)

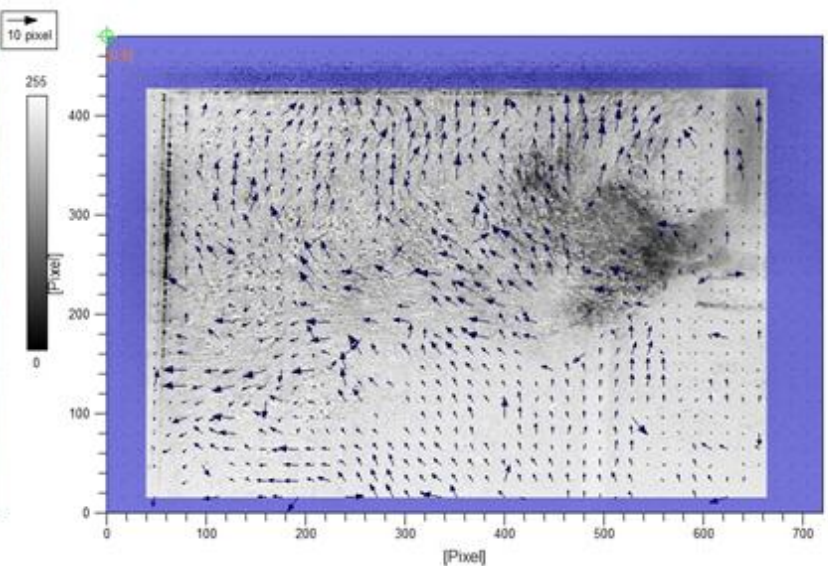

(b)

Figura 5.2-5: Foto modelo físico em funcionamento duplo rolo prejudicado com a) 3361/min de água e 12Nl/min de ar b) Imagem vetores gerados pelo software PIVVIEW para o caso de 3361/min de água e $12 \mathrm{Nl} / \mathrm{min}$ de ar.

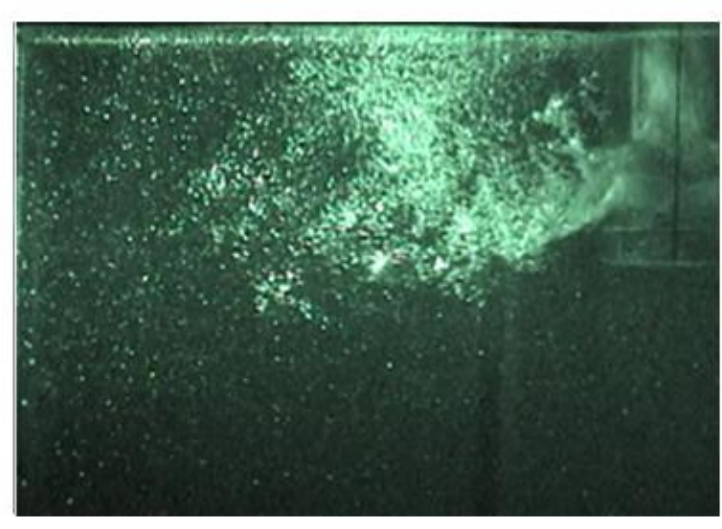

(a)

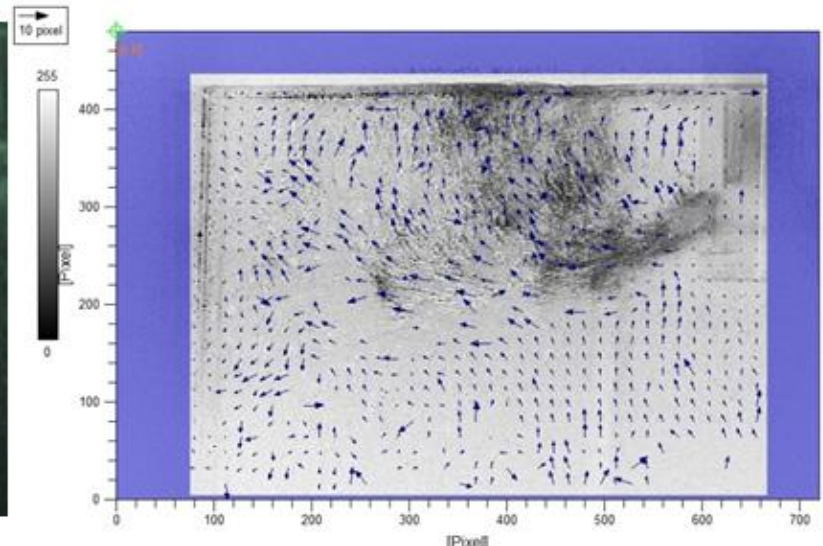

(b)

Figura 5.2-6: Foto modelo físico em funcionamento duplo rolo prejudicado com a) $3361 / \mathrm{min}$ de água e 16Nl/min de ar b) Imagem vetores gerados pelo software PIVVIEW para o caso de 3361/min de água e $16 \mathrm{Nl} / \mathrm{min}$ de ar.

Como já citado neste estudo, para se visualizar adequadamente o fluxo de água no molde foram adicionadas partículas de SG6, conforme mostram as Figura 5.2-3, Figura 5.2-4, Figura 5.2-5 e Figura 5.2-6. Em imagens obtidas sem adição de partículas na vazão de 3361/min fica evidente o fluxo ascendente das bolhas na região próxima a válvula submersa conforme se observa na Figura 5.2-7. 


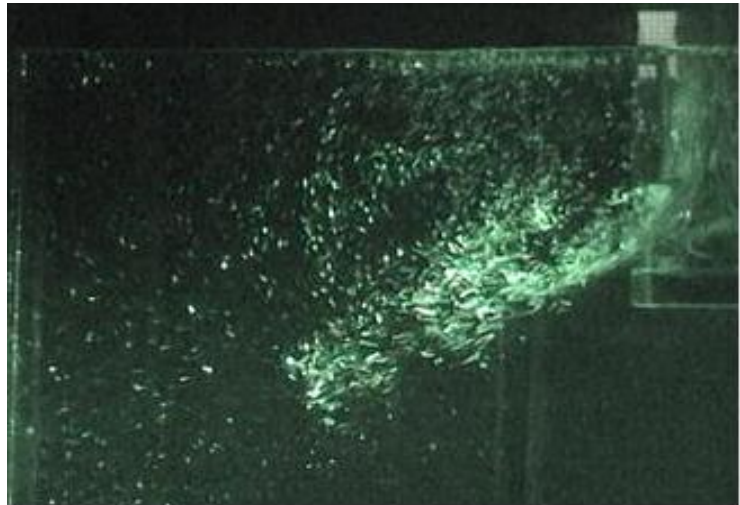

(a)

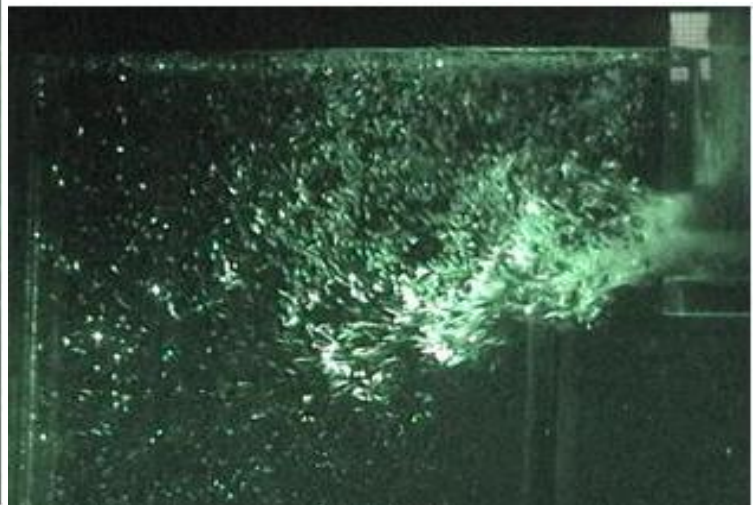

(b)

Figura 5.2-7: Foto modelo físico em funcionamento com a) 3361/min de água e 4Nl/min de ar b) 3361/min de água e $12 \mathrm{Nl} / \mathrm{min}$ de ar.

Observou-se também, para a vazão de água de 3361/min com injeção de 12N1/min e 16N1/min de ar, além do fluxo alterado no menisco, a ocorrência periódica de bolhas com diâmetros maiores saindo da válvula e gerando uma turbulência adicional no menisco (Figura 5.2-8). Conforme comentado por Thomas (1997): "as bolhas se concentram em regiões de baixa velocidade da válvula, as quais inclusive apresentam um fluxo de recirculação e estas regiões incluem a válvula gaveta e a parte superior da saída da SEN". Além das regiões mencionadas por Thomas (1997), observa-se no modelo físico uma concentração de bolhas no fundo e na face superior da saída da SEN, que em princípio seria responsável pela coalescência das bolhas e a modificação do campo de fluxo no molde.

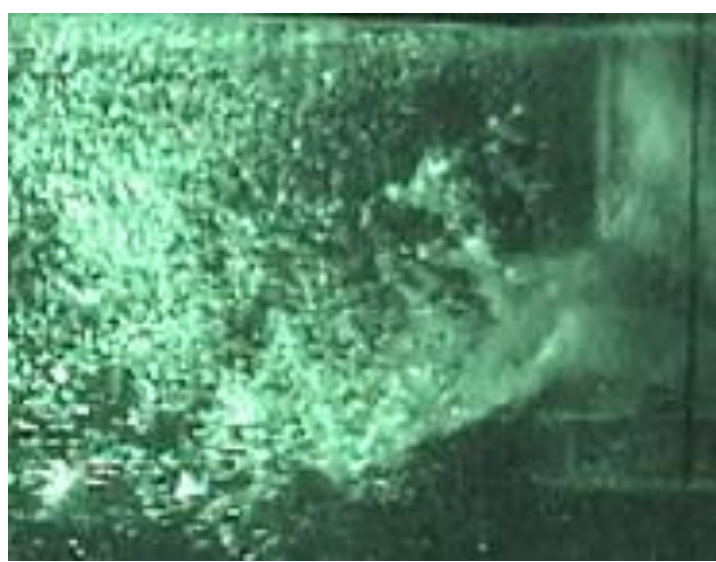

(a)

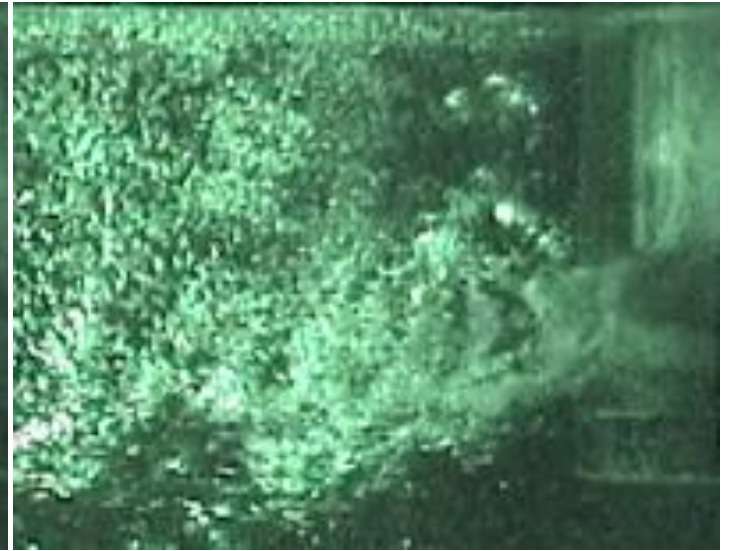

(b)

Figura 5.2-8: Fotos evidenciando as bolhas na saída da SEN para 3361/min com injeção de gás (a) $12 \mathrm{Nl} / \mathrm{min}$ e (b) $16 \mathrm{Nl} / \mathrm{min}$. 
Para vazão de 400 1/min observa-se o fluxo duplo rolo no molde para todas as vazões de ar (4, 8, 12 e 16Nl/min). Nas Figura 5.2-9 a Figura 5.2-12, referente à vazão de água de 4001/min e 4, 8, 12 e 16N1/min de ar, respectivamente, percebe-se que o gás é levado até a lateral do molde e que se distribui de uma maneira muito mais homogênea, ao contrário do observado em vazões inferiores de líquido, $336 \mathrm{l} / \mathrm{min}$. A análise das imagens geradas via software PIVVIEW, para as condições mencionadas mostra claramente a formação do fluxo em duplo rolo (ver Figura 5.2-9 a Figura 5.2-12). Em relação à vazão de 3361/min uma situação que não se observa para a vazão de 4001/min é a formação de bolhas com diâmetros maiores na saída da válvula. Entende-se que a maior vazão gera uma maior turbulência, o que não permite a aglomeração do gás em bolhas maiores. Outro fator que pode influenciar também este fenômeno, é que para vazões maiores de água, espera-se uma redução no tamanho das bolhas (Yuan, 2008; Suzuki, 2003).

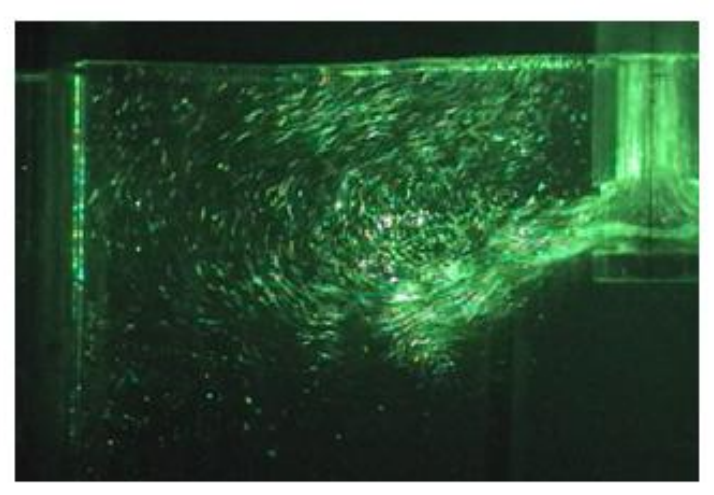

(a)

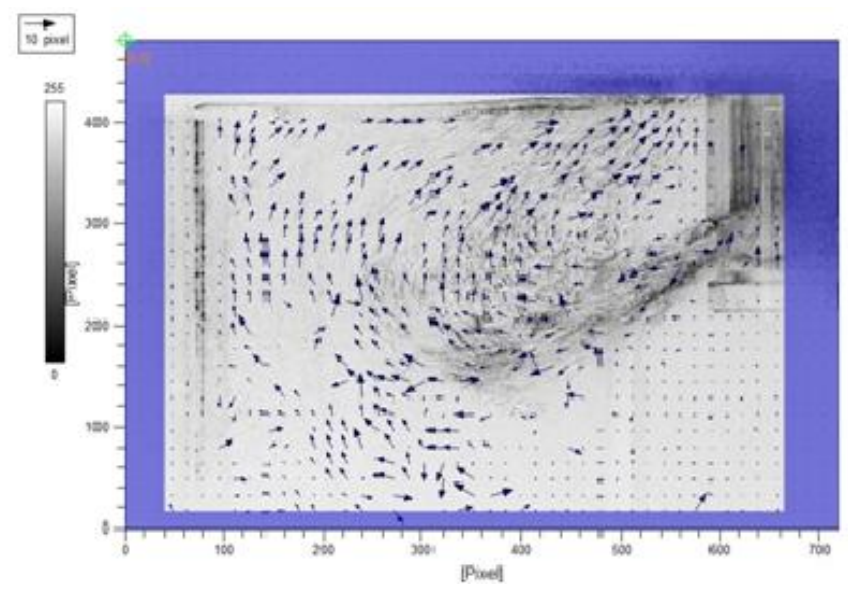

(b)

Figura 5.2-9: Foto modelo físico em funcionamento com 4001/min de água e 4N1/min de ar; Imagem vetores gerados pelo software PIVVIEW para o caso de 4001/min de água e 4Nl/min de ar. 


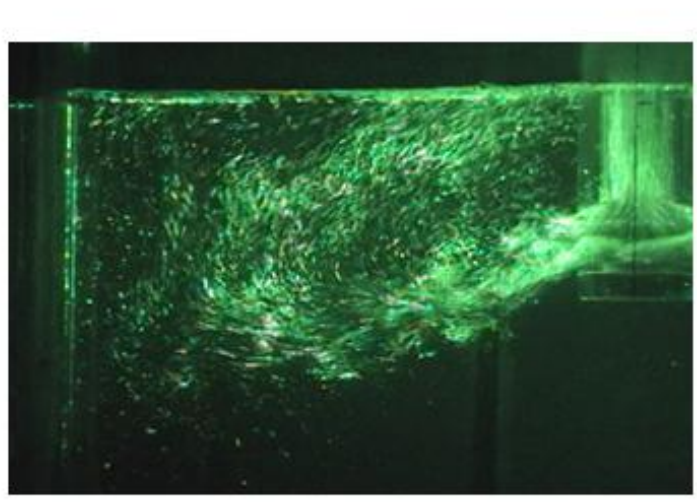

(a)

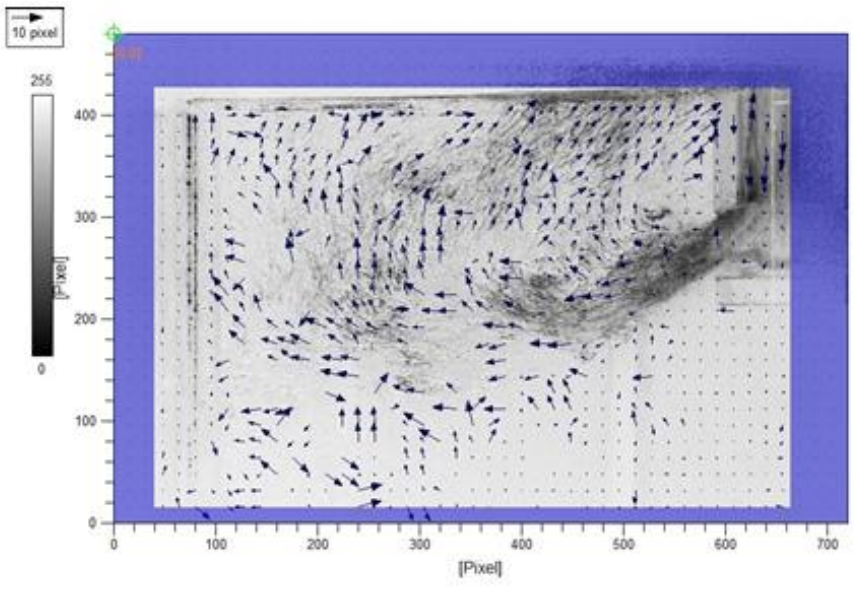

(b)

Figura 5.2-10: Foto modelo físico em funcionamento com 4001/min de água e $8 \mathrm{Nl} / \mathrm{min}$ de ar; Imagem vetores gerados pelo software PIVVIEW para o caso de 4001/min de água e $8 \mathrm{Nl} / \mathrm{min}$ de ar .

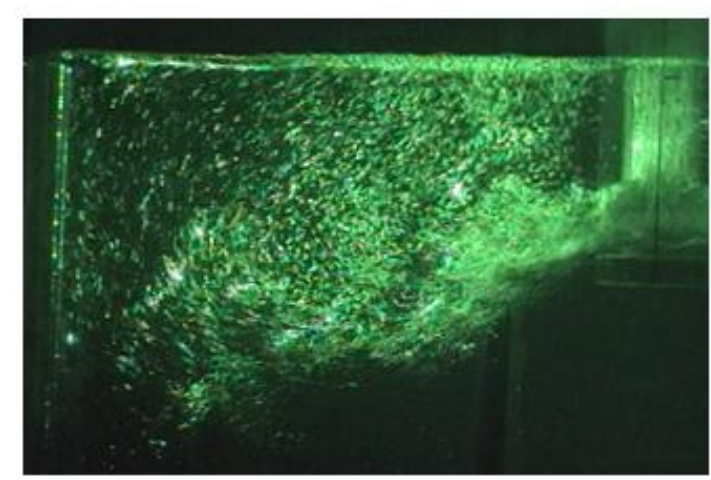

(a)

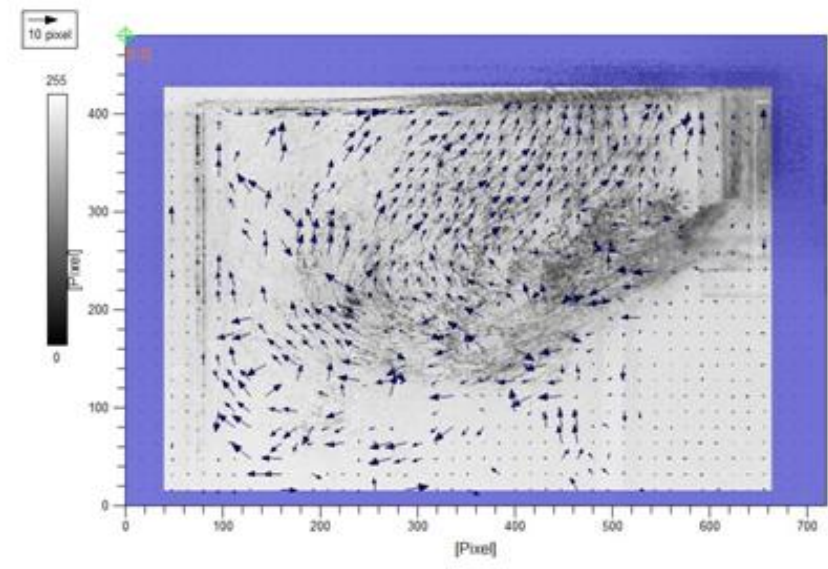

(b)

Figura 5.2-11: Foto modelo físico em funcionamento com 4001/min de água e 12Nl/min de ar; Imagem vetores gerados pelo software PIVVIEW para o caso de 4001/min de água e $12 \mathrm{Nl} / \mathrm{min}$ de ar .

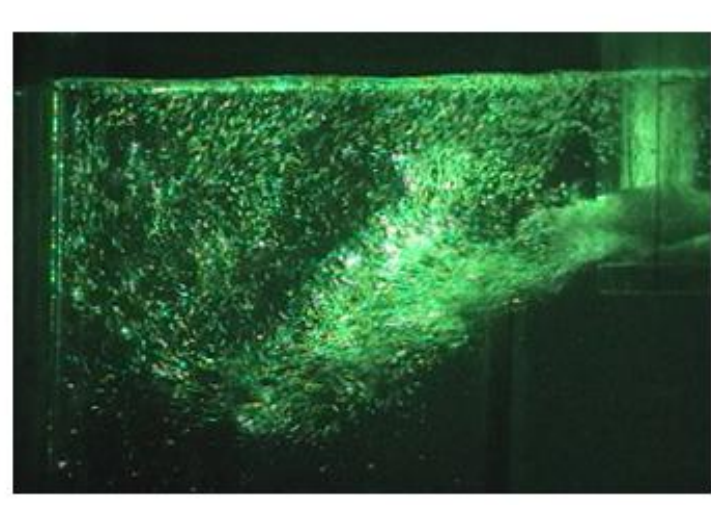

(a)

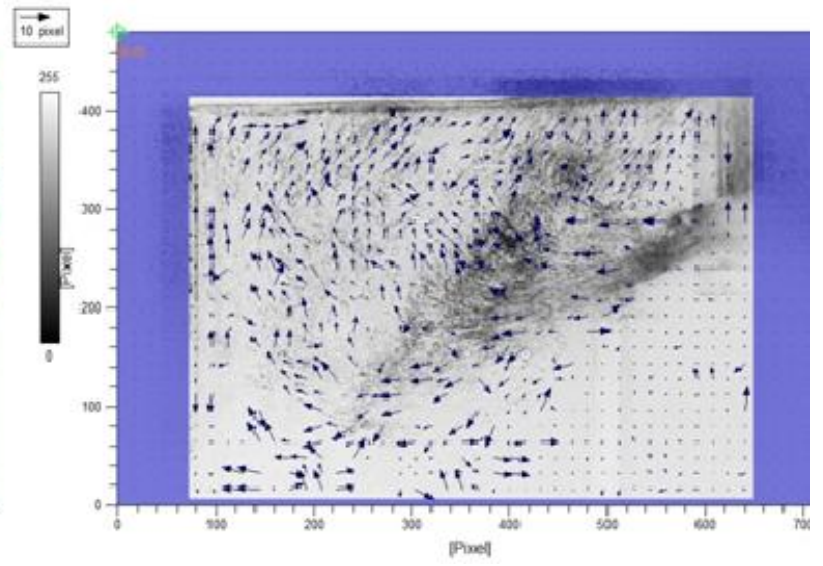

(b)

Figura 5.2-12: Foto modelo físico em funcionamento com 4001/min de água e 16NI/min de ar; Imagem vetores gerados pelo software PIVVIEW para o caso de 4001/min de água e $16 \mathrm{Nl} / \mathrm{min}$ de ar . 


\subsection{Distribuição de gás no interior do molde para válvula superior com duas seções porosas}

Semelhante ao observado para válvula superior totalmente porosa, mostra-se também que o padrão de fluxo no molde para válvula com duas seções é fortemente influenciado pela combinação entre vazão de líquido e de gás. Para vazão de 3361/min e vazão de ar de 4N1/min observa-se a existência do fluxo duplo rolo similar ao da válvula toda porosa (ver Figura 5.3-1 e Figura 5.2-3). Enquanto que para vazões de ar de 8, 12 e 16 Nl/min (Figura 5.2-4, Figura 5.2-5 e Figura 5.2-6), semelhante ao observado para válvula toda porosa, o fluxo duplo rolo fica prejudicado pelo fluxo de ar, o que tende a determinar um fluxo ascendente próximo a saída da válvula (ver Figura 5.3-2).

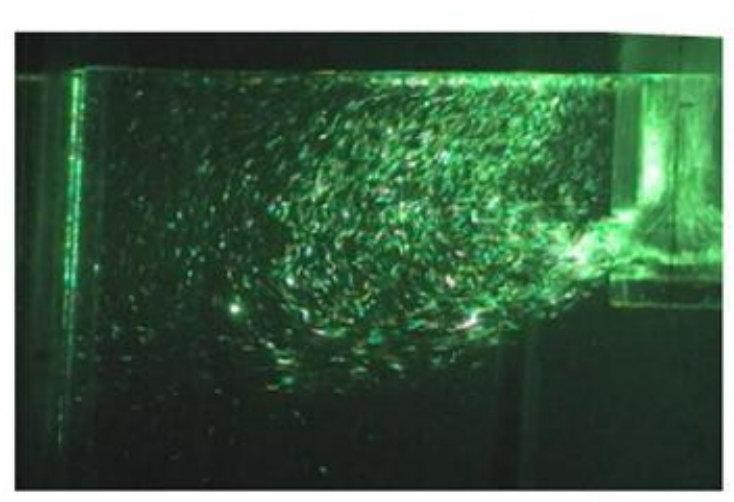

(a)

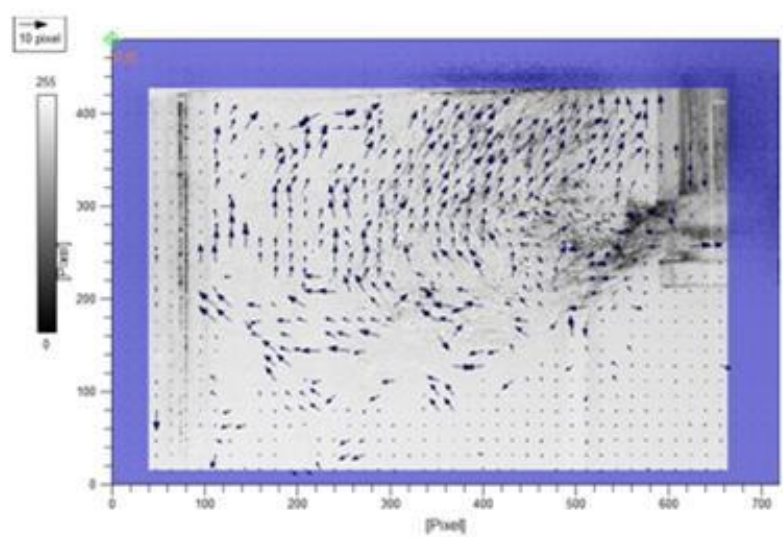

(b)

Figura 5.3-1: Foto modelo físico em funcionamento válvula superior com duas seções porosas a) 3361/min de água e 4Nl/min de ar b) Imagem vetores gerados pelo software PIVVIEW para o caso de 3361/min de água e $4 \mathrm{Nl} / \mathrm{min}$ de ar . 


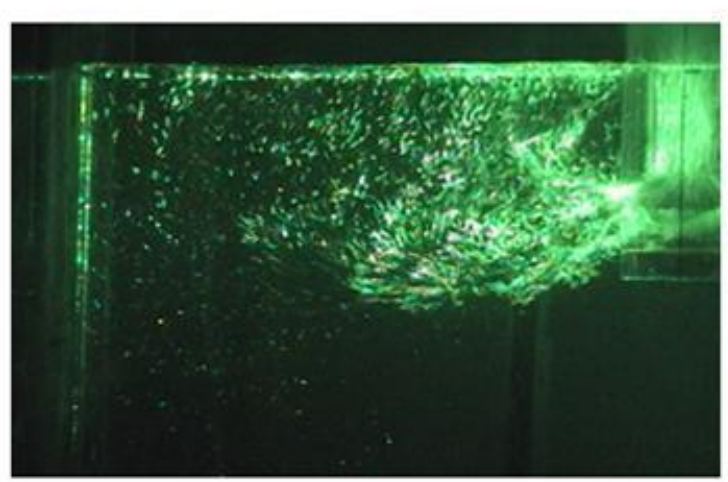

(a)

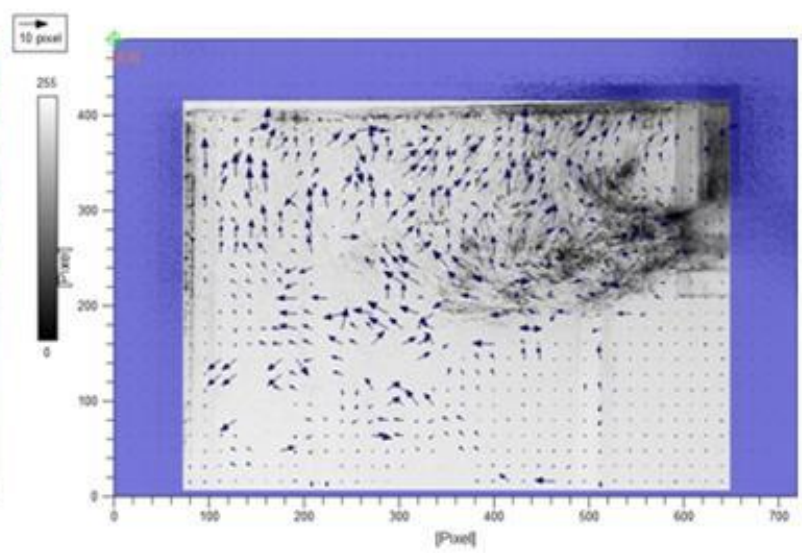

(b)

Figura 5.3-2: Foto modelo físico em funcionamento válvula superior com duas seções porosas a) 3361/min de água e 12Nl/min de ar b) Imagem vetores gerados pelo software PIVVIEW para o caso de 3361/min de água e $12 \mathrm{Nl} / \mathrm{min}$ de ar .

Para vazões de 400 1/min se mantém a formação do fluxo de duplo rolo (ver Figura 5.3-3 e Figura 5.3-4), ou seja, independentemente da vazão de água, quando se avalia o fluxo de água no molde (incluindo a distribuição e trajetória das bolhas; e movimentação do líquido) não se observa diferenças significativas, quer se trate de válvula totalmente porosa ou de válvula com duas seções porosas de injeção. Tal comportamento poderia ser antecipado face à avaliação anteriormente efetuada dos diâmetros das bolhas no interior da SEN; naquele caso também o tamanho das bolhas não se mostrou influenciado pelo tipo de válvula superior.

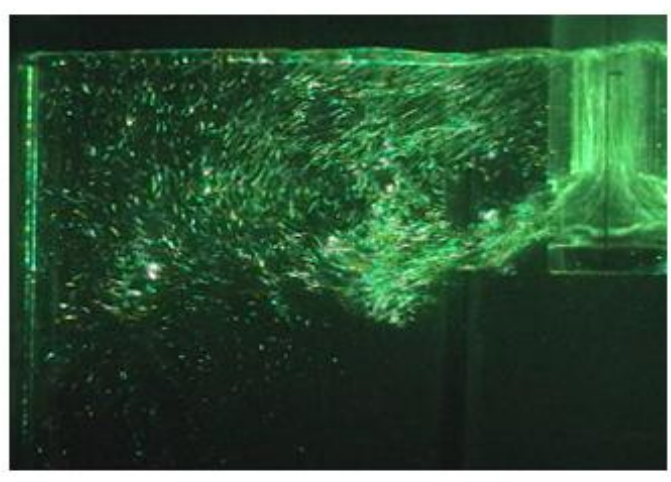

(a)

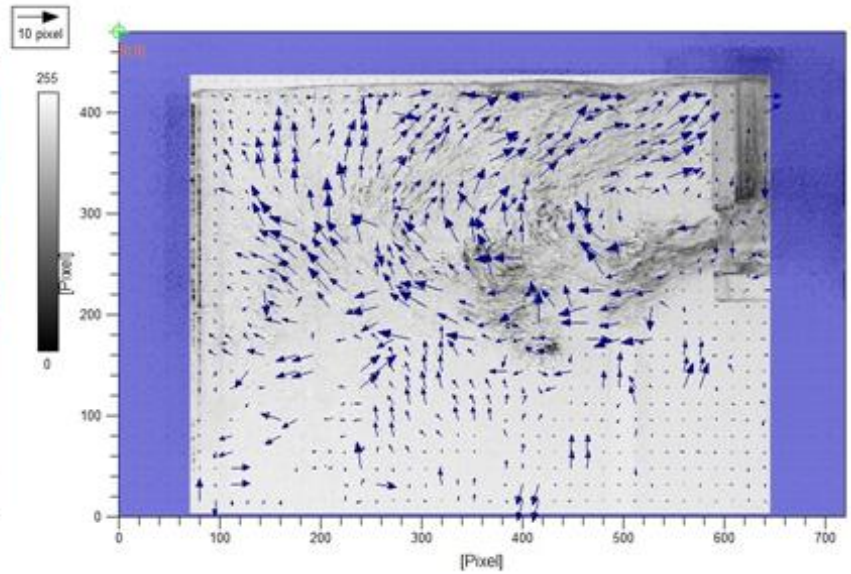

(b)

Figura 5.3-3: Foto modelo físico em funcionamento válvula superior com duas seções porosas (a) $4001 / \mathrm{min}$ de água e 4NI/min de ar (b) Imagem vetores gerados pelo software PIVVIEW para o caso de 4001/min de água e $4 \mathrm{Nl} / \mathrm{min}$ de ar . 


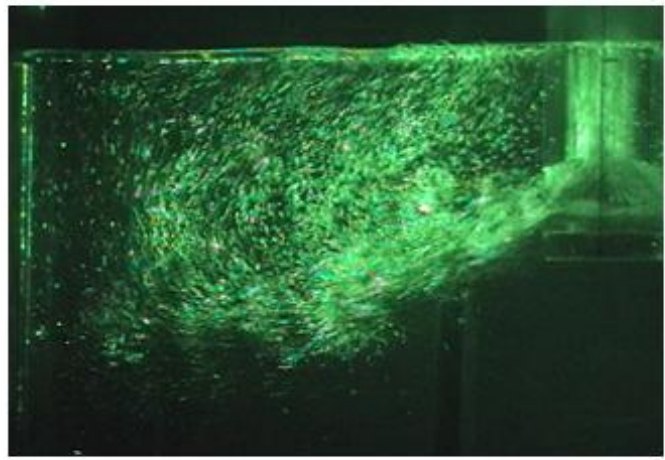

(a)

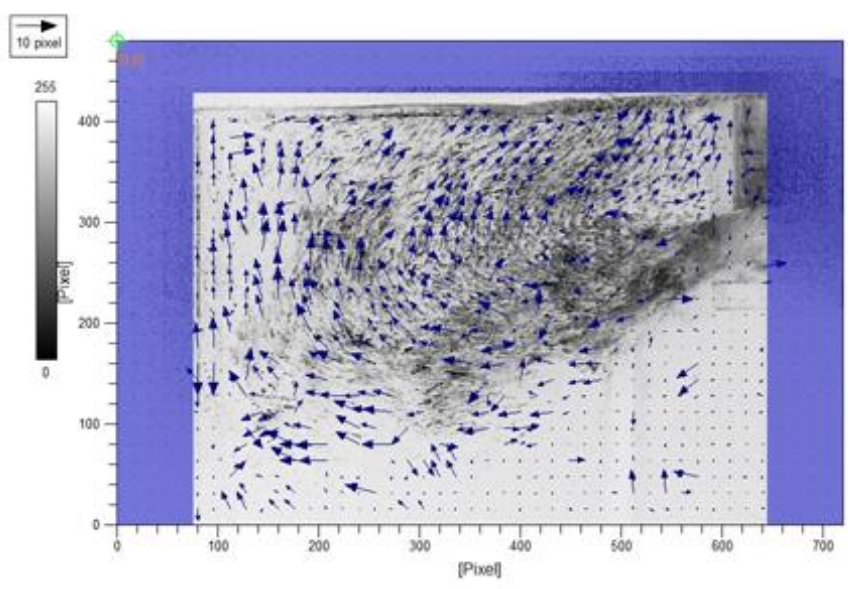

(b)

Figura 5.3-4: Foto modelo físico em funcionamento válvula superior com duas seções porosas (a) 4001/min de água e 12Nl/min de ar (b) Imagem vetores gerados pelo software PIVVIEW para o caso de 4001/min de água e 12Nl/min de ar .

\subsection{Condição de transição de gás no interior do molde para válvula superior com dupla seção porosa}

Para 336 1/min, variando-se de 1 em 1 Nl/min a vazão de ar, para uma faixa de 2 a 10 Nl/min, observou-se que a transição do fluxo de duplo rolo ocorre entre 5 a $7 \mathrm{Nl} / \mathrm{min}$ de ar. Já para 360 1/min, também variando de 1 em $1 \mathrm{Nl} / \mathrm{min}$, para uma faixa de 2 a 16Nl/min, observou-se que a transição do duplo rolo ocorre entre as vazões de 13 a 15 Nl/min (ver Figura 5.4-1 e Figura 5.4-2). Estes resultados por sua vez confirmam a observação de que para a vazão de 4001/min e para vazões de ar entre 4 a 16N1/min o fluxo de duplo rolo se mantém inalterado.
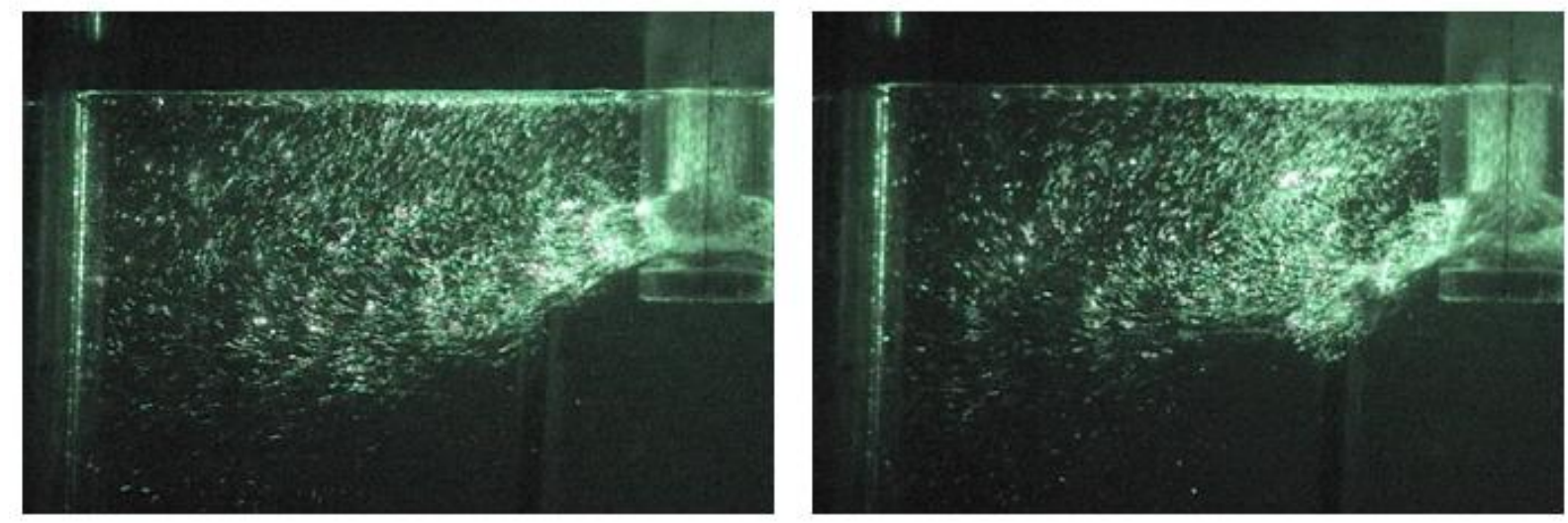

Figura 5.4-1: Foto modelo físico em funcionamento válvula superior com duas seções porosas a) 3361/min de água e $5 \mathrm{Nl} / \mathrm{min}$ de ar b) $336 \mathrm{~m} / \mathrm{min}$ de água e $7 \mathrm{Nl} / \mathrm{min}$ de ar. 

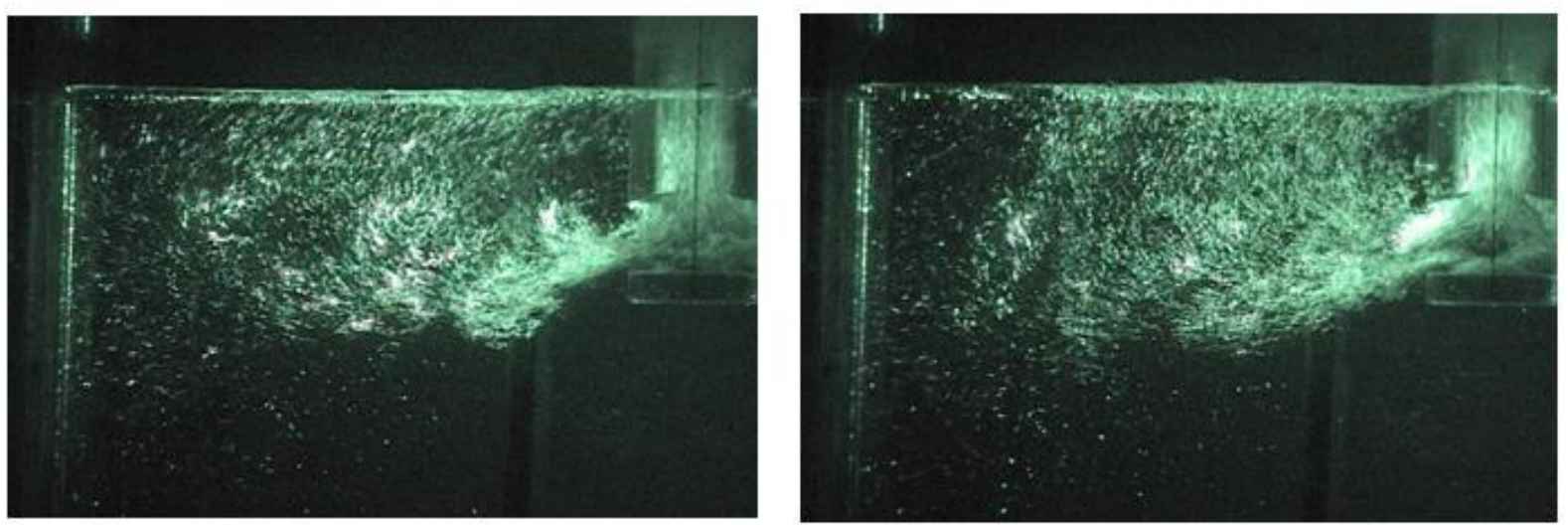

Figura 5.4-2: Foto modelo físico em funcionamento válvula superior com duas seções porosas a) 3601/min de água e $13 \mathrm{Nl} / \mathrm{min}$ de ar b) 360l/min de água e $15 \mathrm{Nl} / \mathrm{min}$ de ar.

Conforme Tabela 5.4-1, observa-se que pequenas modificações na vazão, de 336 para 3601/min (em torno de 7\%), significam pouca alteração na velocidade e no número de Reynolds. Para estes valores de número de Reynolds se pode afirmar que para todas as condições avaliadas no modelo físico o regime é turbulento no interior da válvula submersa (Yavuz, 2010). A alteração de vazão, todavia, modifica em muito a condição de perturbação do fluxo de duplo rolo no molde, conforme já discutido acima (ver Figura 5.4-1 e Figura $5.4-2)$.

Tabela 5.4-1: Reynolds e Velocidade em Função da Vazão de Água e Diâmetro

\begin{tabular}{|c|c|c|c|c|c|}
\hline $\begin{array}{c}\text { Vazão de água } \\
(1 / \mathrm{min})\end{array}$ & $\begin{array}{c}\text { Vazão de água } \\
(\mathrm{m} 3 / \mathrm{s})\end{array}$ & $\mathrm{D}(\mathrm{m})$ & Área $(\mathrm{m} 2)$ & $\begin{array}{c}\text { Velocidade } \\
(\mathrm{m} / \mathrm{s})\end{array}$ & $\operatorname{Re}$ \\
\hline 336 & 0,00560 & 0,070 & 0,003847 & 1,46 & 9894,25 \\
\hline 360 & 0,00600 & 0,070 & 0,003847 & 1,60 & 10600,99 \\
\hline 400 & 0,00667 & 0,070 & 0,003847 & 1,73 & 11778,88 \\
\hline
\end{tabular}

\subsection{Simulação Numérica}

Para a simulação com vazão de água de 336L/min, injeção de ar de 12 Nl/min e diâmetro de bolha igual a 3mm sem a consideração de empuxo para as bolhas, pôde-se observar que a distribuição volumétrica do gás acompanha o campo de fluxo (ver Figura 5.5-1). Contudo, quando se compara a Figura 5.5-2 com resultado dos quadros da distribuição volumétrica (prevista pelo modelo matemático CFX), imagem à esquerda, e a distribuição de bolhas 
observada no modelo físico, sem uso de partículas, à direita, para a mesma condição de vazão de água e de gás, observa-se uma clara discrepância entre o modelo matemático e o modelo físico. Enquanto no modelo físico as bolhas apresentam um movimento ascendente logo após a saída da SEN, no modelo matemático o gás acompanha o fluxo da fase líquida até a extremidade estreita do molde.

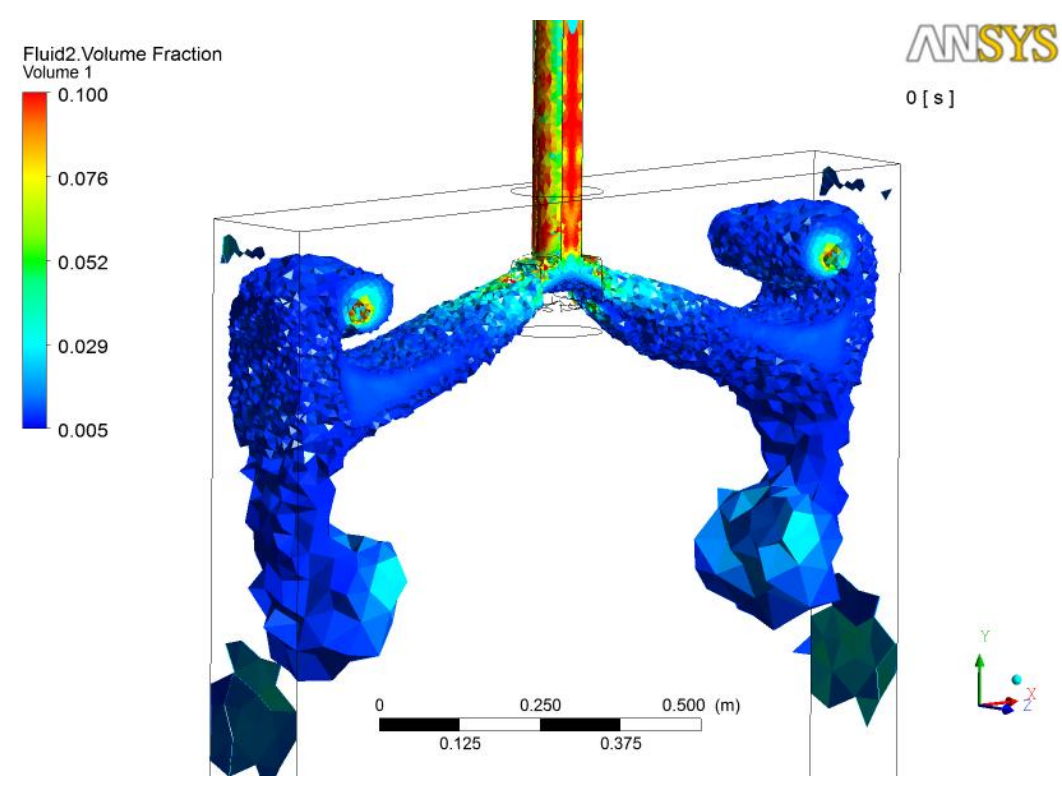

Figura 5.5-1: Distribuição gasosa gerada na simulação matemática vista 3-D, vazão 336 lpm e 12 Nl/min de gás com diâmetro de bolha de $3 \mathrm{~mm}$ sem empuxo.

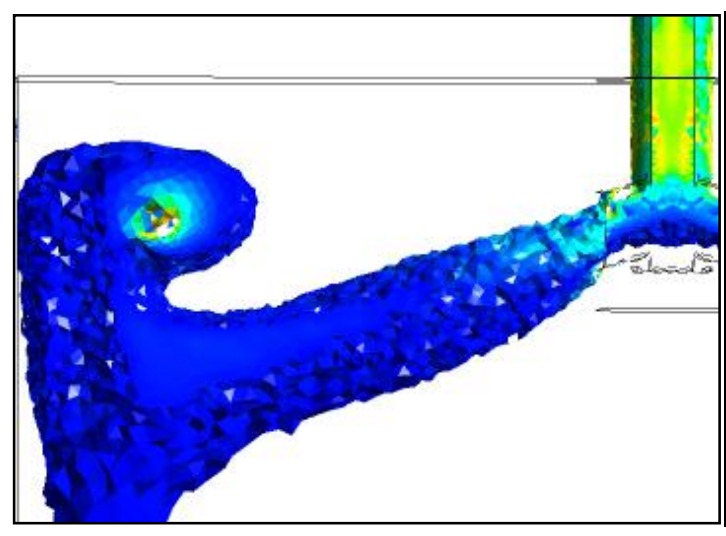

(a)

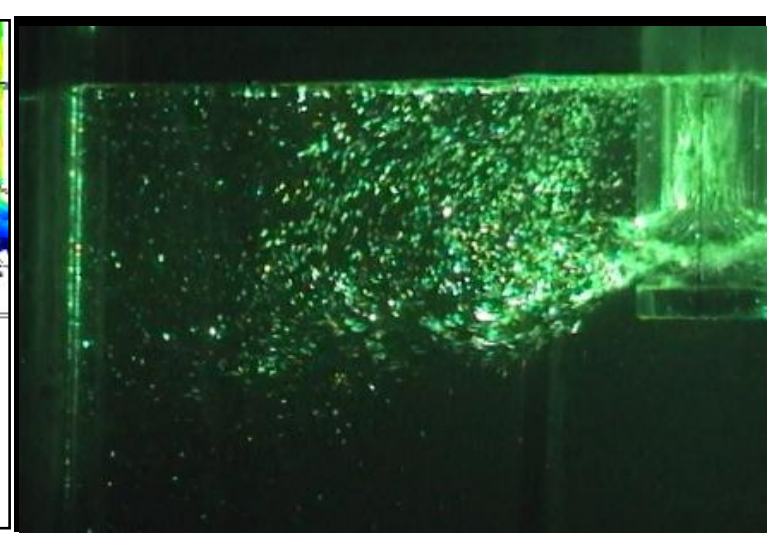

(b)

Figura 5.5-2: Imagem da distribuição gasosa gerada na simulação matemática (a), gás vai até a parede estreita do molde (sem empuxo), e foto da simulação física (b), com fluxo de gás ascendente próximo a saída da SEN, ambas com 336 lpm e 12 NI de gás por minuto sem partículas

Todavia, quando avalia-se o caso de 3361/min de água, $12 \mathrm{Nl} / \mathrm{min}$ de ar e diâmetro de $3 \mathrm{~mm}$, com a consideração de empuxo para as bolhas, observa-se que o modelo, imagem à esquerda 
(Figura 5.5-3), apresenta a fração volumétrica em um movimento inicialmente direcionado pelo fluxo do líquido na região próxima a saída da válvula, e posteriormente em um movimento claramente ascendente a medida que se afasta da válvula submersa, desde a saída da válvula até cerca da metade da largura do molde, o que coincide com o movimento da fase gasosa observada no modelo físico, imagem a direita (Figura 5.5-3). O que demonstra, nas condições simuladas, a importância da consideração do empuxo para a fase gasosa para obter-se um ajuste adequado do modelo matemático.

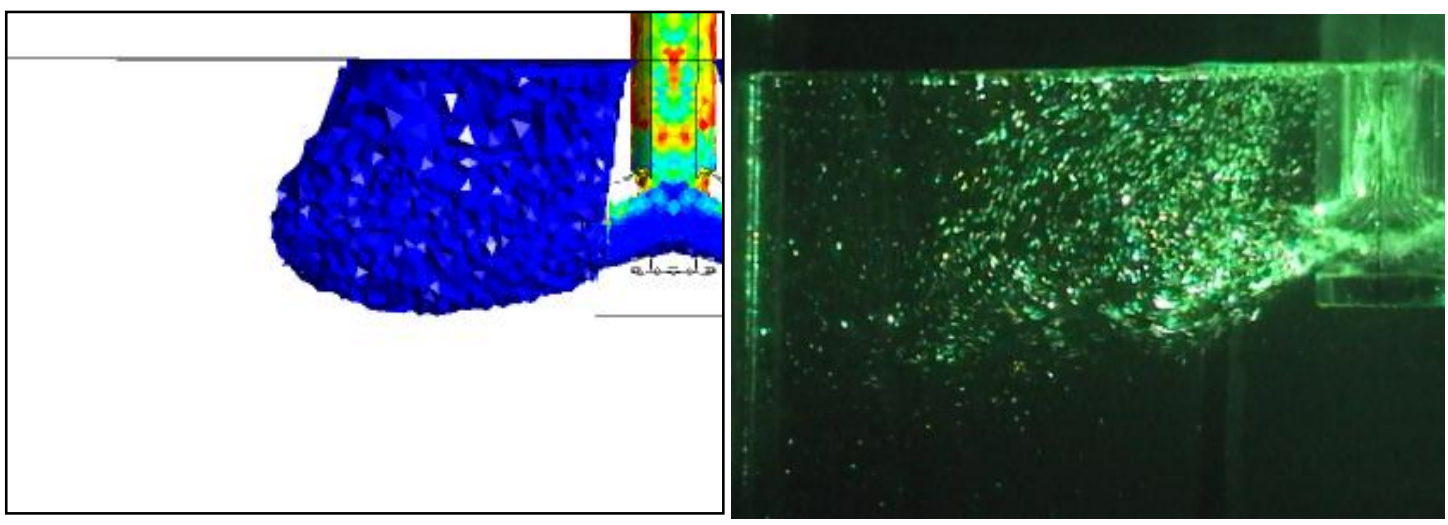

Figura 5.5-3: Imagem distribuição gasosa gerada na simulação matemática (com empuxo) e na simulação física, 336 lpm e 12 Nl de gás por minuto.

A observação anterior se confirma pela avaliação da distribuição volumétrica de gás no plano central do molde (Figura 5.5-4). Para a condição sem empuxo, imagem à esquerda, observase que os pontos de concentração de gases estão em uma pequena região na saída da válvula e próximo à face estreita do molde (cor vermelha), enquanto que para a condição com empuxo, imagem à direita, a maior concentração da fração volumétrica se encontra na região desde a saída da válvula até a superfície do molde, o que por sua vez confirma a semelhança do modelo físico com o modelo matemático com empuxo. O ajuste adequado do modelo matemático com empuxo fica evidente, quando se compara a imagem do modelo matemático (Figura 5.5-4 b) com a imagem ampliada da região próxima a saída da válvula obtida a partir do modelo físico (Figura 5.2-8 a), para a mesma condição, 3361/min de água e 12N1/min de gás. 


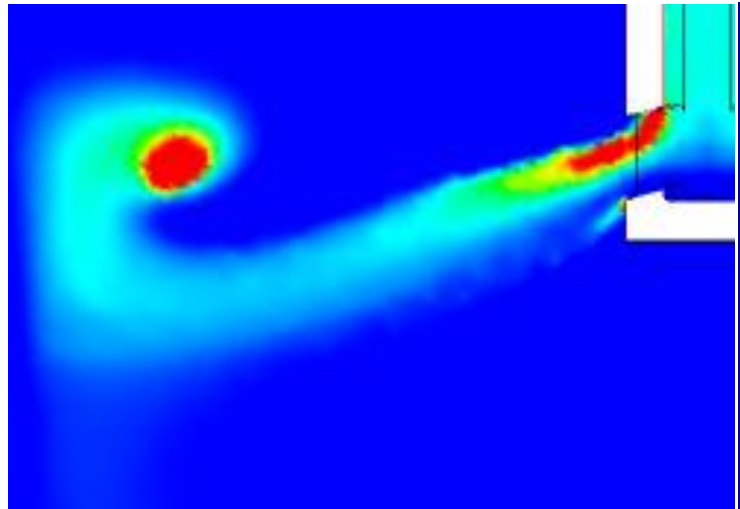

(a)

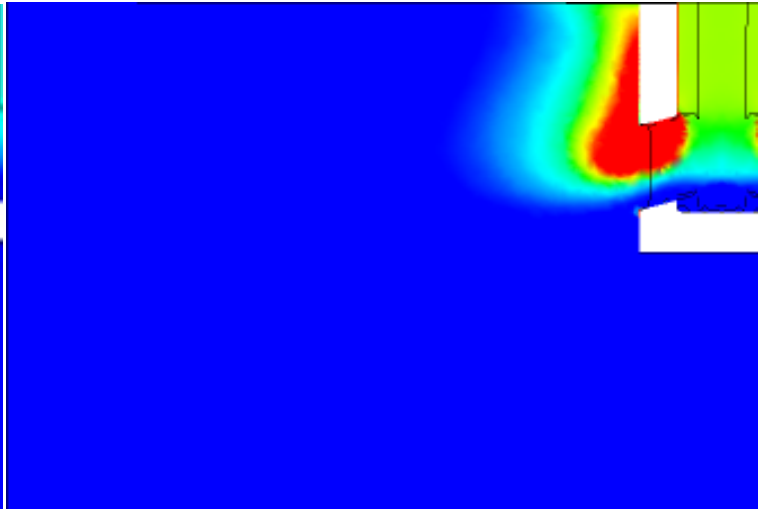

(b)

Figura 5.5-4: Imagem 2-D da distribuição gasosa no plano central do molde gerada na simulação matemática, (a) sem e (b) com empuxo, para 336 lpm e 12 Nl/min.

Para a condição de 3361/min de água com 12Nl/min de ar com empuxo e bolhas com diâmetro de $2 \mathrm{~mm}$ e $3 \mathrm{~mm}$ (ver Figura 5.5-5) observa-se, como seria esperado, que a redução do diâmetro da bolha implica em forças de empuxo menores e consequentemente uma expansão da região da fração volumétrica. Todavia, como já mencionado neste estudo, para vazões mais baixas de água, ocorre um processo de coalescência de bolhas e/ou desprendimento de bolsas de gás localizadas na região de recirculação na saída da SEN ou no fundo da mesma. Em função deste fenômeno o diâmetro de bolha igual a $3 \mathrm{~mm}$ é o que ajusta melhor o modelo matemático ao modelo físico, apesar dos resultados obtidos neste estudo do diâmetro médio das bolhas no interior da SEN estarem mais próximos de $2 \mathrm{~mm}$. O que por sua vez coincide com as observações realizadas por SUZUKI (2003) em relação ao aumento do diâmetro médio da bolha para vazões mais baixas de líquido.

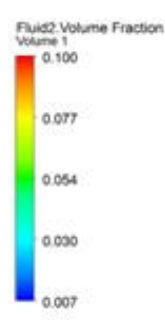

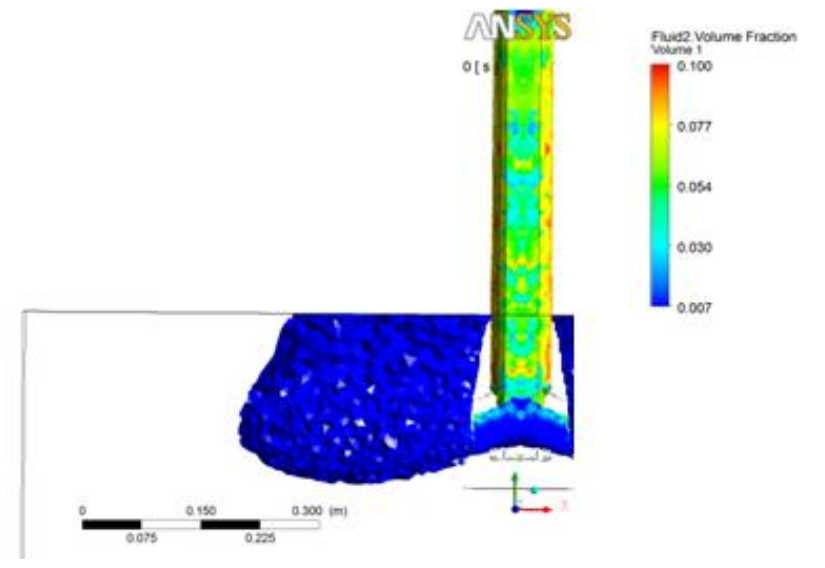

(a)

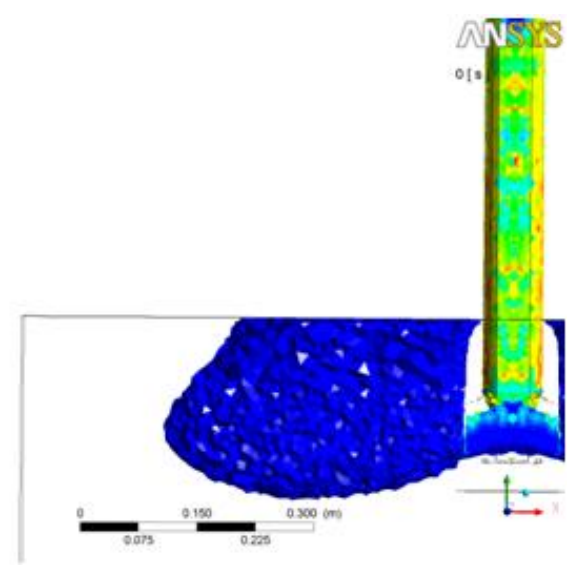

(b)

Figura 5.5-5: Imagem distribuição gasosa gerada na simulação matemática vista 3-D, vazão 336 lpm e 12 Nl/min de gás com empuxo (a) diâmetro de bolha de 3 mm e (b) diâmetro de bolha 2 mm. 
O mesmo se observa quando se avalia a fração volumétrica no plano central do molde (Figura 5.5-6 e Figura 5.5-7). Para diâmetro de bolha de 3mm, observa-se uma maior concentração próxima a saída da válvula submersa, o que por sua vez se adequa melhor a condição observada nas imagens obtidas através do modelo físico para as simulações de $336 \mathrm{lpm}$ de vazão de água e 12N1/min de vazão de ar (ver Figura 5.5-8).

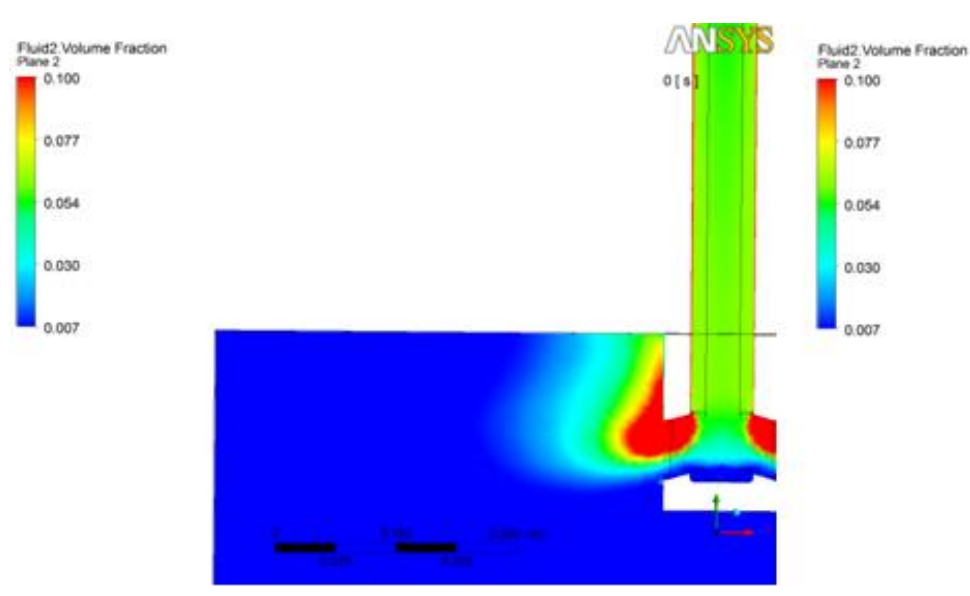

(a)

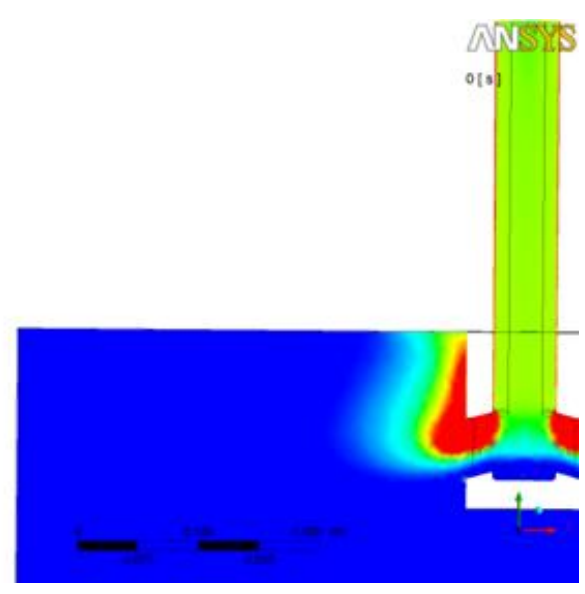

(b)

Figura 5.5-6: Imagem 2-D da distribuição gasosa do plano central do molde gerada na simulação matemática, com empuxo, para 336 lpm e 12 Nl/min (a) diâmetro de bolha $2 \mathrm{~mm}$ e (b) diâmetro de bolha 3 mm.

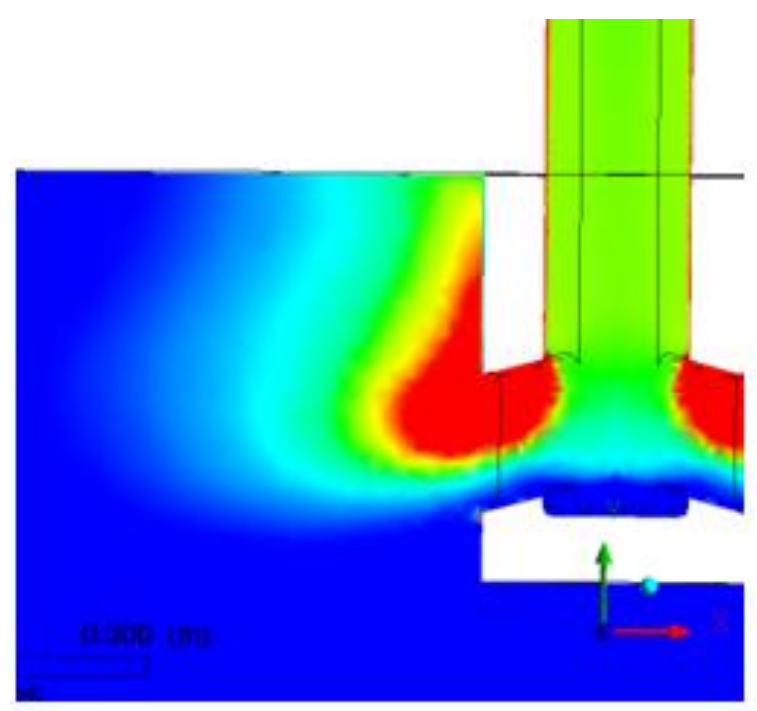

(a)

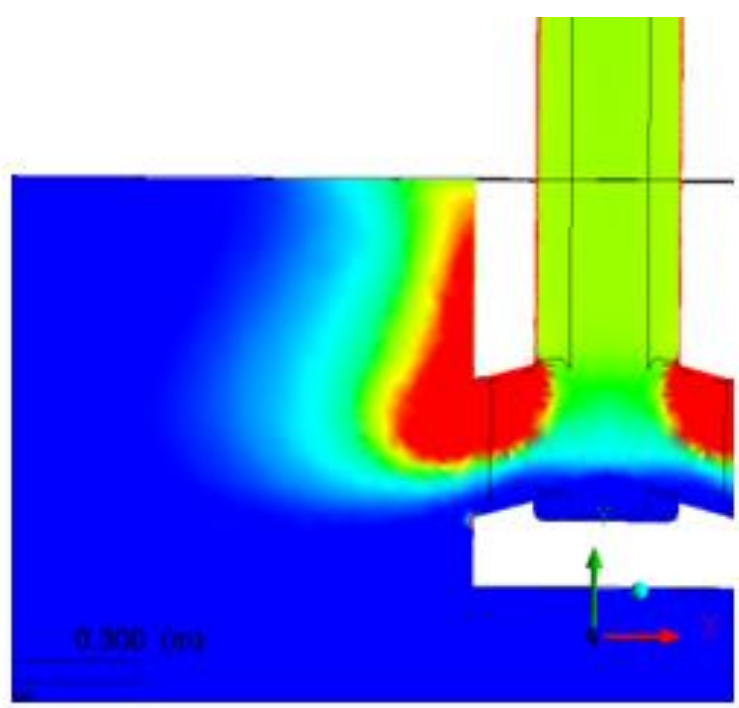

(b)

Figura 5.5-7: Imagem 2-D ampliada da distribuição gasosa do plano central do molde gerada na simulação matemática, com empuxo, para $336 \mathrm{lpm}$ e $12 \mathrm{Nl} / \mathrm{min}$ (a) diâmetro de bolha $2 \mathrm{~mm}$ e (b) diâmetro de bolha $3 \mathrm{~mm}$. 


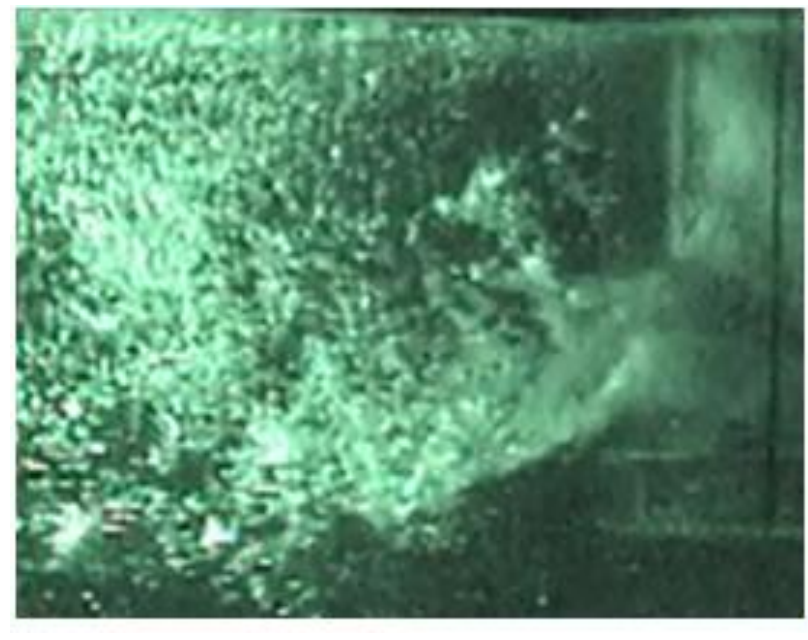

(a)

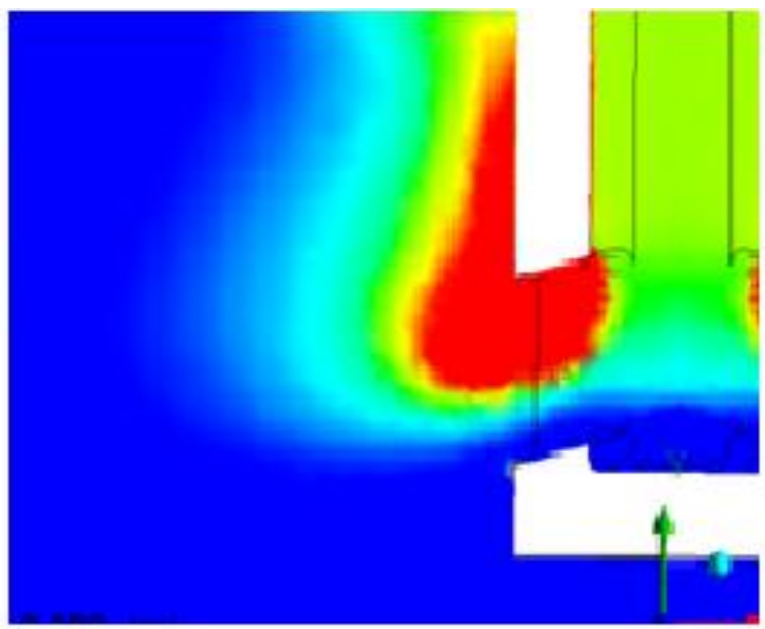

(b)

Figura 5.5-8: Imagens referentes a $336 \mathrm{lpm}$ e $12 \mathrm{Nl} / \mathrm{min}$, (a) simulação física e (b) simulação matemática com diâmetro de bolha de 3mm com empuxo, corte no plano central.

Quando se compara as imagens do modelo matemático para a simulação de 336lpm com bolhas de $2 \mathrm{~mm}$ com a simulação de $4001 \mathrm{pm}$ com bolhas de $3 \mathrm{~mm}$ (Figura 5.5-9), vê-se que a região da fração volumétrica é muito semelhante para ambos os casos. A vazão de gás utilizada nos dois casos foi de $12 \mathrm{Nl} / \mathrm{min}$ de ar. Contudo, ao observar-se mais atentamente é possível perceber que a condição de 3361 pmin com diâmetro de $2 \mathrm{~mm}$, apresenta uma região mais expandida de fração volumétrica, que a condição de $4001 \mathrm{pm}$ com diâmetro de $3 \mathrm{~mm}$. Esta observação se confirma também na avaliação das imagens do plano central para estas duas simulações (ver Figura 5.5-10). Isto por sua vez demonstra que o diâmetro da bolha no molde, e os mecanismos que determinam este tamanho, ruptura e coalescência da bolhas, é fator crítico na determinação do comportamento da fase gasosa no molde. Desta maneira a vazão do fluido, para as faixas de vazão avaliadas neste estudo, também se mostra determinante no processo de distribuição do gás no molde, mas além da alteração direta da velocidade e da energia cinética do jato na saída da válvula, tem-se o efeito destes parâmetros no diâmetro da bolha no molde, ou seja, maiores vazões de água acarretam em menores diâmetros de bolhas no molde. Isto foi observado nas imagens das simulações físicas (Figura 5.2-5, Figura 5.2-11, Figura 5.3-2 e Figura 5.3-4). 


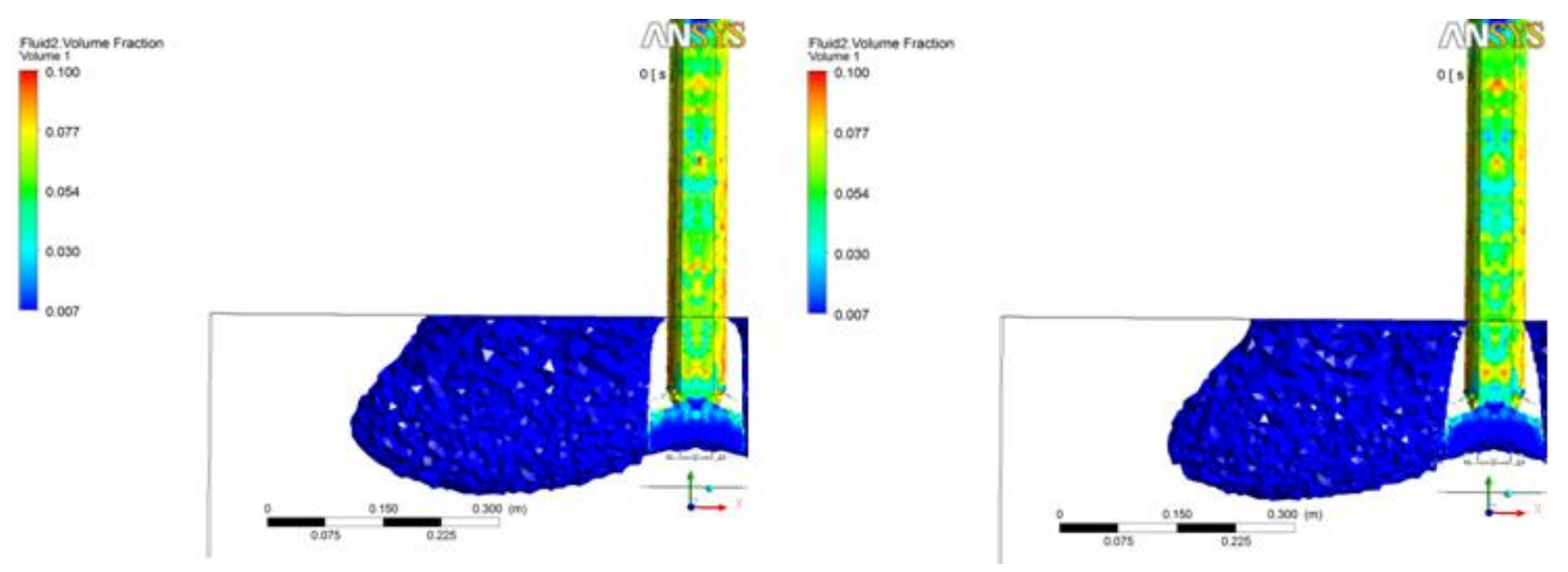

Figura 5.5-9: Imagem distribuição gasosa gerada na simulação matemática vista 3-D, (a) vazão 336 lpm e 12 Nl/min de gás com empuxo e diâmetro de bolha de 2 mm e (b) 400 lpm e 12 NL/min diâmetro de bolha com empuxo e diâmetro de bolha de $3 \mathrm{~mm}$.

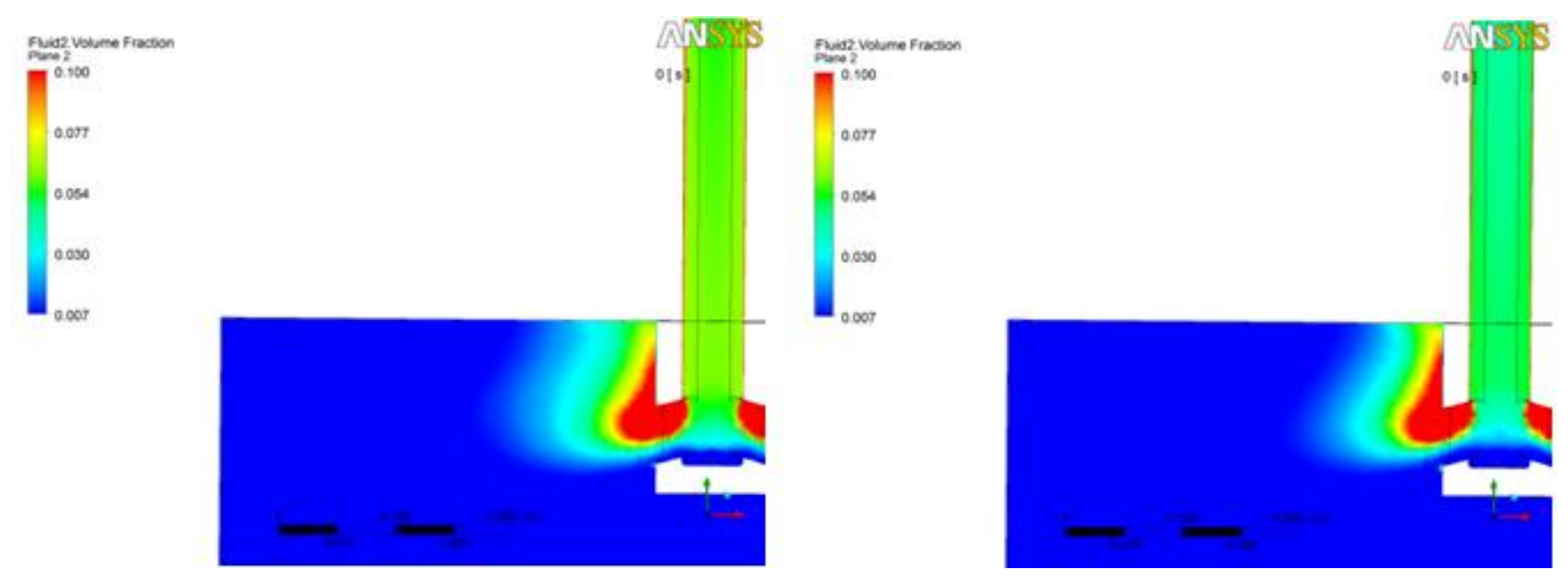

Figura 5.5-10: Imagem 2-D da distribuição gasosa do plano central do molde gerada na simulação matemática, com empuxo, para (a) $336 \mathrm{lpm}$ e $12 \mathrm{Nl} / \mathrm{min}$ diâmetro de bolha de $2 \mathrm{~mm}$ e (b) $4001 \mathrm{pm}$ e 12Nl/min com diâmetro de bolha de $3 \mathrm{~mm}$.

Todavia ao avaliar-se a condição de $400 \mathrm{lpm}$ com bolhas de 2 e $3 \mathrm{~mm}$, ver Figura 5.5-11 e Figura 5.5-12, se encontra a melhor concordância com o observado no modelo físico, quando se admite no modelo matemático um diâmetro médio de bolha igual a $2 \mathrm{~mm}$. Isto por sua vez confirma que o mecanismo de coalescimento e ruptura de bolhas no fundo e na saída da SEN, fator crítico para determinação do tamanho médio da bolha no molde, apresenta papel importante na definição do fluxo no molde. Nas imagens do modelo físico observam-se bolhas menores no molde sem a coalescência de bolhas grandes na saída da SEN (ver Figura 5.2-11 e Figura 5.3-4). Resultados similares também foram observados por Thomas (Parte I 2001) e Sengupta (2010). 


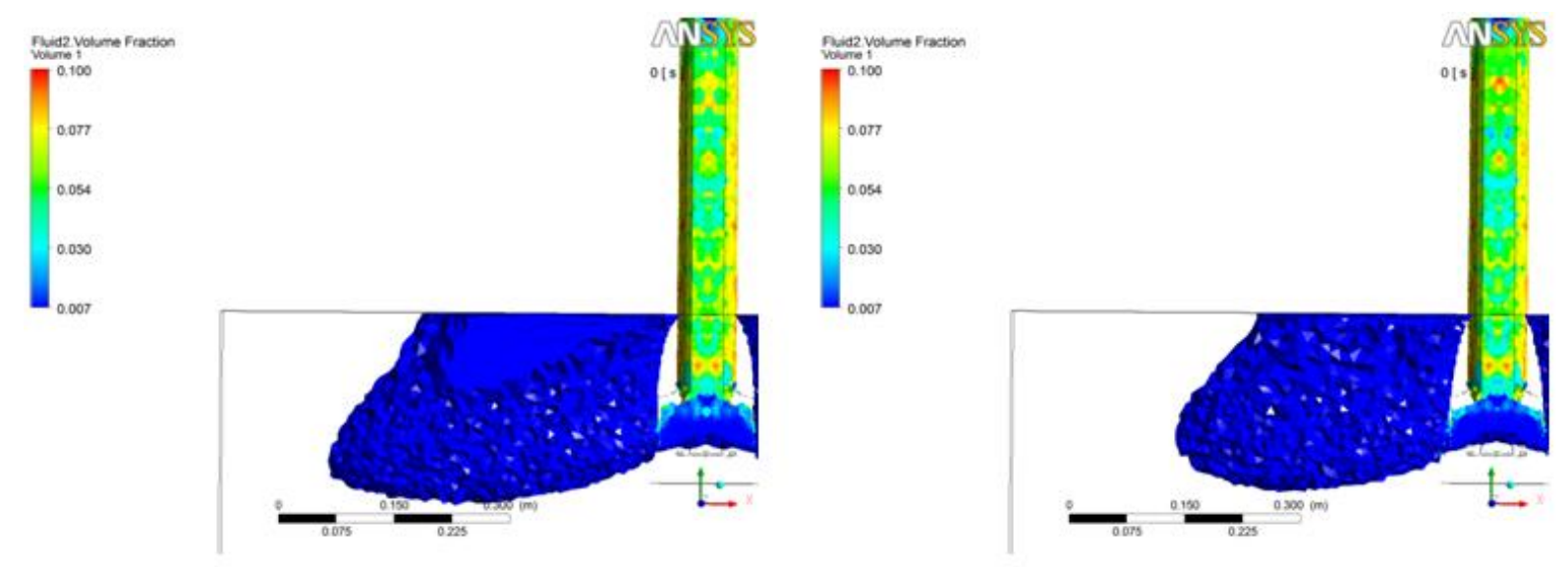

Figura 5.5-11: Imagem distribuição gasosa gerada na simulação matemática vista 3-D vazão de 400 lpm e 12Nl/min, com diâmetro de (a) 2 mm e (b) 3 mm.
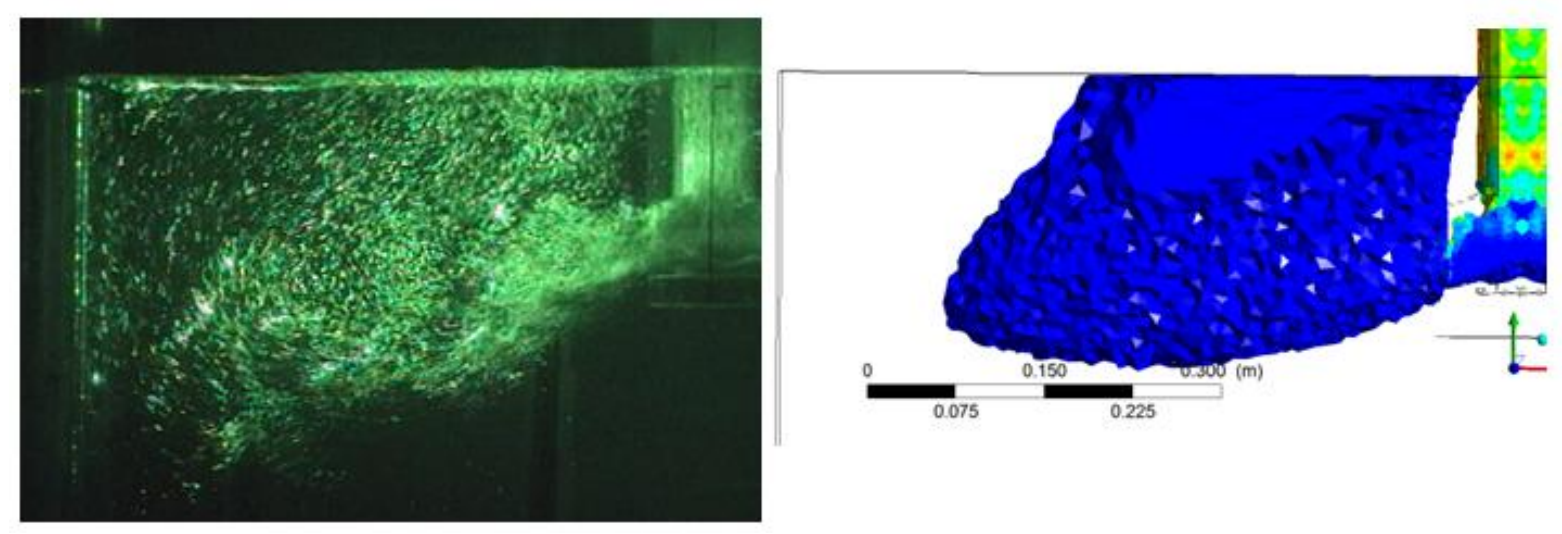

Figura 5.5-12: Imagem distribuição gasosa gerada na simulação física e matemática, $400 \mathrm{lpm}$ e $12 \mathrm{Nl}$ de gás por minuto, diâmetro de bolha $2 \mathrm{~mm}$.

A imagem dos vetores de fluxo e sua velocidade para condição de 336lpm de vazão de água e $12 \mathrm{Nl} / \mathrm{min}$, com diâmetro de bolha de 3mm e com empuxo, Figura 5.5-13(a), sugere que a formação do fluxo de duplo rolo nesta condição fica prejudicada. $\mathrm{O}$ movimento ascendente das bolhas gera uma distorção do movimento do rolo superior e um fluxo ascendente próximo à saída da válvula que reduz a velocidade do menisco nesta região. Na Figura 5.5-13 (b) o resultado sem empuxo para as mesmas condições representa um fluxo de duplo rolo inalterado. Outro ponto que pode ser observado, Figura 5.5-13(a), é o formato e o ângulo do jato principal para a condição com empuxo: o fluxo central, com maior velocidade, se expande e apresenta um ângulo superior reduzido em relação a Figura 5.5-13 (b). Estes resultados ressaltam a necessidade de consideração do empuxo nestas simulações 
matemáticas e por consequência da definição precisa do tamanho da bolha. Esta ocorrência também foi observada e comentada por Thomas (1997).

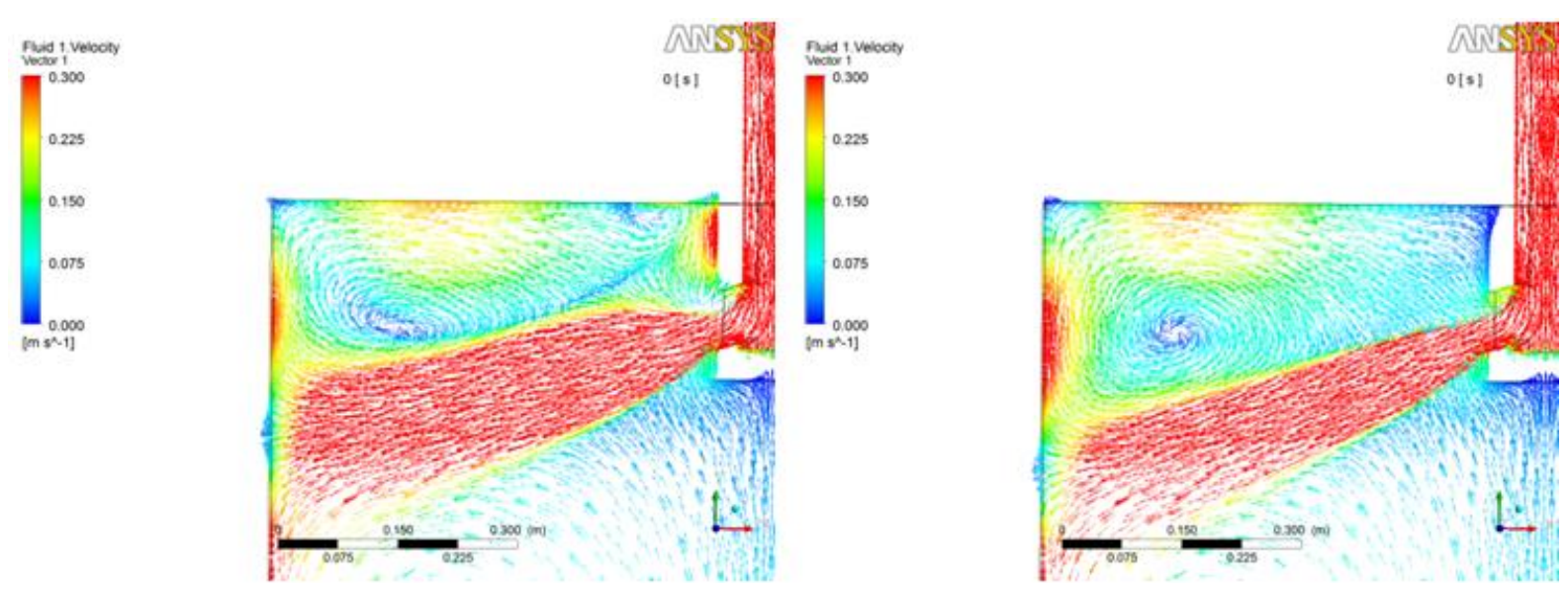

Figura 5.5-13: Imagem vetores de velocidade $336 \mathrm{lpm}$ e 12Nl/min de gás com bolhas com diâmetro de 3mm (a) com empuxo e (b) sem empuxo.

O mesmo fenômeno é observado para a condição de 400lpm com $12 \mathrm{Nl} / \mathrm{min}$ e bolhas com diâmetro de $3 \mathrm{~mm}$. Nota-se uma modificação do fluxo central e de seu ângulo superior o que altera por sua vez o fluxo de duplo rolo (Figura 5.5-14 (a)). Também se observa um pequeno fluxo ascendente próximo a saída da válvula submersa. Na simulação física este fenômeno não é perceptível, provavelmente devido ao fato de que as bolhas para a condição de 4001pm se apresentam menores no modelo físico, o que propicia o arraste para junto da face estreita. Um efeito que fica perceptível com a injeção de ar, (Figura 5.5-14 (a)), é o aumento da velocidade do menisco na área central do molde. Quando se compara a condição com empuxo, Figura 5.5-14 (a), com a condição sem empuxo, Figura 5.5-14 (b), percebe-se que o efeito da injeção de gases na inclinação do jato central acarreta em uma elevação da velocidade na região do menisco. Novamente estes resultados ressaltam a necessidade de consideração do empuxo e da definição precisa do tamanho da bolha. As velocidades da região central do menisco ficam entre $0,23 \mathrm{~m} / \mathrm{s}$ e $0,3 \mathrm{~m} / \mathrm{s}$, o que conforme Yavuz (2010) e (Forman et al, 2010) está dentro da faixa ideal de velocidades para se evitar defeitos em placa. 


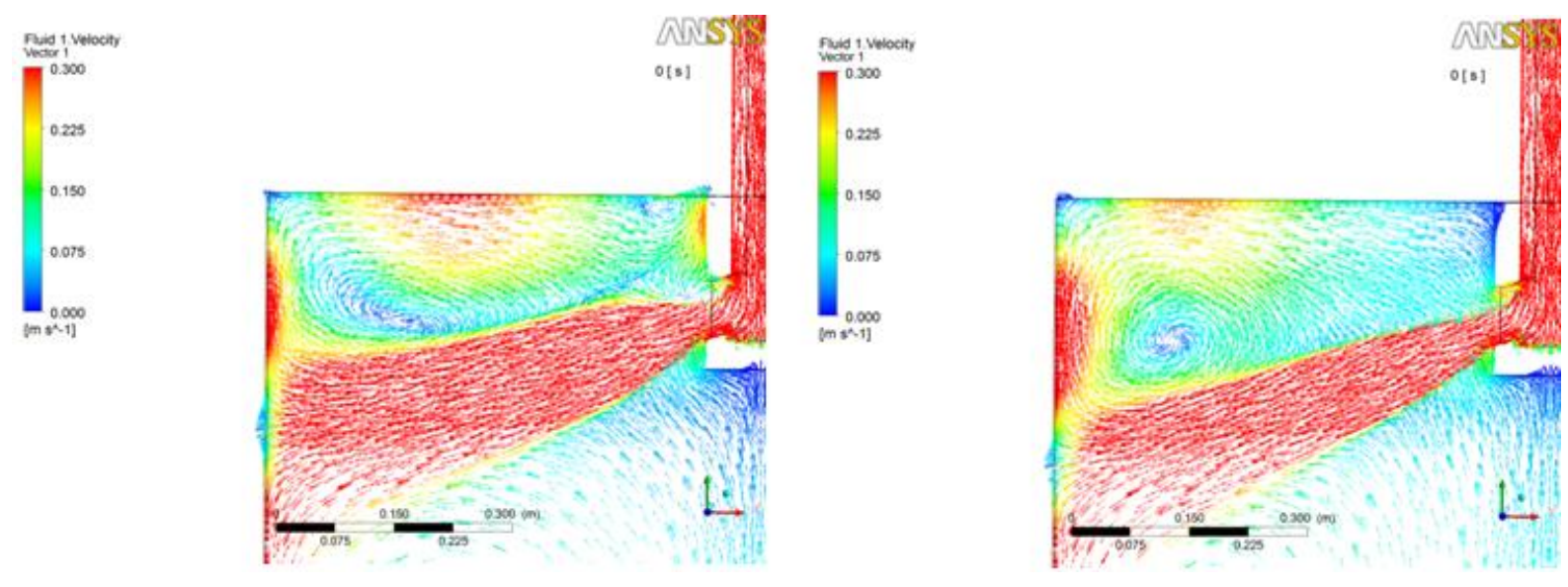

Figura 5.5-14: Imagem vetores de velocidade $400 \mathrm{lpm}$ e $12 \mathrm{Nl} / \mathrm{min}$ de gás com bolhas com diâmetro de $3 \mathrm{~mm}$ (a) com empuxo e (b) sem empuxo.

Ao se comparar a condição de 336lpm com 4001pm, Figura 5.5-15, se confirma a criticidade da condição de baixa vazão para a produção de aço com exigências de limpidez, caso do UBC para parte exposta crítica. Conforme já mencionado, para 336lpm o duplo rolo fica prejudicado e também a velocidade no menisco. Diferentemente da condição do fluxo de aço no molde para 400lpm com injeção de gás, a qual apresenta uma melhora do perfil de velocidades no menisco, conforme mencionado e discutido por Yavuz (2010) e (Forman et al, 2010).
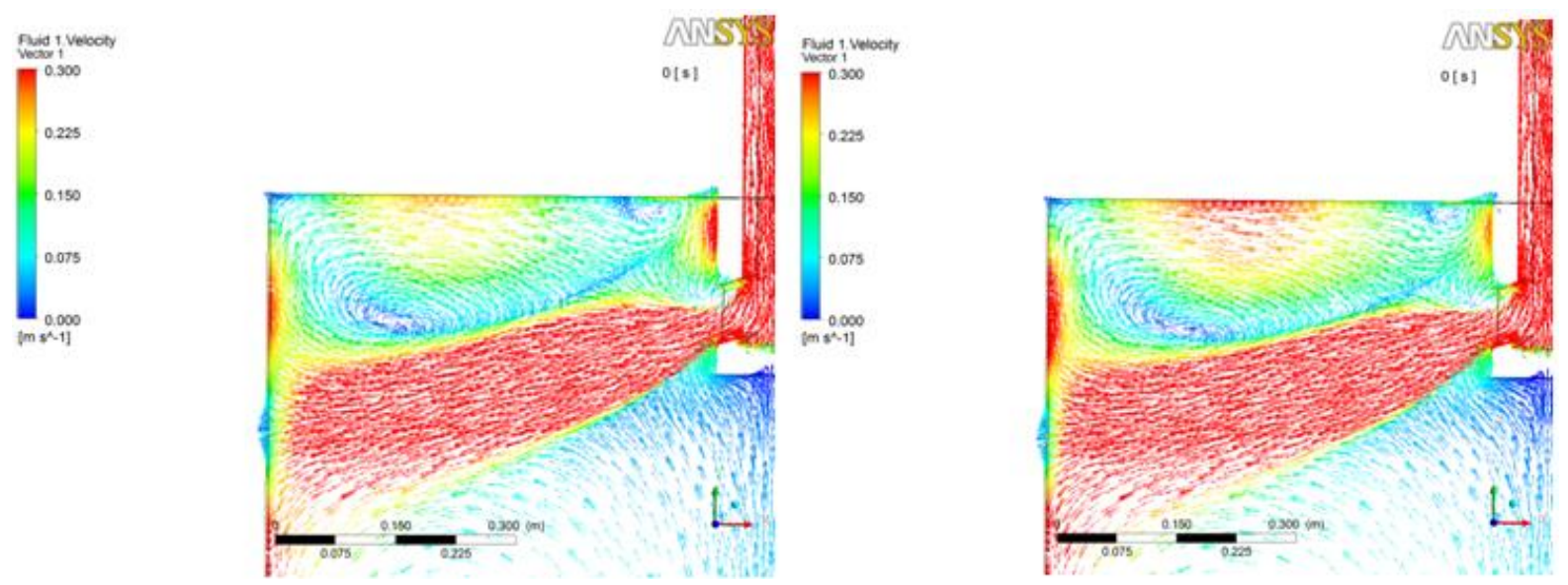

Figura 5.5-15: Imagem vetores de velocidade com bolhas com diâmetro de $3 \mathrm{~mm}$ e empuxo para (a) 336lpm e 12Nl/min e (b) $400 \mathrm{lpm}$ e $12 \mathrm{Nl} / \mathrm{min}$.

Quando se compara a condição do fluxo no molde para $400 \mathrm{lpm}$ com bolhas de 2 e $3 \mathrm{~mm}$, ver Figura 5.5-16, observa-se que para $2 \mathrm{~mm}$ a velocidade do menisco ficaria abaixo de $0,225 \mathrm{~m} / \mathrm{s}$; e que os resultados são afetados de modo significativo pela escolha do diâmetro. $\mathrm{O}$ 
processo de coalescência e ruptura de bolhas no molde, tal como descrito no estudo de Banderas et al (2005), se caracteriza pela produção de uma distribuição de tamanho de bolhas não uniforme ao longo do molde. Ao se considerar diâmetro de bolha igual a $2 \mathrm{~mm}$ parece que a distribuição gasosa se aproxima melhor daquela observada na simulação física (Figura 5.5.12). Por outro lado o diâmetro de bolha de $3 \mathrm{~mm}$ é o que melhor se adequa ao critério de velocidade crítica de menisco.
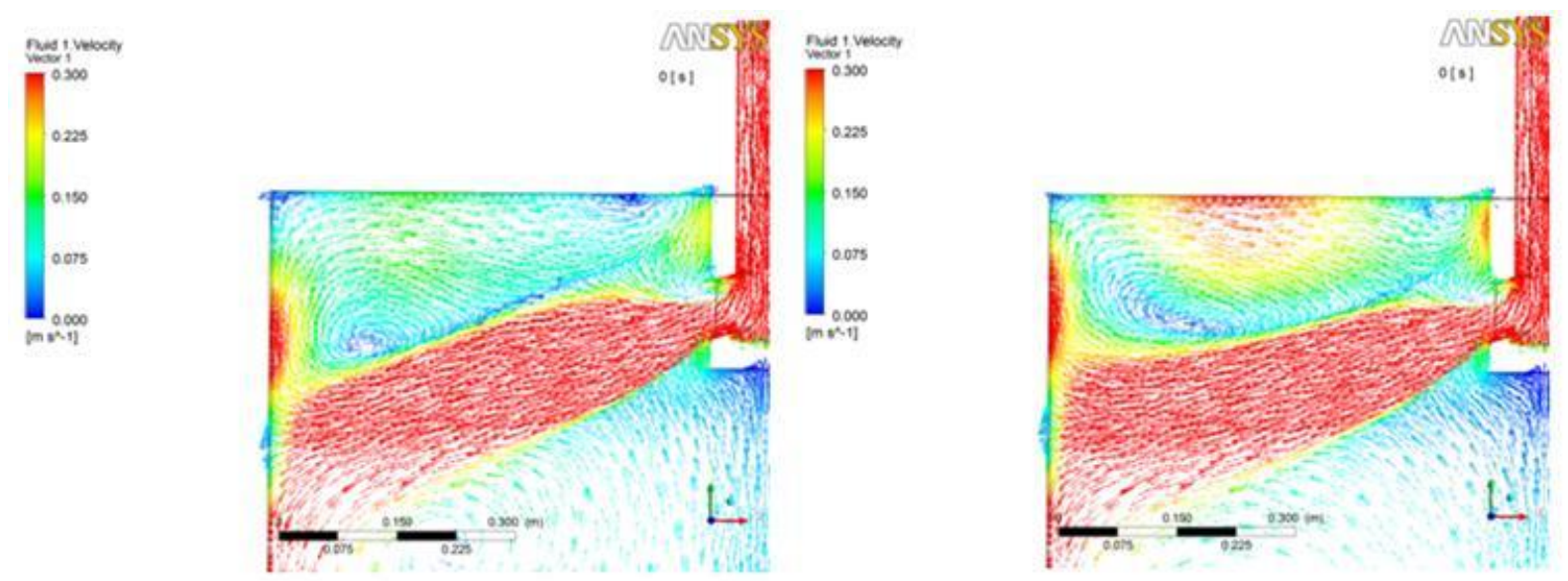

Figura 5.5-16: Imagem vetores de velocidade $400 \mathrm{lpm}$ e 12Nl/min de gás com bolhas com diâmetro de, (a) $2 \mathrm{~mm}$ e (b) $3 \mathrm{~mm}$.

Desta maneira, para a vazão de 400 lpm, sugere-se que uma condição dinâmica no molde que contemple a variação do diâmetro de bolha de $2 \mathrm{~mm}$, na região próxima a saída da SEN, e posterior aumento deste diâmetro para $3 \mathrm{~mm}$, para a região central do molde até a face estreita do molde, representaria melhor as observações realizadas no modelo físico. O que perfeitamente se encaixa nas observações e resultados de Banderas et al (2005). Desta maneira a fixação do diâmetro de bolha no CFX se torna um limitador para avaliar condições diferenciadas de lingotamento. 


\section{CAPÍTULO 6: CONCLUSÕES}

Para as condições operacionais investigadas em modelo físico e matemático, foram obtidos os seguintes resultados:

- O diâmetro das bolhas no interior da SEN é maior para vazões de água menores e para vazões de gás maiores. Entretanto a diferença de diâmetro observada entre o uso de He e ar, 0,13 mm, é pequena e por isto pode ser desconsiderada.

- O diâmetro de bolhas somente pode ser determinado para baixas vazões, 2 e $4 \mathrm{Nl} / \mathrm{min}$; para vazões superiores o processo de coalescência, ruptura e sobreposição/ aglomeração de bolhas não permite uma determinação precisa do diâmetro médio das bolhas.

- Para o uso de válvula superior porosa ou válvula superior com dupla seção porosa não se observou na válvula submersa ou no molde (simulação em água), diferença perceptível entre os diâmetros de bolha e o fluxo da fase líquida.

- Para vazão de $336 \mathrm{lpm}$ de água somente se mantém o fluxo duplo rolo no molde para baixa vazão de gás (4Nl/min). Nas outras vazões de gás, 8,12 e 16Nl/min, o processo de coalescência de bolhas no fundo e na porta da SEN é predominante. Isto acarreta em bolhas com diâmetro maiores e consequentemente em um fluxo ascendente destas bolhas próximo a saída da SEN, prejudicando o processo de formação do duplo rolo e gerando regiões de baixa velocidade de menisco e espumação na superfície do molde.

- Para vazão de 400lpm de água o fluxo de duplo rolo se mantém para todas as vazões de gás avaliadas, 4, 8, 12 e $16 \mathrm{Nl} / \mathrm{min}$ com boas condições operacionais (velocidade de menisco, diâmetro de bolhas e fluxo de aço na parede estreita do molde).

- A simulação matemática, para a condição de $3361 \mathrm{pm}$ e $12 \mathrm{Nl} / \mathrm{min}$, que melhor reproduziu os resultados observados no modelo físico, foi a que se considerou 
diâmetro de bolha de $3 \mathrm{~mm}$ com empuxo, tanto em relação à fração volumétrica do gás, quanto em relação aos vetores de fluxo da fase líquida.

- Para 4001pm com $12 \mathrm{Nl} / \mathrm{min}$ a condição que melhor reproduziu os resultados observados no modelo físico, foi aquela que considerou o empuxo, com diâmetro de bolha de $2 \mathrm{~mm}$, no caso de comparação entre as frações volumétricas, e diâmetro de $3 \mathrm{~mm}$, para o caso de comparação entre os vetores de fluxo da fase líquida. 


\section{CAPÍTULO 7: SUGESTÕES PARA TRABALHOS FUTUROS}

Avaliar ajustes necessários no modelo matemático para se considerar os fenômenos de coalescência e ruptura de bolhas no interior, no fundo e na porta da SEN e no molde. 


\section{REFERÊNCIAS}

1. YUAN, F. Numerical simulation of $\mathrm{Al} 2 \mathrm{O} 3$ deposition at a nozzle during continuous casting. Journal of the University of Science and Technology Beijing, Vol 15, Number 3, p. 227, Jun. 2008.

2. SUZUKI, H. eT al. Structure of Porous Upper Nozzle for Tundish and Gas Bublle Behavior. Shinagawa Technical Report, 2003.

3. BORGES, R. N. Estudo do escoamento de aço e argônio no interior de válvulas submersas com controle de vazão tipo válvula gaveta para diferentes condições de injeção de argônio na válvula superior e na válvula submersa. Laboratório de Simulação Numérica - Magnesita Refratários S.A. Belo Horizonte, 2005.

4. THOMAS, B. et al. Behavior of Argon Bubbles during Continuous Casting of Steel. ISS $80^{\text {th }}$ Steelmaking Conference, p. 375-384. 1997

5. FORMAN, B. et al. Optimization of a Submerged Entry Nozzle Design to Reduce Non-metallic Inclusions in Line Pipe Steel. AISTech 2010 Proceedings - Volume II.

6. YAVUZ, M. M.; SENGUPTA, J. Nozzle Design for ArcelorMittal Dofasco's $\mathrm{N}^{\mathrm{o}} 1$ Continuous Caster for Minimizing Sliver Defects. AISTech 2010 Proceedings Volume II.

7. THOMAS, B. G.; BAI, H. Turbulent Flow of Liquid Steel and Argon Bubbles in Slide-Gate Tundish Nozzles: Part I. Effect of Operation Conditions and Nozzle Design. Metallurgical and materials transactions. Vol. 32B. Abril, 269 p. Illinois, 2001.

8. THOMAS, B. G.; BAI, H. Turbulent Flow of Liquid Steel and Argon Bubbles in Slide-Gate Tundish Nozzles: Part II. Effect of Operation Conditions and Nozzle Design. Metallurgical and materials transactions. Vol. 32B. Abril, 269 p. Illinois, 2001.

9. BORGES, R. N. Estudo do escoamento de aço e argônio no interior de válvulas submersas com controle de vazão tipo válvula gaveta para avaliação da geometria da válvula superior e sede do distribuidor. Laboratório de Simulação Numérica Magnesita Refratários S.A. Belo Horizonte, 2004.

10. BORGES, R. N.; SANTOS, H. A.; RIBEIRO, B. A. B. Estudo do gradiente de pressão no conjunto de válvula gaveta avaliação do escoamento. Laboratório de Simulação Numérica - Magnesita Refratários S.A. Belo Horizonte, 2005.

11. PRASSER, H. M.; KREPPER, E.; DIRK, L. Evolution of the two-phase flow in a vertical tube - decomposition of gas fraction profiles according to bubble size classes using wire-mesh sensors. International Journal of Thermal Sciences. Vol 41, p 17-28, 2002, Germany. 
12. BANDERAS, A. R.; MORALES, R. D.; SANCHEZ-PÉREZ， R.; GARCIADEMEDICES, L.; SOLIRO-DIAZ, G. Dynamics of two-phase downwards flows in submerged entry nozzle and its influence on the two-phase flow in the mold. International Journal of Multiphase Flow, Vol. 31, p 643-665, 2005, Mexico.

13. Sengupta, J; et al. Direct Measurement of Sub-meniscus Velocity at ArcelorMittal Dofasco's $\mathrm{N}^{\mathrm{o}} 1$ Continuous Caster to Evaluate Mold Fluid Flow at Different Casting Conditions. AISTech 2010 Proceedings - Volume I.

14. Lee, G. G; et al. Investigation of Refractory Properties on the Initial Buble Behavior in the Water Model of Continuos Casting Process. Materials Science and Technology Conference, AIST/ TMS, Pittsburgh, PA, 2009.

15. Sengupta, J; et al. Micrograph evidence of meniscus solidification and sub-surface microstructure evolution in continuos-cast-ultralow-carbon steels. Acta Materialia, ed 54, 2006, p 1165-1173.

16. BIRD et al. Transport phenomena. Copyrighted material. 2 ed. United States of America, 1960, pg 158-161.

17. J. Szekely, O.J. Ilegbusi. The Physical and Mathematical Modeling of Tundish Operations.Ed Springer-Verlag. Alemanha, 1989, pag 34.

18. THOMAS, B. G. HUANG, X. Effect of Argon Gas on Fluid Flow in a Continuous Slab Casting Mold. Effect of Operation Conditions and Nozzle Design. Metallurgical B. Vol. 25B, N 4 . Agosto, 1994, pg 527-547. 